
Div. 736

Report Nos. FAA-RD-79-51

HE COPY

NBSIR 79-1616

\title{
TITANIUM COMBUSTION IN TURBINE ENGINES
}

\author{
Thomas R. Strobridge \\ John C. Moulder \\ Alan F. Clark \\ Thermophysical Properties Division \\ National Engineering Laboratory \\ National Bureau of Standards \\ Boulder, Colorado 80303
}

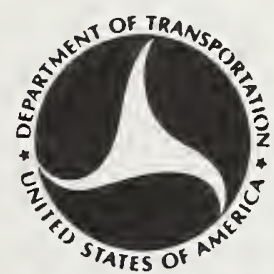

July 1979

Final Report

Document is available to the U.S. public through the National Technical Information Service, Springfield, Virginia 22161.

Prepared for

\section{U.S. DEPARTMENT OF TRANSPORTATION} FEDERAL AVIATION ADMINISTRATION

Systems Research \& Development Service

Washington, D.C. 20590 
NOTICE

This document is disseminated under the sponsorship of the Department of Transportation in the interest of information exchange. The United States Government assumes no liability for its contents or use thereof. 
MBS-IILA (REV.

\begin{tabular}{|c|c|}
\hline U.S. DEPT. OF COMM. & 1. PUBLICATION OR REPORT NO. \\
BIBLIOGRAPHIC DATA & FAA-RD-79-51 \\
SHEET & NBSIR 79-1616 \\
\hline
\end{tabular}

4. TITLE AND SUBTITLE

Titanium Combustion in Turbine Engines
5. Publication Date

July 1979

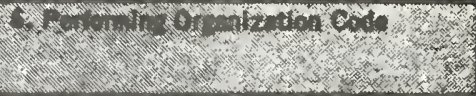

8. Performing Organ. Report No.

7. AUTHOR(S)

Thomas R. Strobridge, John C. Moulder, Alan F. Clark

9. PERFORMING ORGANIZATION NAME AND ADDRESS

NATIONAL BUREAU OF STANDARDS

DEPARTMENT OF COMMERCE

WASHINGTON, DC 20234

12. SPONSORING ORGANIZATION NAME AND COMPLETE ADDRESS (stroet, city, state, zIP)

U. S. Department of Transportation

Federal Aviation Administration

Research and Development

Washington, D.C 20591

15. SUPPLEMENTARY NOTES

Document describes a computer program; SF-185, FIPS Software Summary, is attached.

16. ABSTRACT (A 200-word or leso factual summary of most significant information. Il document includos a signilicant bibliography or literature survey, mention it here.)

Pure and alloyed titanium components are routinely used in aircraft turbine engines because of their uniquely high strength-to-weight ratios among structural metals, combined with excellent fatigue and corrosion resistance. Like most other metals, titanium is combustible under certain conditions of temperature, pressure and oxygen concentration and in fact there have been several instances of titanium combustion in service engines. Contemporary titanium use in aircraft turbine engines and the limits of that use are explored. Combustion incidents and their causes are discussed as well as the typical extent of damage. Current preventative measures are outlined. For better understanding, the-fundamentals of metal combustion and the experimental research related to titanium combustion are thoroughly treated and analytical combustion models are presented. Finally, the relevant experimental combustion dataare correlated as a function of static temperature and Reymolds number and compared to the model predictions.

17. KEY WORDS (six to twelve entries; alphabetical order; capitalize only the firet letter of the first key word unless a proper name; separated by semicolona)

Aircraft turbine engine; analytic models; combustion; compressor, correlation of experiments; dynamic combustion; ignition; jet engine; metal combustion; metal oxidation; oxidation; static combustion; thermodynamics; titanium alloys; titanium com-

18. AVAILABILITY bustion. $\quad \square$ Unlimited

For Official Distribution. Do Not Release to NTIS

Order From Sup. of Doc., U.S. Government Printing Office, Wasinington, DC 20402, SD Stock No. SNOO3-003-

X] Order From National Technical Information Service (NTIS), Springfield, VA. 22161

\begin{tabular}{|l|c|}
$\begin{array}{l}\text { 19. SECURITY CLASS } \\
\text { (THIS REPORT) }\end{array}$ & $\begin{array}{c}\text { 21. NO. OF } \\
\text { PRINTED PAGES } \\
\text { UNCLASSIFIED }\end{array}$ \\
\hline $\begin{array}{l}\text { 20. SECURITY CLASS } \\
\text { (THIS PAGE) }\end{array}$ & 22. Price \\
UNCLASSIFIED & \\
\hline
\end{tabular}




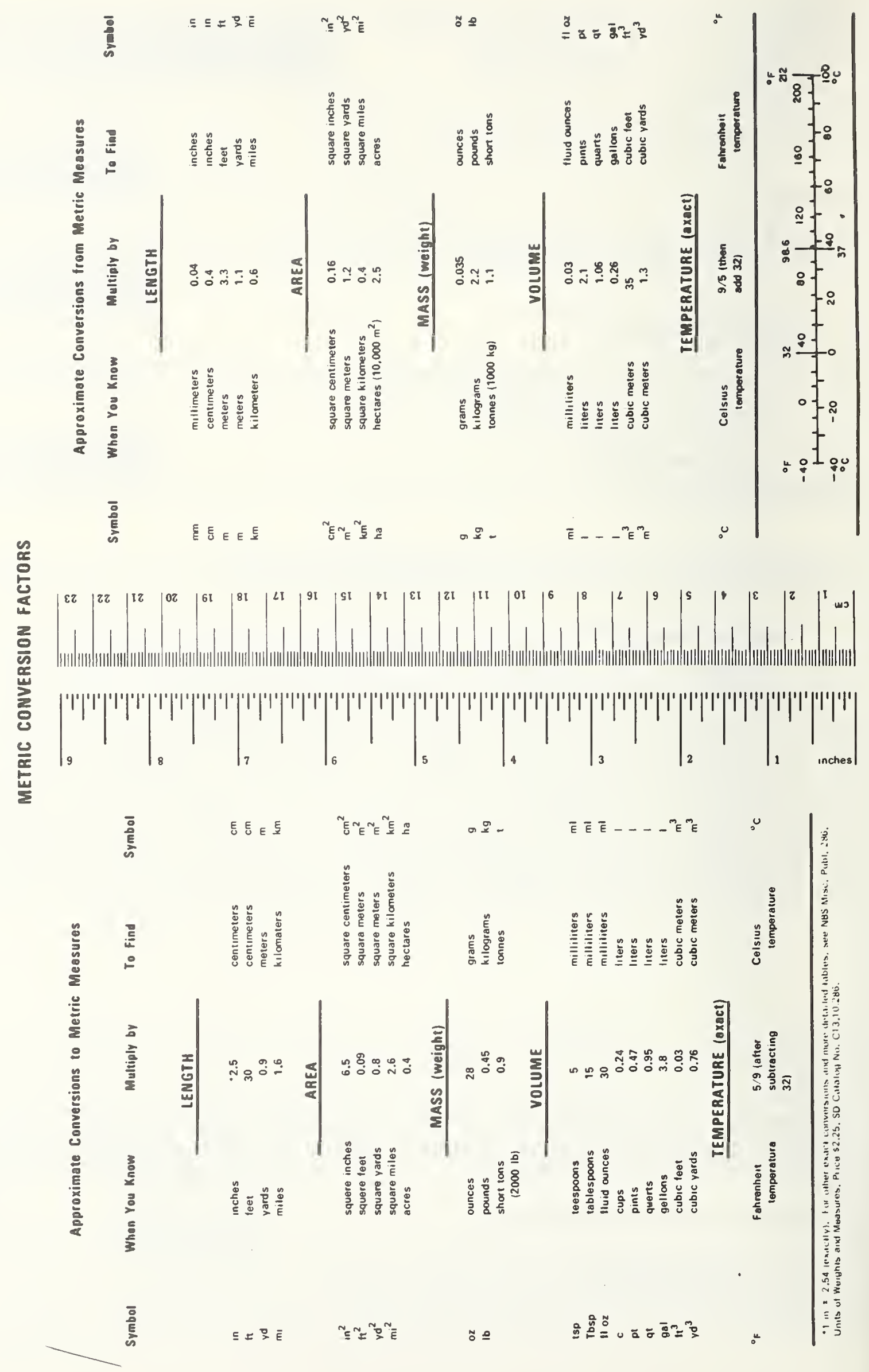


Abstract . . . . . . . . . . . . . . . . . . . iii

List of Tables . . . . . . . . . . . . . . . . iv

List of Figures. . . . . . . . . . . . . . . . . v v

1. INTRODUCTION •. . . . . . . . . . . . . . . . . 1

1.1 Reasons for Using Titanium. . . . . . . . . . . . 2

1.2 Basic Metallurgy. . . . . . . . . . . . . 3

1.3 Report Format . . . . . . . . . . . . . 7

2. CURRENT TITANIUM USE • . • . . . • • • • • . . 7

2.1 Titanium Applications in Turbine Engines. . . . . 7

2.2 Limits to Titanium Use. . . . . . . . . . . 8

3. TITANIUM COMBUSTION EXPERIENCE . . . . . . . . . . 10

3.1 Combustion Sources. . . . . . . . . . . . . 10

3.2 Combustion Occurrences. . . . . . . . . . . . 10

3.3 Extent of Combustion Damage . . . . . . . . . 13

4. PRECAUTIONS AND PREVENTIVE MEASURES. . . . . . . . . . 20

4.1 Design Philosophy : . . . . . . . . . . . . 20

4.2 Design Measures . . . . . . . . . . . . . 20

4.3 Extinguishment. . . . . . . . . . . . . . . 24

5. FUNDAMENTALS OF METAL COMBUSTION • • • • . . . . . . . 26

5.1 Characteristics of Metal Combustion . . . . . . 27

5.2 Thermodynamics of Metal-oxygen Reactions. . . . 32

6. EXPERIMENTAL RESEARCH ON TITANIUM COMBUSTION • • • . 35

6.1 Oxidation . . . . . . . . . . . . 36

6.2 Ignition. . . . . . . . . . . . . . . . 41

6.3 Static Combustion.............. . 47

6.4 Dynamic Combustion. . . . . . . . . . . . . . 61

6.5 Analytical Models of Titanium Combustion. . . . 70

7. CORRELATION OF COMBUSTION EXPERIMENTS. • . . . . . . . 75

7.1 Prediction of Self-Sustained Combustion . . . . . 75

7.2 Analysis of Experimental Data . . . . . . . . 77

8. DISCUSSION AND CONCLUSIONS • • • • . . . . . . . . 87

9. ACKNOWLEDGMENTS • • • • • • • • • • • . • • . . 93

10. REFERENCES • • • . . . . . . . . . . . . . 95 APPENDICES

A. Glossary of Metal Combustion Terminology . . . . A-l

B. Excerpt from British Civil Airworthiness . . . . B-l Requirements

C. Metallurgical Examination of Combustion Specimens. C-1 


\section{LIST OF TABLES}

1. Titanium Components in Four Modern Turbofan Engines.

2. Titanium Combustion Occurrences.

3. Circumstances Preceding or Event Leading to Titanium Combustion.

4. Factors Affecting Metal Combustion.

5. Adiabatic Combustion Temperatures in Oxygen at one Atmosphere Pressure.

6. Titanium Alloy Combustion Rates. 
1. Estimated engine mass reduction through the use of titanium.

2. Schematic relationships: Titanium alloying effects on structure and selected alloy characteristics.

3. Schematic of modern fan engine.

4. Artist's rendition showing blade trailing edge damage.

5. Artist's rendition showing progressive damage to blades.

6. Artist's rendition showing combustion products on burned blades.

7. Weight gain versus time for oxidation of titanium.

8. Titanium-oxygen phase diagram.

9. Ignition temperature of titanium as a function of oxygen pressure.

10. Ignition and propagation limits for titanium in heliumoxygen and steam-oxygen mixtures.

11. Experimental arrangement for determining temperature and oxygen uptake during combustion of titanium in oxygen.

12. Three frames from high-speed movies of titanium burning in l-atmosphere oxygen.

13. The effect of flow on the rate of oxygen uptake for $\mathrm{Ti}-6 \mathrm{Al}-4 \mathrm{~V}$.

14. Composite time sequences from high speed movies showing propagation of combustion.

15. Effect of angle-of-attack on combustion propagation in wind tunnel experiments.

16. Physical model for the combustion of titanium airfoils.

17. Model discrimination Iines and CAA recommendation as functions of static temperature and Reynolds member.

18. Experimental titanium combustion data from references 10 and 46 .

19. Experimental titanium combustion data from reference 10.

20. Experimental titanium combustion data from reference 10 . 
21. Experimental titanium combustion data from reference 46.

22. Experimental titanium combustion data from reference 7.

23. Experimental titanium combustion data from reference 13.

C-1 Photomicrographs of the unburned and burned sides of a specimen cut from the compressor case of an engine.

C-2 Unburned and burned portions of a specimen from the compressor case.

C-3 Recast layer near a penetration in the bleed air manifold.

C-4 Microhardness as a function of depth below rub strip for an unburned specimen.

C-5 Microhardness as a function of depth below burned surface of compressor case.

C-6 Microhardness as a function of depth below burned surface of compressor case. Different symbols denote independent traverses of specimen.

C-7 Microhardness as a function of distance from penetration site in bleed air manifold. Different symbols denote independent traverses of specimen. 
T. R. Strobridge, J. C. Moulder and A. F. Clark Thermophysical Properties Division

National Engineering Laboratory

National Bureau of Standards

Boulder, Colorado 80303

\section{INTRODUCTION}

A major portion of the titanium and its alloys produced each year is used in turbine engines and airframes, taking advantage of the metal's low density, high specific strength and corrosion resistance. In the evolution of jet engines, the addition of a two stage titanium fan to a basic straight jet helped produce 42 percent more take-off thrust while reducing the fuel consumption and specific weight by 13 and 18 percent.[1] The current generation of large, high-bypass-ratio engines have substantial amounts of titanum alloys in the fan and compressor sections as well as in other structures. These engines could not have been built without titanium alloys[2], although numerous research programs have been and are being conducted to develop alternate materials such as glass-epoxy, graphite-polyimide and boron-aluminum composites and nickel superalloys. The potential of reduced weight and cost to improve aerodynamic and economic performance is the primary driving force in the search for improved materials.

Titanium's ability to support combustion is not unusual; in the proper environment all metals except gold, silver and platinum will burn. Titanium is combustible above certain combinations of air pressure, temperature and velocity. While the boundary between combustible and non-combustible regions on the pressure-temperature-velocity surface is not well defined at this time, there 
are locations in modern turbine engines in which the values of these parameters are high enough to support sustained or even propagating combustion if titanium were present and were somehow ignited. Instances of sustained or propagating titanium combustion have occurred[3] in turbine engines both on test stands and in aircraft and naval ship service. This study, specifically excluding military engines, concentrated on the experience of engines operated in subsonic commercial air transport service.

We define titanium combustion as any rapid oxidation; selfsustained combustion as the continued or non-quenched rapid oxidation of a structure, for example a stator vane; and, propagating combustion as the spreading of rapid oxidation to structures other than those initially ignited.*

If there is an instance of titanium combustion wherein the engine case remains intact but power production is reduced severely, the effect will be considered the same as an unscheduled engine shut-down caused for any other reason. Should the case burn through or be mechanically penetrated, then molten titanium drops can be entrained by the high pressure air flowing through the case wall into the nacelle area where fuel and oil lines and reservoirs are located; the potential for further damage is obvious. We cannot give the rate of occurrence of titanium combustion incidents relative to flight or engine operating hours but the rate is apparently small compared to other causes of engine damage or unscheduled shut-down.

1.1 Reasons for Using Titanium

Considerable leverage exists in the relationship between airframe and engine mass. Jahnke has stated [4] that every unit of mass removed from an engine translates to four to eight units

* See glossary of combustion related terminology in Appendix A. 
that may be removed from the airframe and shows, figure 1, engine mass reductions made possible by using titanium and its alloys rather than other materials available in 1968. For a rotating element, the stresses produced by centrifugal loads are pruportional to the material density. We quote from a review article[5], "The use of titanium alloys instead of steels for compressor blades permits use of titanium disks of reduced section compared to that of steel and so an all-titanium blade-disk assembly shows a greater weight saving (about 52 percent) than would be expected (about 42 percent) from the difference in the densities of the respective materials." Taking advantage of titanium's unique strength-to-weight properties is clearly beneficial and is reflected in one engine which is about 35 percent titanium by mass, concentrated primarily in the fan and compressor. Many factors are traded-off when selecting a material for a particular temperature-stress regime. Today, titanium is not used at steady state above about $700 \mathrm{~K}$ ( $800 \mathrm{~F})$ primarily because of lower creep strength at elevated temperatures.

1.2 Basic Metallurgy

The first jet engine powered flight was in 1939 while the first production engine for commercial service using titanium went on the market in about $1954^{[1]}$. In the evolution of the engines, the amount of titanium in the structures increased; concurrently, efforts were devoted to improving strength-to-weight ratio, fatigue and corrosion resistance and tolerance for mechanical and thermal shock. At room temperature, the equilibrium crystal structure of titanium is close packed hexagonal (cph); this structure is denoted $\alpha$. At high temperatures, the equilibrium crystal structure is body centered cubic (bcc), called $\beta$. For pure titanium, the phase transformation between alpha and beta crystal 


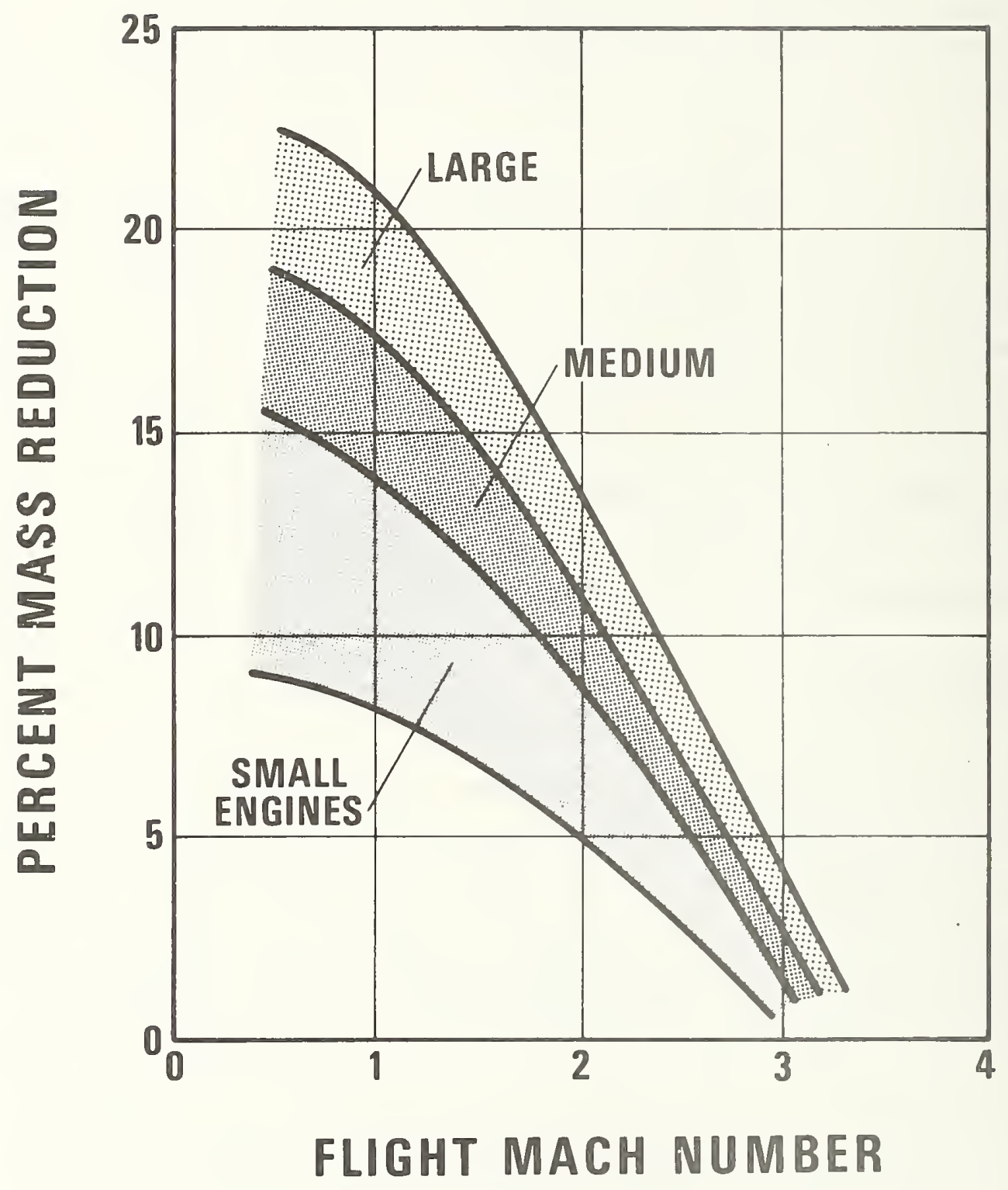

Figure 1. Estimated engine mass reduction through the use of titanium. (Reprinted from The Science, Technology and Application of Titanium by L.P. Jahnke by permission of Pergamon Press. Year of first publication 1970). 
structures, or beta transus, occurs at about $1160 \mathrm{~K}$ (1625F). Most close packed hexagonal metals are more ductile than body centered cubic metals which have higher moduli and lower toughness.

1.2.1 Effects of alloying elements.

Alloying elements not only modify such properties as strength, moduli, hardness and toughness, but also alter the beta transus temperature which affects the heat treating procedures for the different alloys. Aluminum is an alpha stabilizer (raises the transus temperature) along with carbon, oxygen and nitrogen while copper, chromium, columbium, iron, manganese, molybdenum, tantalum and, importantly, vanadium act as beta stabilizers, lowering the transus temperature[6]. We quote from [6]: "Alpha alloys are weldable, non-heat treatable, stable up to about 1000F, strong and tough at cryogenic temperatures, more oxidation resistant than beta or alpha-beta alloys and relatively difficult to form. Beta alloys are generally heat treatarle, weldable, stable up to about $600 \mathrm{~F}$, strong at higher temperatures for short time periods, relatively strong below - l00F and quite formable at room temperature.

"Alpha-beta alloys are somewhat of a compromise between the single phase alpha and beta alloys. They are heat treatable, stable to $800 \mathrm{~F}$ (in some cases $1000 \mathrm{~F}$ ), strong and more formable than alpha alloys. However, they are less tough than alpha alloys and, for the most part, difficult to weld."

The effects of some of the alloying elements on the crystal structure and properties are shown in figure 2 which makes a further distinction in structure of near alpha and near beta.

As materials properties research progressed, emphas is was also placed on processing and fabrication development. For 
Alpha-Stabilizing
Elements

For example:

Aluminum

Oxygen

Nitrogen
Beta-Stabilizing

Elements

For example:

Molybdenum

Iron

Vanadium

Chromium

Manganese

Increasing Quantities of Alpha Stabilizers Promote Alpha Phase

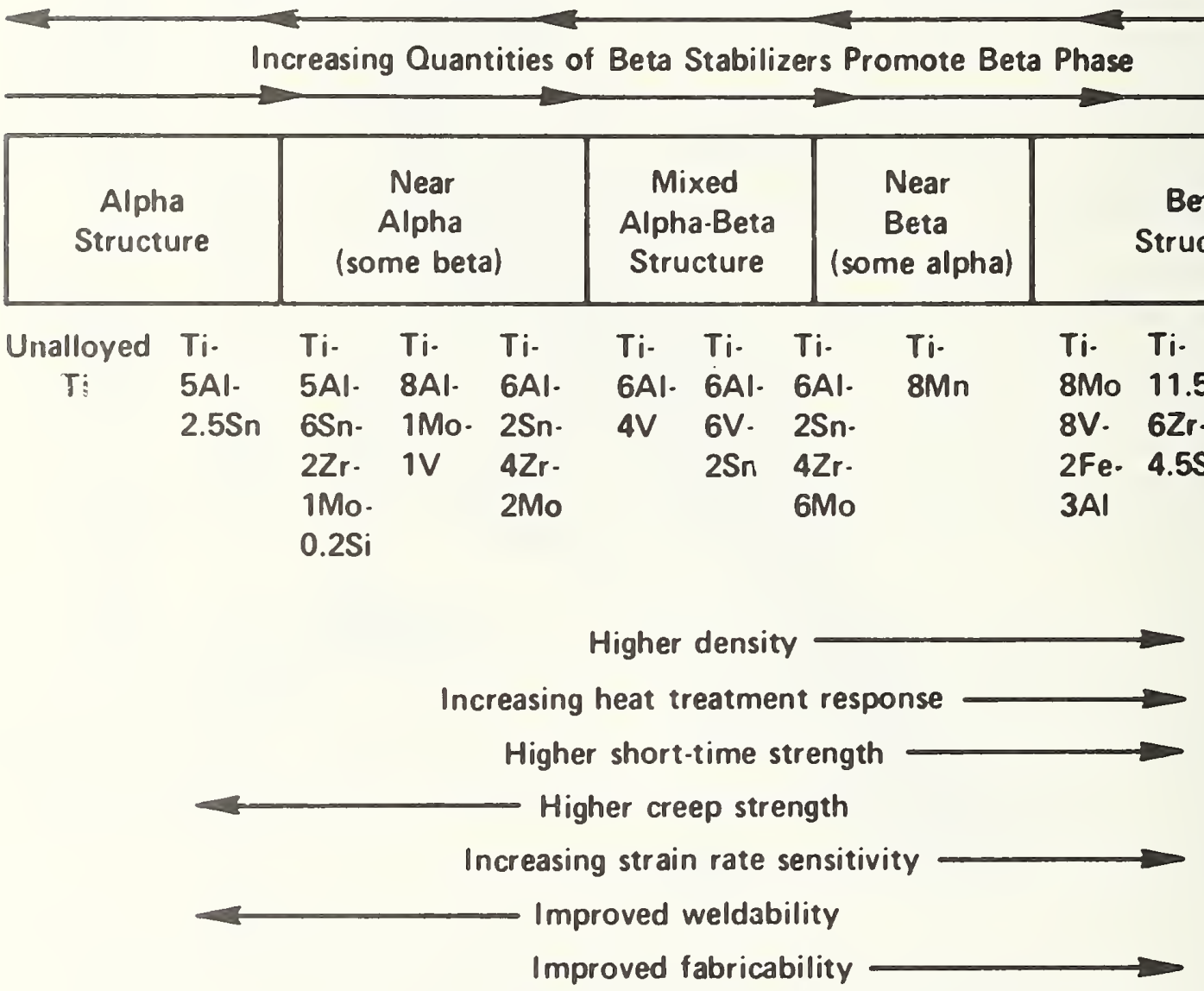

Figure 2. Schematic relationships: Titanium alloying effects on structure and selected alloy characteristics. (Reprinted from The Titanium Industry in the mid-1970's by R.H. Wood by permission of The Metals and Ceramics Information Center. Battelle Columbus Laboratories. Year of first publication, 1975 ). 
example, double and even triple vacuum arc, consumable electrode melting was found necessary to reduce the amount of hydrogen to below embrittlement levels, eliminate tungsten from fixed electrodes and prevent alloying element segregation [2]. Improved techniques for heat treatment, welding, machining, casting, forging and diffusion bonding were developed, all aimed at lower cost, lower weight or improved performance.

\subsection{Report Format}

The report that follows discusses where titanium is used in turbine engines, what the experience has been with combustion of these parts, including a breakdown of probable causes and the extent of possible damage, and what preventive measures have been taken to limit this damage. Further, the fundamentals of titanium combustion are outlined with a discussion of both static and dynamic laboratory experiments. An analysis of some of these experiments shows a potential correlation which is followed by a general discussion of the whole survey. Conclusions appear on page 87 .

\section{CURRENT TITANIUM USE}

2.1 Titanium Applications in Turbine Engines

The list of titanium components in Table 1 was compiled from the information available to us on four current commercial engines. Obviously, not all of the parts are in each of the engines because of design differences, rather the lists in the table are composites. However, all four engines have titanum fan blades, fan disks or hubs, low-pressure compressor blades and disks or drums, and high pressure compressor blades and disks or impellers. The titanium components in a modern turbofan engine are shown in figure 3 . 
Table 1

Titanium Components in Four Modern Turbofan Engines*

$\underline{\text { Fan }}$

Parts of spinner

Blades

Hub or disk

Case

Inlet guide vanes

$1 / 4$ stage cone

Bearing support

Mid ring

Bypass stator vanes

splitter lip

Main mount frame

Exit case

$$
\begin{aligned}
\text { *Alloys } & \text { Ti-6Al-4V } \\
& \text { Ti-5Al-25Sn } \\
& \text { Ti-6Al-2Sn-4 } \mathrm{Ar}-2 \mathrm{MO} \\
& \text { Ti-8Al-1V-1Mo }
\end{aligned}
$$

Low Pressure

Compressor

Blades

Disks

Inlet guide vanes

Stator vanes

Stator vane spacers

Case
High Pressure

Compressor

Blades

Disks

Case

Impeller

Bleed Air Manifolds

2.2 Limits to Titanium Use

The alloys selected for similar components vary among the manufacturers but none use titanium above about 700K (800F). This steady state temperature limit is imposed by insufficient creep strength, not by combustion considerations. At this time, there is no clear evidence that any of the currently used alloys, including pure titanium, are more or less easily ignited or prone to sustained or propagating combustion. Differences in combustion characteristics have been noted [7] but the effects are not 


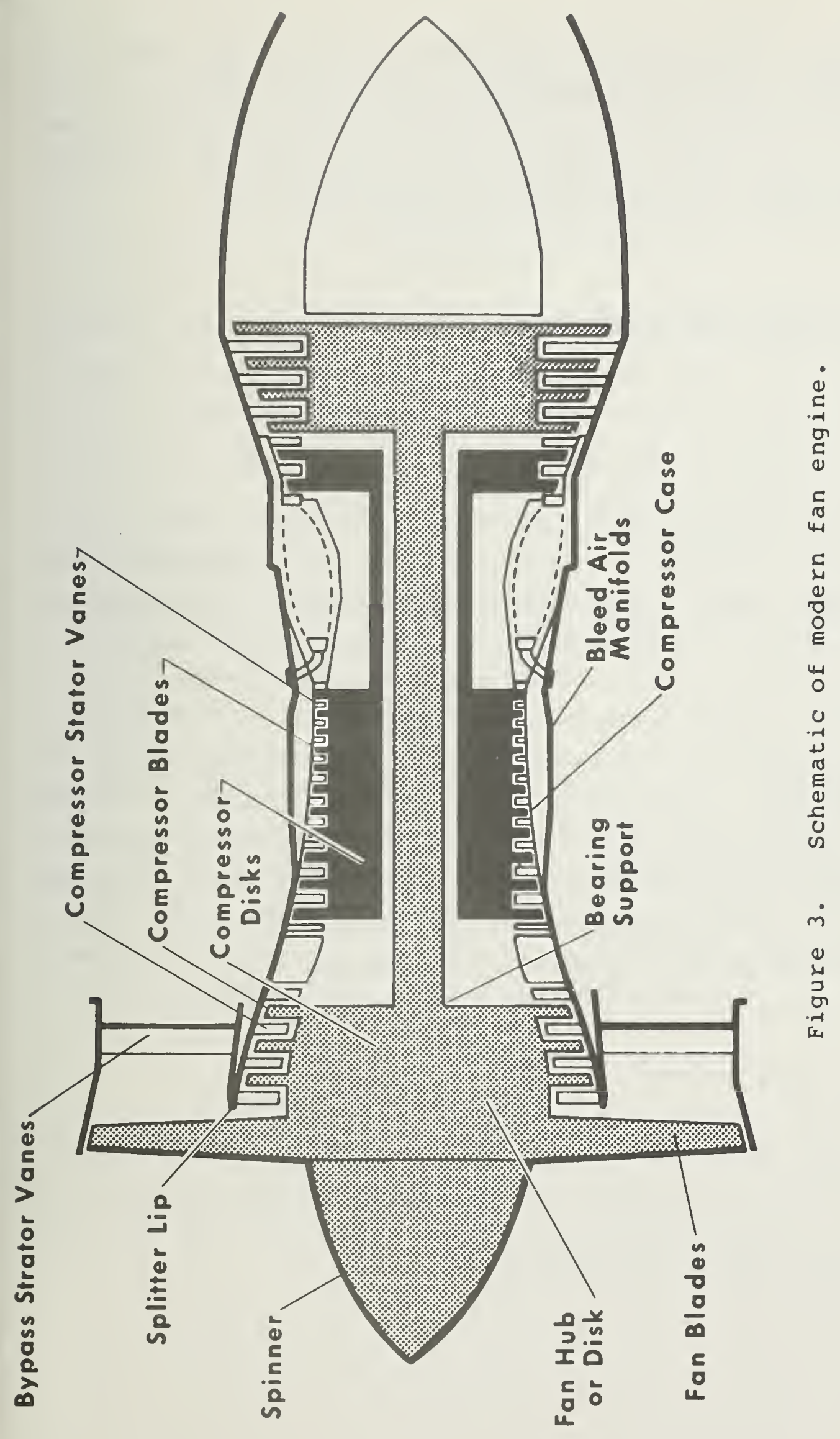


fully understood. The question of whether or not alloy substitution would prevent combustion propagation under the same initiating circumstances has not been answered and alloy substitution may not be possible for certain components for many reasons including strength, brittleness, manufacturing problems and room.

\section{TItANIUM COMBUStion EXPERIENCE}

\subsection{Sources}

The open literature rarely contains mention of titanium combustion in engines[4], [5], [8], [9], [10], [11] and never, to our knowledge, any detail of the event(s). The information for this section comes from four engine manufacturers, the Federal Avaition Administration (FAA), National Transportation Safety Board (NTSB) and one airline. The tabulations are incomplete since all possible sources could not be contacted and all events may not be reported to central offices. Certain events may go unnoticed; for example, minor blade tip combustion may be attributed to erosion. Finally, we are not aware of any requirements or avenues for reporting and compiling information relative to titanium combustion in aircraft engines within the FAA, NTSB or the military, and the manufacturers and operators are generally hesitant to reveal such information although there are exceptions.

\subsection{Combustion Occurrences}

Table 2 gives the total number of occurrences known to us of titanium combustion in aircraft gas turbine engines since 1957 and the number of contained and non-contained cases. In only two cases were engine damage details available [3]. 
Table 2

Titanium Combustion Occurrences*

$\begin{array}{lr}\text { Total known } & 144 \\ \text { Contained+ } & 85 \\ \text { Non-contained }^{+} & 59\end{array}$

*These data accumulated since 1957 from both U. S. and foreign sources are incomplete for reasons given above and therefore the division between contained and non-contained cases may be biased. We believe that each occurrence resulted in engine shutdown.

+Contained is defined as titanium combustion which did not penetrate the case.

+Non-contained is defined as a case penetration caused by titanium combustion.

Since the limiting service temperature for titanium and it's alloys of about $700 \mathrm{~K}(800 \mathrm{~F})^{\prime}$ is well below the ignition temperature of titanium in air of about $1900 \mathrm{~K}$ (2900F), some upset of the normal operating conditions must occur to either mechanically or aerodynamically raise the temperature of a titanium structure to the ignition point before combustion can occur. The upset mechanisms can be catagorized as: 
Mechanical rubbing

Foreign or domestic objects

Imbalance

Rotor displacement

Case bending

Stall induced mechanical displacement

- Aerodynamic heating

Stall

Mechanical rubbing or jamming can arise from several causes. Loose particles of solid material, either ingested from outside or articles broken within the engine can interfere between rotating and static structures or bend blades so that they strike the vanes. Very rapid temperature rise from frictional heating is possible. Failure of a rotating part (disk, spool or blade) can result in rotor unbalance sufficiently large to cause heavy rubbing. A failed bearing can allow radial or axial displacement of the rotor with subsequent rubbing and in some instances rubbing has occurred because of case flexing. Reverse flow through the compressor resulting from surge or compressor stall can deflect the rotating blades into the static structure and flow from the aft combustion section of the engine can be at high temperature. (Combustor flames temperature is typically $1900 \mathrm{~K}$ (2900 F)).

In so far as possible, Table 3 lists the circumstances preceeding or the primary events leading to titanium combustion. Many of the test cell events occurred while the engine was deliberately being operated outside of the design envelope. The large number of cases in which the primary cause is not known points out the inadequacy of the data base with which we must deal at this time.

Disregarding the test cell events and those for which the cause is unknown, blade failure contributed to 22.5 percent of the incidents followed by turbine failures at 20 percent. 
Table 3

Circumstances Preceeding or Event Leading to Titanium Combustion

$\begin{array}{lr}\text { Unknown } & 97 \\ \text { Blade failure } & 9 \\ \text { Turbine failure } & 8 \\ \text { Test cell } & 7 \\ \text { Bird strike } & 4 \\ \text { Disk or spool failure } & 4 \\ \text { Vane failure } & 3 \\ \text { Bearing failure } & 3 \\ \text { Stall } & 3 \\ \text { Other } & 3 \\ \text { FOD } & 2 \\ \text { Air Seal } & \text { TOTAL } \\ \end{array}$

From these data it is not obvious that there is one major cause of titanium combustion in aircraft engines. In some of the cases, it is evidently straightforward to determine the cause and the following sequence of events. For other cases, it may be impossible to determine the cause and to trace the mechanical and chemical damage progression in the four to twenty seconds that have been estimated for the duration of a typical event.

\subsection{Extent of Combustion Damage}

Combustion damage has ranged from light tip and trailing edge combustion of airfoils to massive metal involvement [10], sometimes with $360^{\circ}$ case penetration [3]. Once started in an engine, titanium combustion continues until either the titanium fuel is depleted, the air pressure falls below some critical value, the combustion zone progresses to a heavy section where enough heat 
is conducted away for quenching or the ignition energy source is removed. Energy from the exothermic reaction is transferred away from the combustion site by solid conduction, radiation, convection and in the products of combustion and molten metal that may be blown or thrown away. As long as the heat of combustion is greater than or equal to the heat transfer away from the site and there is sufficient oxygen, the reaction will continue. The thin leading and trailing edges of an airfoil appear to be preferentially damaged with several possible contributing factors. Conduction away from the combustion site is inhibited by the smaller cross sectional area so the temperature of the base metal will rise. Additionally, the reaction may take place on both sides of the thin section. Finally, the nature of the airflow all around the blade and the flow of molten metal toward the trailing edge can explain some of the effects. Minor trailing edge damage is shown in figure 4, while the tendency to consume the thin sections is evident from the rounded shape of the blades in figures 5 and 6 . In figure 5, the rough deposits are titanium oxides which are brittle and shaded from grey at the tip of the stub to black inboard on the blade. If the deposits are on one side only, heat effects are see on the undisturbed side progressing from neutral grey at the tip to light brown, to neutral grey to blue, a hint of the brown and finally parent metal color.

Below is a description of an engine intended to illustrate the nature and extent of damage possible in a severe event. The description is a composite of several damage reports. Typical heavy damage with the first evidence of sustained titanium combustion at midstage of the high pressure compressor, could be as follows:

1. High pressure compressor rotor

1.1 Forward of midstage, evidence of heavy tip rub several stages.

1.2 First few stages, very light blade damage from rub. 


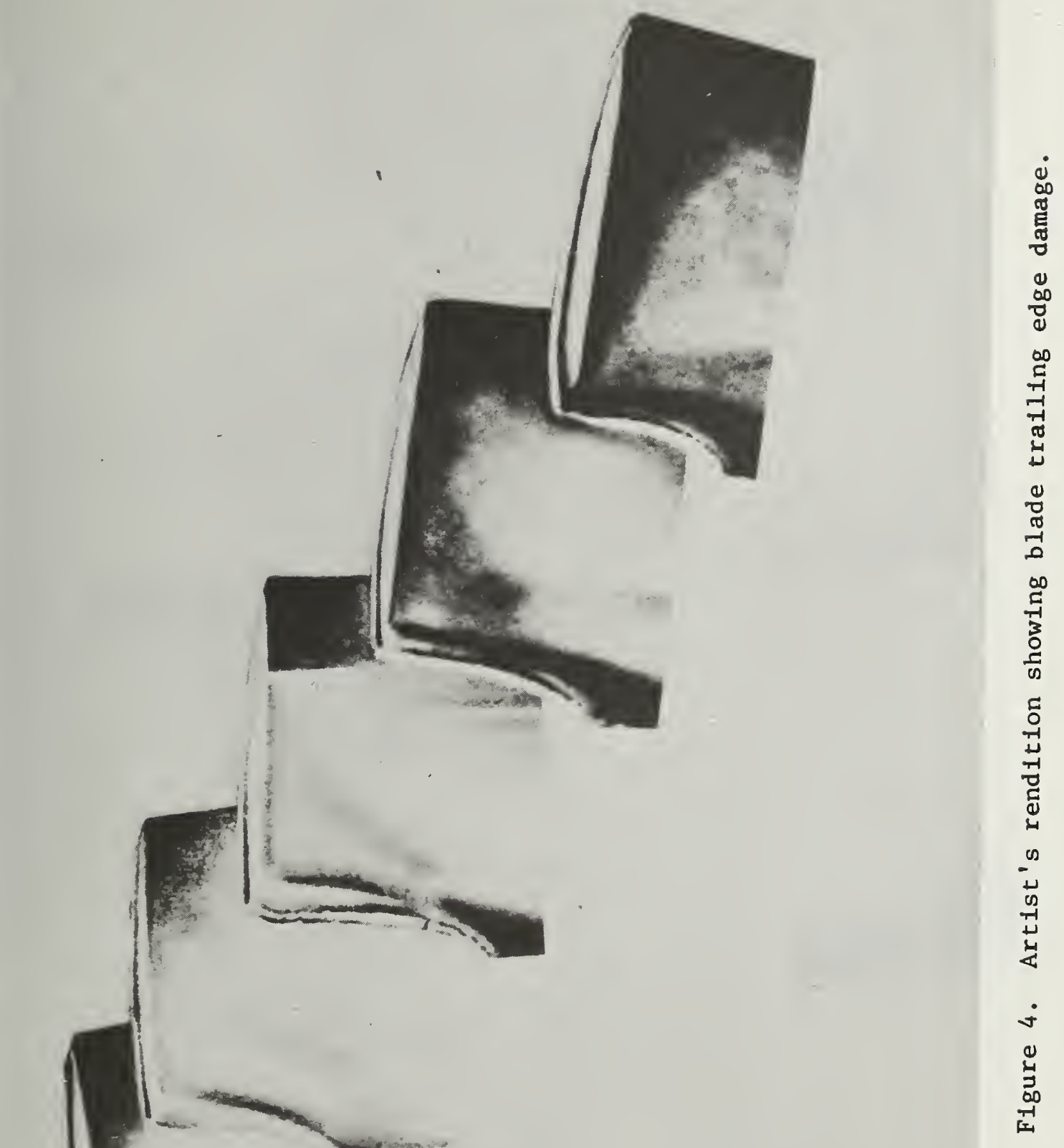



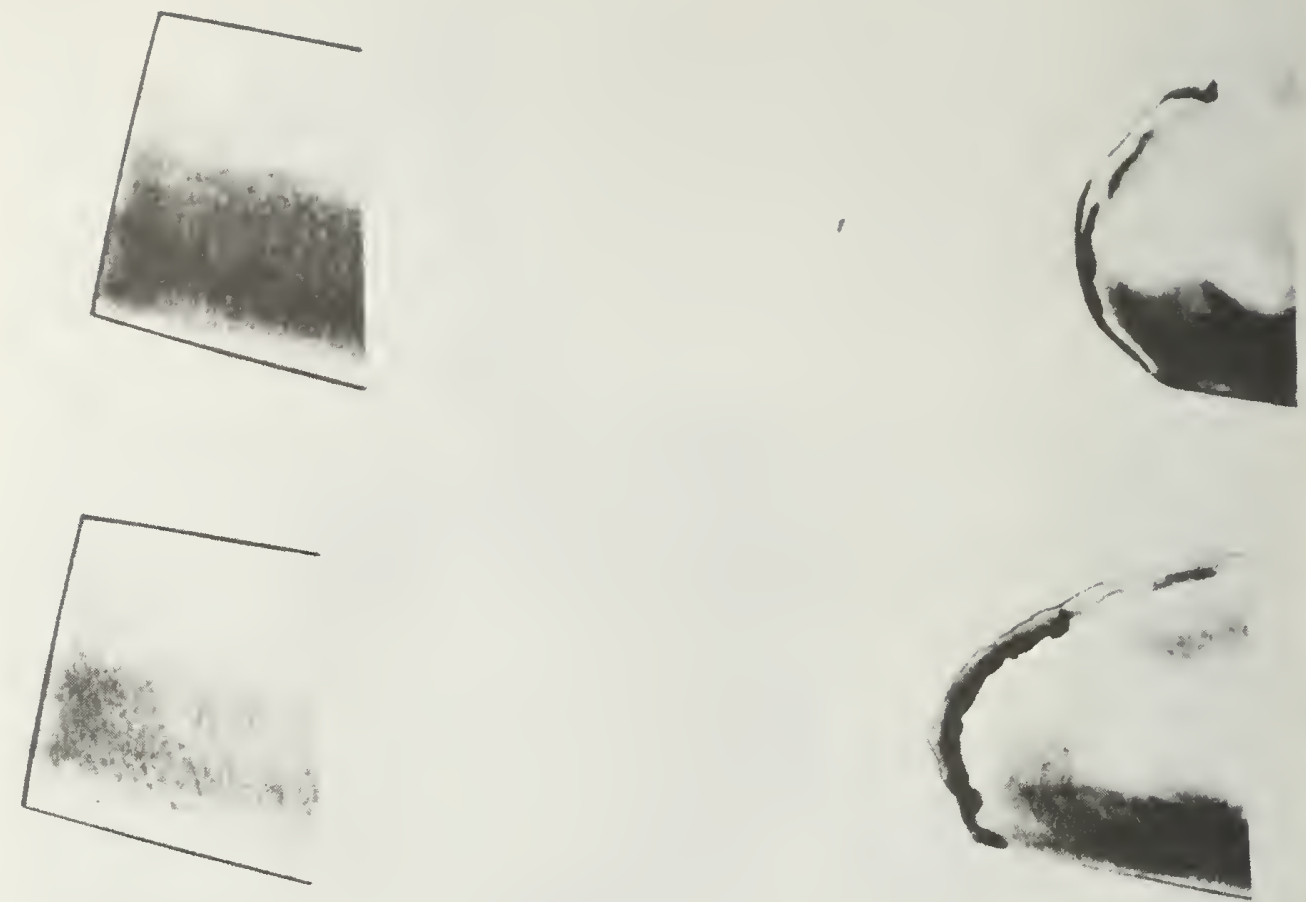

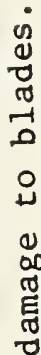
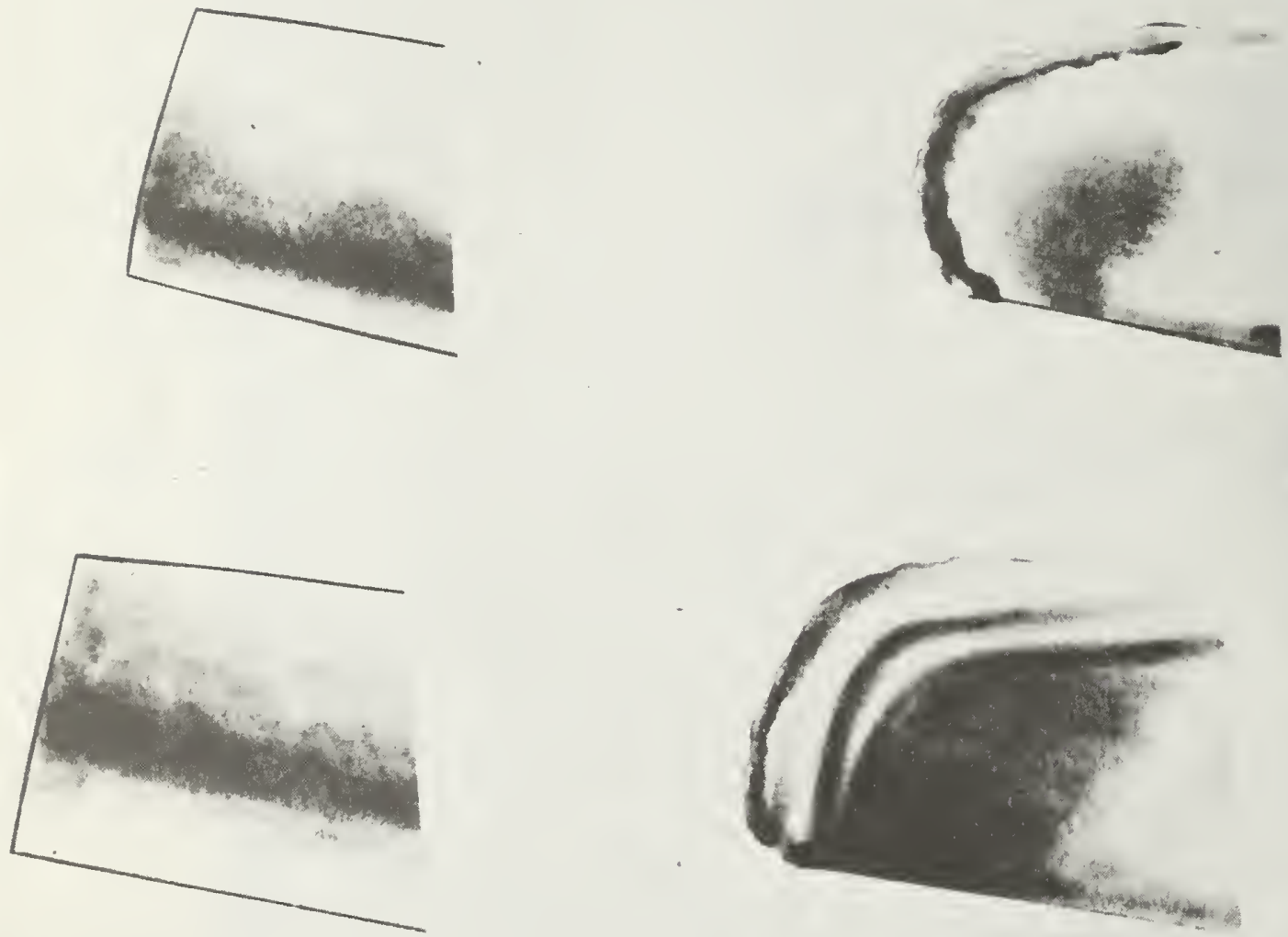

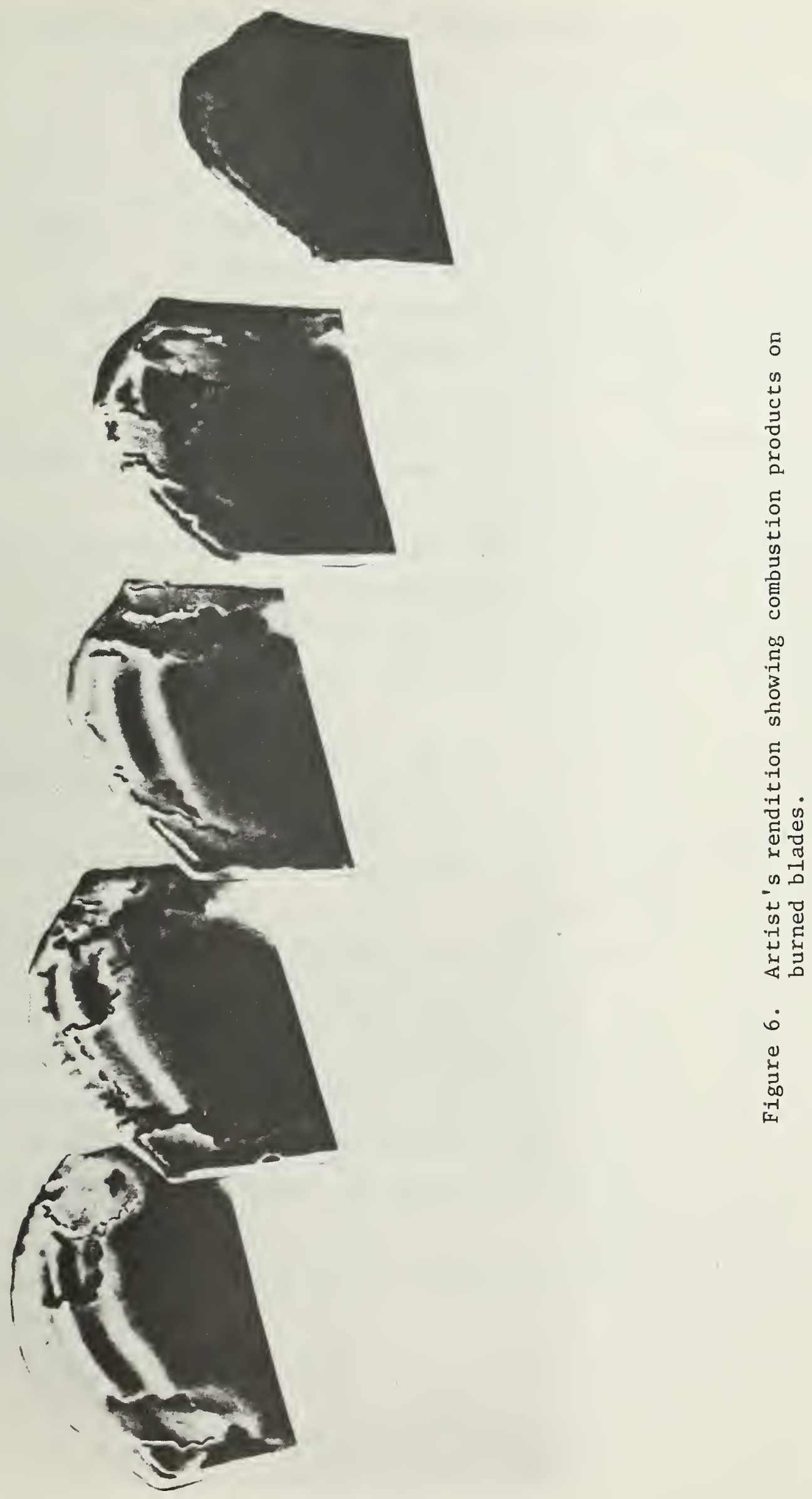
1.3 Next few stages, increasing evidence of combustion products on aft side of airfoils. Witness marks show some blades had touched neighbor.

1.4 Next few stages, evidence of non-sustained airfoil melting or combustion on tips and trailing edges. Accumulation of combustion products or slag on aft side of airfoils.

1.5 Midstage, substantial blade combustion.

1.6 Aft of midstage, heavy combustion, all airfoils gone.

2. Combustors

2.1 Deposits of combustion products, especially at fuel nozzles.

2.2 Liner burning, cracking and distortion due to flow irregularities.

3. Turbine section

3.1 Distortion of inlet guide vanes with heavy metal deposition.

3.2 Deposits of combustion products decreasing in aft direction. Heat distortion under some deposits.

4. High pressure compressor case

4.1 Forward of midstage, evidence of heavy rub several stages.

4.2 First few stages, evidence of light stator vane shroud rub from forward deflection.

4.3 Next few stages, unharmed, increasing evidence of combustion products on aft side of vanes.

4.4 Next few stages, evidence of non-sustained vane melting or combustion at trailing edge. Accumulations of combustion products or slag, both sides.

4.5 Midstage substantial vane combustion. 
4.6 Aft of midstage, heavy combustion, all vanes gone.

4.7 Just forward of midstage, case overheated $360^{\circ}$, light combustion

4.8 Midstage, case overheated, evidence of molten titanium.

4.9 All bleed air manifolds penetrated by combustion.

4.10 Aft manifold penetration directed airflow carrying molten titanium toward forward manifold, causing melt through.

5. Exterior to case

5.1 Several air and oil lines penetrated by combustion. Fuel lines intact but shroud penetrated.

5.2 Fire warning system wires parted by melting.

5.3 Overpressure damage to cowling. 


\subsection{Design Philosophy}

Millions of hours of service experience coupled with research to reduce the chance of titanium combustion and limit damage have induced modifications of design philosophy in several areas over the years. Design goals sought by the manufacturers can be summarized as follows:

- Reduce possibility of ignition.

- Minimize possibility of propagating combustion.

- Eliminate case penetration.

Several precautionary measures can be incorporated to try to achieve these design goals. After a brief discussion of which titanium parts are susceptible, some of these measures are discussed below, several of which also have other purposes (e.g. rub strips for increased efficiency). Rub strips, coatings, and increased clearances help reduce ignition possibilities and the alternate materials and linings help inhibit propagation.

\subsection{Design Measures}

The trend [3] is toward less aggressive use of titanium in modern designs, especially for static structures in the higher pressure section of the compressor. We are not aware of any instance of titanium combustion in the fan or lower pressure compression regions where the oxygen concentration and temperature are low. While rotor blades and structures have been involved in combustion events and indeed are frequently the ignition source, the stator vanes and casing are susceptible to extended damage since molten metal tends to sling off the rotating blades and collect on the static parts. A drop of molten titanium on a blade tip may be 
subjected to radial acceleration of $10^{4}$ to $10^{5}$ times the acceleration of gravity. The centripetal force holding a growing molten drop on a blade tip is coupled to the drop through surface tension. At some drop diameter, the surface tension force is no longer sufficient to provide the centripetal acceleration and the drop breaks away, traveling tangentially. A first order calculation, neglecting aerodynamic drag forces, shows that the drops leaving a $76 \mathrm{~cm}$ (30 in) diameter rotor revolving at 10,000 RPM will be about $0.1 \mathrm{~mm}$ $(0.004 \mathrm{in})$ in diameter, a fine spray with a high surface to volume ratio. This high surface to volume ratio, both 'while traveling to the static structure and after impinging more or less evenly, promotes high rates of oxygen solution.

Molten, reacting metal leaving the blades and arriving on the case and vanes is a highly effective heat transfer mechanism that tends to quench the blades and heat the static structures. Ignition of the static structures is entirely possible and one instance of a steel case being melted or burned through by a pool of molten titanium has been recorded[3].

\section{Rub Strips}

Aside from stall or aerodynamic heating, rubbing, can cause ignition. Rubs may result from foreign object damage (FOD), domestic object damage (DOD), stall, bearing failure or case deflection. During a titanium-on-titanium rub, both low thermal conductivity titanium structures may rapidly rise to the ignition temperature which is below the melting point. Therefore, designs incorporate rub strips or coatings on lands and seals that prevent for example, the rotating titanum blades from touching the titanium case. There is a limit to the amount of violence these rub materials can tolerate since they have finite thickness. A deep incursion may penetrate, wear away or melt the rub strip and bond layer exposing underlying titanium. Nonetheless, the rub strips appear to 
significantly reduce ignition. Note that it is. improbable that rubs will be eliminated and that some light rubbing is considered normal.

Several different materials are used for rub strips ranging from filled elastomers in the low temperature regions to sprayed metallic coatings, felt metals and steel at higher temperatures. To be successful, the rub strip must be able to limit the energy deposition and hence the temperature in the underlying titanium. Some of the materials will deform or abrade away easily. The elastomers are physically cut out or abraded away by interferring blade tips or labyrinth knife edges with relatively low force which translates to low energy. Felt metals, used at higher temperatures are deformed by interference also with low energy. Others such as aluminum and steel may melt and provide large enough clearance so there is no longer interference. Aluminum's relatively high thermal conductivity tends to spread the friction energy over a larger volume with resulting lower temperatures.

Another purpose served by these sacrificial rub materials is that they can, in a sense, absorb molten titanium emanating from the rotating structure. The temperature of a molten reacting titanium drop will be at least $2000 \mathrm{~K}$ (3200F). Upon impinging on aluminum, for example, heat transfer will immediately start to cool the drop and heat the aluminum to the melting point thus tending to quench the reaction. If the drop temperature goes below about $1850 \mathrm{~K}$ ( $2900 \mathrm{~F})$ the combustion reaction will stop.

\section{Coatings}

Coatings and surface treatments to prevent ignition and combustion of titanium structures offer some promise. Some proprietary experimental work has been done, the military have conducted programs directed to harden structures against laser damage and 
NASA is conducting protective coatings evaluations. The coatings are intended to prevent ignition by conducting heat away from the potential ignition site or to quench combustion, also by conduction. The degree to which molten titanium will wet the coating can also be important or some of the materials could break down before ignition temperature is reached. At this time, a few candidates have been found to suppress ignition and combustion but lack required mechanical properties. The effects of shot peening have not been reported.

\section{Clearances}

Wider radial and axial clearances have been suggested (and in some cases employed) to reduce the occurrence of tip rub and rubbing trapped debris. Larger axial clearance reduces the chance of stator vane-rotor blade clashing caused by stall; however the stall margin will be decreased. The effects of wider clearances on efficiency are not within the scope of this report; however, efficiency is usually degraded by opening up clearances.

\section{Other}

Some more flexible engines have been found susceptible to rubbing caused by deflections from thrust and maneuvering as well as unbalance loads. Offset machining has been used to inhibit ignition from deflection rubs and stiffer case designs have been proposed[12]. Offset machining of the case provides greater radial clearance where deflection rubs may occur.

Bleed air manifold entrance edges, found to be susceptible to ignition by molten titanium spray have been protected by steel grommets[12], in a sense coating those areas. All-steel linings for the manifolds have been suggested in some cases. 
Increased tolerance to foreign objects is desirable for many reasons other than just a reduction in the chance for titanium combustion. However, there is a practical limit to the type or size of ingested material that will not cause damage. Both FOD and DOD (arising from a mechanical failure in the engine) will probably never be eliminated although blade, disk and vane design, materials and inspection techniques are continuously being improved to increase toughness and reliability.

Finally, substitution of alternate materials for titanium in those regions of the engine most susceptible to combustion is an avenue taken in some designs and suggested by the British Civil Aeronautics Authority (CAA) (see Appendix B). The CAA document requires that thin titanium sections not be employed as static structures in the engine where the pressure exceeds 2 atm (29.4 psia) and the velocity is above $50 \mathrm{~m} / \mathrm{s}(164 \mathrm{ft} / \mathrm{s})$. This proposal would rule out titanium stator vanes in all but about the first four stages of compression (assuming a compression ratio of 1.2 per stage). As mentioned, the weight penalty incurred by substituting other materials for titanium in static structures is lower than for rotating parts. A CAA paper referenced in Appendix B shows that there have been titanium fires in all three of the example engines with titanium stator vanes while seven out of the eight engines without titanium stator vanes have not had any known combustion events. However, complete compliance with the suggested guidelines might not assure complete elimination of titanium combustion.

\subsection{Extinguishment}

From start to finish, the time for propagating titanium combustion in an engine has been estimated at 4 to 20 seconds. We are not sure of the titanium extinguishing effectiveness of on board agents such as carbon fluoride or carbon bromide driven by 
fluorocarbons, but Fox [13] has shown that $\mathrm{CO}_{2}$ supports titanium combustion better than air. At 23 percent $\mathrm{CO}_{2}$ by volume, the combustion rate increased 50 percent and at nearly 100 percent $\mathrm{CO}_{2}$, the increase in burn rate was 300 percent. A 60 percent by volume mixture of argon in air effectively extinguished titanium fires. It is suspected that helium would also be effective. In either case, the short duration of the event inside the engine, coupled with the need for large amounts of agent make detecting, reacting and extinguishing seem impractical at this time. No studies have been done as part of this effort to evaluate the aerodynamic and mechanical effects of suddenly introducing enough argon at molecular weight 39.9 into the airstream to raise the concentration to 60 percent. 
Experiments on metal combustion date back to at least 1782, when von Ingenn-Hausz plunged heated spirals of iron and steel into oxygen and observed that they ignited and burned, producing a great deal of heat and light[14]. Although nearly two hundred years have passed, metal combustion remains a little studied, poorly understood phenomenon, as previous reviewers have noted $[15,16]$. It is only during the past twenty years that significant progress has been made toward understanding the complex processes that occur when a metal burns. Yet, when our understanding of metal combustion is compared to the detailed knowledge we have of metal oxidation or the combustion of ordinary fuels, it is clear that the field of metal combustion is still in its infancy.

There are a number of reasons for the present lack of understanding. Foremost among them is the small amount of research on metal combustion, although it must be realized that until relatively recently there were few technologically important applications. Another factor contributing to our ignorance is the limited nature of the majority of research that has been published. There are few fundamental studies; most research has been applications-oriented and has focused on one or another aspect of the problem. Contributing to the confusion, there is no single forum for presentation of results: data pertinent to metal combustion is published in a wide range of journals crossing many disciplines. Finally, perhaps overriding all other considerations is the enormous complexity of metal combustion, consisting, as it does, of a large number of complex, interrelated chemical and physical processes. Indeed, to characterize completely the combustion of a single metal would require the services of a solid state physicist, a surface scientist, a physical chemist, an analytical chemist, a 
chemical engineer, a mechanical engineer, a thermodynamicist, a physical metallurgist, a pyrometallurgist, and a specialist in fluid dynamics. To date, no such interdisciplinary team has been assembled, although recent efforts of several independent groups funded by the USAF to study different aspects of titanium combustion are a step in this direction.

Because of the great complexity of metal combustion processes and the large number of factors that affect them, this section of the report begins with a general introduction to the distinctive characteristics of metal combustion and a discussion of fundamental concepts. These include the thermodynamics of metal-oxygen reactions, their kinetics, and the various mechanisms of metal oxidation, ignition and combustion. The remainder of the report reviews research on the oxidation, ignition and combustion of titanium and titanium alloys, with particular emphasis on research since 1972 on the problem of titanium fires in aircraft gas turbine engines. For the reader's convenience, there is a glossary of metal combustion terminology included as Appendix A.

\subsection{Characteristics of Metal Combustion}

Some insight into the difficulties facing the scientist who wishes to study metal combustion may be gained by examining Table 4 , which lists the factors affecting metal combustion. While the list is fairly inclusive, it is by no means exhaustive. In addition to the usual environmental factors that affect a chemical reaction (temperature, pressure, concentration of oxygen), there are a number of factors that depend on the particular configuration of the metal (size, shape, history, etc.) and a large number of material properties that affect the combustion process. Note that in most cases, the relevant material properties are needed for both the metal 


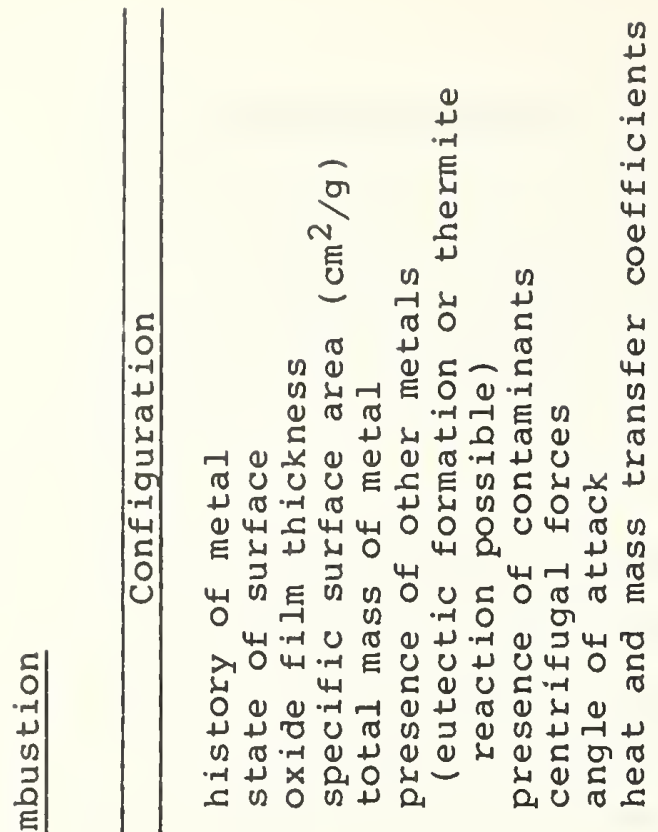

\footnotetext{
c5

$\rightarrow$

䓀艺

प्र $\rightarrow$ व

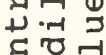

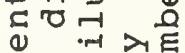

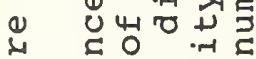

3 出

$\pi$ 讨 0

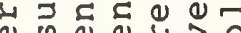

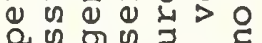

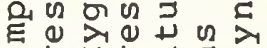

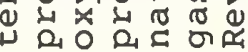

0
0
0
0
0
0
0
0

Oิ $\quad$ E $\bar{E}$

ซิ-

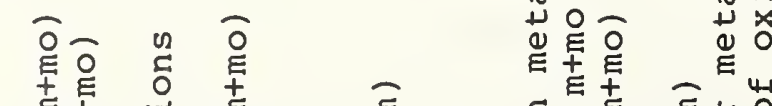

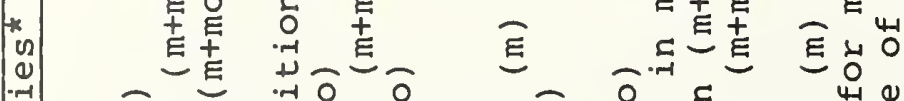
Oิ E.

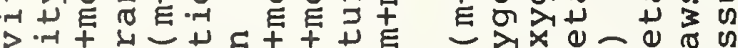
( EN.

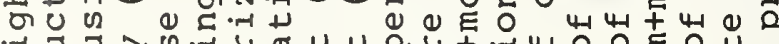

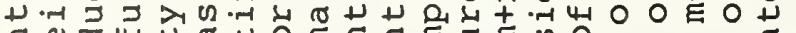

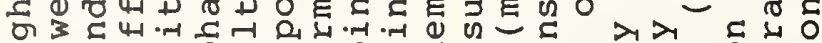

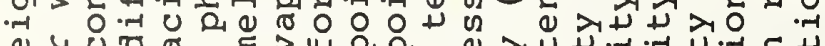
(1) 近 U ठ 3 0 , ( न1 न त . य ट ह (1) O

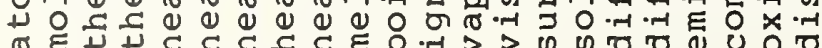


and its oxides. Where these properties vary with temperature, the variation must be known. In some cases, e.g. viscosity and surface tension, the properties change not only with temperature, but with the concentration of oxygen as well, and this dependence must be known too.

Many of the distinctive features of metal combustion are a direct result of the stability exhibited by most of the metal oxides. Their stability implies that the heats of formation for the compounds will be large and so a great deal of energy may be released during metal combustion. But the oxides' stability also means that the products of combustion, as well as the fuel, will be present in the reaction zone as condensed (solid or liquid) phases. Several important implications that follow directly from this fact are discussed below.

In the first place, very high temperatures will be attained during metal combustion. In the combustion of an ordinary hydrocarbon, the flame temperature is limited by dissociation of $\mathrm{CO}_{2}$. This begins to become appreciable at temperatures of about $1700 \mathrm{~K}$ $\left(1427^{\circ} \mathrm{C}\right)$ and effectively limit hydrocarbon flame temperatures to less than $2500 \mathrm{~K}\left(2227^{\circ} \mathrm{C}\right)$. Although most oxides decompose partially at elevated temperatures, the dissociation pressure of the base metal oxides remains very low at quite high temperatures. Thus, the upper limits on the temperature of a metal flame will be the boiling point of the metal oxide. Because metal oxides evaporate nonstoichiometrically, the boiling point must be defined in terms of the equilibrium of the condensed oxide with its gas phase decomposition products at the ambient pressure. The adiabatic combustion temperatures (see glossary) for several metals burning in oxygen at 1 atm are listed in Table 5[14]. It is obvious that temperatures in excess of $3000 \mathrm{~K}\left(2727^{\circ} \mathrm{C}\right)$ are quite common in metal combustion. 
Table 5. Adiabatic Combustion

Temperatures in Oxygen at 1-Atmosphere Pressure [14].

$\begin{array}{lr}\text { Metal } & \begin{array}{c}\text { Adiabatic Core } \\ \text { Temperature }\end{array} \\ \text { Al } & 2900 \\ \text { Ba } & 3000 \\ \mathrm{Be} & 4300 \\ \mathrm{Ca} & 3800 \\ \mathrm{Cr} & 3300 \\ \mathrm{Fe} & 3000 \\ \mathrm{Hf} & 4800 \\ \mathrm{Mg} & 3350 \\ \mathrm{Mn} & 3400 \\ \mathrm{Mo} & 3000 \\ \mathrm{~Pb} & 1800 \\ \mathrm{Sn} & 2700 \\ \mathrm{Sr} & 3500 \\ \mathrm{Th} & 4700 \\ \mathrm{Ti} & 3300 \\ \text { W } & 3200 \\ \mathrm{Zn} & 2200 \\ \mathrm{Zr} & 4800 \\ & \end{array}$

The presence of metal oxides in the reaction zone also means that at they will play a role in determining the rates and mechanisms of the combustion process. This is perhaps best illustrated in the criterion proposed by Glassman to predict the combustion mode for metals[17]. If the boiling point of the metal oxide is higher than that of the metal, then the flame temperature can exceed the metal's boiling point, the metal will evaporate and combustion will occur in the vapor phase. On the other hand, if the metal oxide's boiling point is lower than that of the metal, the flame temperature cannot reach the metal boiling point and surface combustion will result. Because vapor phase combustion can be suppressed, either by the formation of a protective oxide layer or by reduction of the flame temperature below the metal boiling point by radiation losses, this criterion must be modified slightly. Thus, the metal oxide's boiling point exceeding that of the metal is a necessary but not sufficient condition for vapor phase combustion, while the opposite case of a metal's boiling point exceeding that of the oxide is a sufficient but not necessary condition for surface combustion. 
On the basis of Glassman's criterion, titanium, iron, steels, nickel, zirconium, and hafnium are predicted to burn on the surface, while magnesium, calcium, strontium, barium, and aluminum, are predicted to burn in the vapor phase.

The presence of metal oxides in the combustion zone can also have a strong influence on the propagation of metal fires. Due to the refractory nature of metal oxides, most of the heat of reaction will reside in the enthalpy of the products. In a surface burning metal, the molten oxide products will collect on the surface where their heat content aids in melting more metal. This molten mixture of metal and oxide with a high heat content can then be spread to other parts of a structure by centrifugal action or by aerodynamic forces and thus aid in spreading a fire rapidly.

Two other characteristics of metal combustion deserve mention: the very high radiant emission of burning metals and the frequent occurrence of fragmentation and explosions during combustion. The highly luminous character of metal flames is, of course, a direct result of their high temperatures; at temperatures in excess of $3000 \mathrm{~K}\left(2727^{\circ} \mathrm{C}\right)$, a significant fraction of the thermal radiation falls within visible wavelengths. Even metals that burn in the vapor phase have highly luminous flames owing to the presence of large numbers of condensed oxide particles which give the flames a high emissivity. This characteristic feature of metal flames is used to good advantage in one of the continuing practical applications of metal combustion: the photographic flashbulb.

The violent fragmentation and explosions which often accompany metal combustion are not as readily understood. Explosions are most often observed during the combustion of small particles ( $d<1 \mathrm{~mm}$ ) of reactive metals like zirconium, titanium, tantalum and aluminum[10]. Small particles of these metals will explode 
shortly after being ignited in an oxidizing atmosphere. Nelson discovered that for zirconium droplets to burn explosively, nitrogen had to be present, either in the metal or in the oxidizing atmosphere[21,22]. Presumably similar considerations apply to the other metals. When larger quantities of metal are burned (> $100 \mathrm{mg}$ ), they no longer explode violently, but rather "boil" vigorously, ejecting a continuous spray of small molten droplets which continue to burn and may, themselves, explode[23]. A photograph showing this behavior during the later stages of titanium combustion is included in figure 12 (see section 6).

It must be emphasized at the outset that there is no fundamental difference between oxidation and combustion, only one of degree. Chemically and thermodynamically, metallic oxidation is really just slow burning: slow enough that the metal can dissipate the heat generated to its surroundings, thus preventing a temperature rise. Ignition is a thermal instability that occurs when the heat generation rate from the chemical reaction exceeds the metal's ability to dissipate it, thus leading to a thermal runaway. The steady state combustion that follows ignition is a new equilibrium state where, again, the heat generation rate, which is now governed by a new set of rates and mechanisms, is just balanced by the heat lost to the surroundings. The critical difference between oxidation and combustion, and it is an important one, is the rate at which the chemical reaction proceeds. During the linear, non-protective oxidation of titanium at $1268 \mathrm{~K}\left(995^{\circ} \mathrm{C}\right)$, the rate of oxidation is $2 \times 10^{-3} \mathrm{mg} \mathrm{O} \mathrm{O}_{2} / \mathrm{cm}^{2} \cdot \mathrm{s}[18]$. The corresponding rate during steady-state combustion at $3250 \mathrm{~K}\left(2977^{\circ} \mathrm{C}\right)$ is $1 \times 10^{2} \mathrm{mg} 0_{2} / \mathrm{cm}^{2} \cdot \mathrm{s}$ [19]. The combustion rate is thus 50,000 times faster than the oxidation rate.

\subsection{Thermodynamics of Metal-oxygen Reactions}

None of the metallic elements are chemically inert, although their relative activities vary markedly, depending on position in the periodic table. In particular, with the exception of gold, no metal or alloy is stable in air at room temperature. All other metals and alloys will form oxides; many form nitrides as well. 
The force that drives metal oxidation is the free energy change associated with the formation of a metal oxide. Since the metal oxides are as a rule highly stable, they have a lower free energy than the free metal; consequently, metal oxidation is a thermodynamically favored process.

The overall chemical equation for the reaction between a metal and oxygen to form the metal oxide may be written as

$$
\mathrm{aMe}+\frac{\mathrm{b}}{2} \mathrm{O}_{2}=\mathrm{Me}_{\mathrm{a}} \mathrm{O}_{\mathrm{b}}
$$

This is a reversible reaction; the direction it proceeds depends upon the concentration of oxygen present in the gas phase. If the partial pressure of oxygen is greater than the dissociation pressure of the oxide at the ambient temperature, then the metal will be oxidized. The metal will remain unaffected and any metal oxide will decompose if the ambient oxygen partial pressure is lower than the dissociation pressure. The noble metals have dissociation pressures that are greater than or equal to ambient oxygen pressures at temperatures below their melting point. This is why these metals ( $\mathrm{Au}, \mathrm{Ag}, \mathrm{Cu}$ ) can be heated in air without oxidizing excessively and why they may be found natively in their pure, unoxidized state. The base metals have much lower dissociation pressures and will oxidize under most conditions found terrestriallly. Titanium, for example, has a dissociation pressure of $10^{-16}$ atm at $1873 \mathrm{~K}\left(1600^{\circ} \mathrm{C}\right)$, which helped to explain its remarkable affinity for oxygen.

Although the chemical driving force for metal oxidation is the standard free energy of formation, $\Delta G^{\circ}$, the heat liberated during the chemical reaction is often the determining factor in sustaining and propagating a reaction. This important thermodynamic quantity, the standard heat of formation, $\Delta H^{\circ}$, may be calculated from the standard free energy and the entropy change, $\Delta S^{\circ}$, by use of the well-known Gibbs-Helmholtz equation,

$$
\Delta H^{\circ}=\Delta G^{\circ}+T \Delta S^{\circ}
$$


or obtained from readily available tabulations[24,25]. There are also several excellent textbooks that discuss the chemical thermodynamics of metal-oxygen reactions and give examples of thermophysical calculations[26-28]. 
Due to the complexity of metal-oxygen reactions, as discussed in the preceeding sections, experimenters usually concentrate on one aspect of the overall process. For this reason it is convenient to divide the research into four categories: oxidation, ignition, static or steady-state combustion, and dynamic or propagating combustion. In general, the degree of complexity of the phenomena involved increases in the same order as presented; as complexity increases, the experimenters' ability to control all the variables decreases correspondingly.

In the following sections we discuss, for each of these categories, relevant research on titanium that is available in the open scientific literature. Information on the basic rates and mechanisms of titanium oxidation are required because the kinetics of oxide film formation govern the ignition process. Ignition studies are usually simple go/no go tests that seek to define the temperature, oxygen pressure, and gas velocity necessary to initiate a combustion reaction. Static combustion experiments are done in a static or slowly flowing gas environment to obtain the maximum amount of experimental control and reproducible results. These experiments give basic information on the rates and mechanisms governing steady-state titanium combustion. In the experiments on dynamic combustion, an effort is made to reproduce, to some extent, the conditions prevailing in a gas turbine engine by conducting the experiments in a wind tunnel. Such experiments give a great deal of insight into the mechanisms by which a titanium fire spreads, and have been instrumental in establishing the temperature-pressure-velocity limits for sustained titanium combustion in engine environments. They have also led to an analytical model that has been able to predict with some success the conditions under which titanium will undergo self-sustained combustion. To date, no experiments have tried to duplicate high rotational speeds in concert with high velocity airflow. 
Finally, in section 7, we present a correlation of all available experimental data on the limits for sustained titanium combustion with the limits predicted by existing models and guidelines. No such correlation for all of the available data has been published before and the results are both interesting and encouraging. In general, there is good agreement between the limits predicted on the basis of analytical models and the limits found by dynamic combustion experiments.

It is worth noting that there has been a great deal of proprietary research on the titanium engine fire problem. One manufacturer[3] estimated that over 100 man-years had been expended in research on the titanium fire problem in the last few years alone. Of course, many of these tests are full scale runs on an engine test stand, and require many personnel. Nonetheless, a great deal of work has been done by the manufacturers themselves on rub mechanics, development of new rub strip materials, design changes in engines, new alloy testing and development, and development of protective coatings. Very little of this information was available to us because of its proprietary nature; no proprietary information has been included in this report.

\subsection{Oxidation}

The isothermal oxidation kinetics for titanium have been studied by a number of investigators, and much of the data has been summarized by Kofstad[18]. Oxidation proceeds according to various rate laws depending on temperature and time of exposure. This behavior is illustrated in figure 7 (taken from Kofstad), which is a double logarithmic plot of weight gain vs. exposure time for pure titanium oxidizing at different temperatures in 1 atmosphere oxygen. We quote directly from Kofstad's characterization of titanium's oxidation behavior[18]: "Below about $400^{\circ} \mathrm{C}$ the oxidation is logarithmic, whereas at $400-600^{\circ} \mathrm{C}$ a transition from logarithmic to parabolic or an approximately cubic 


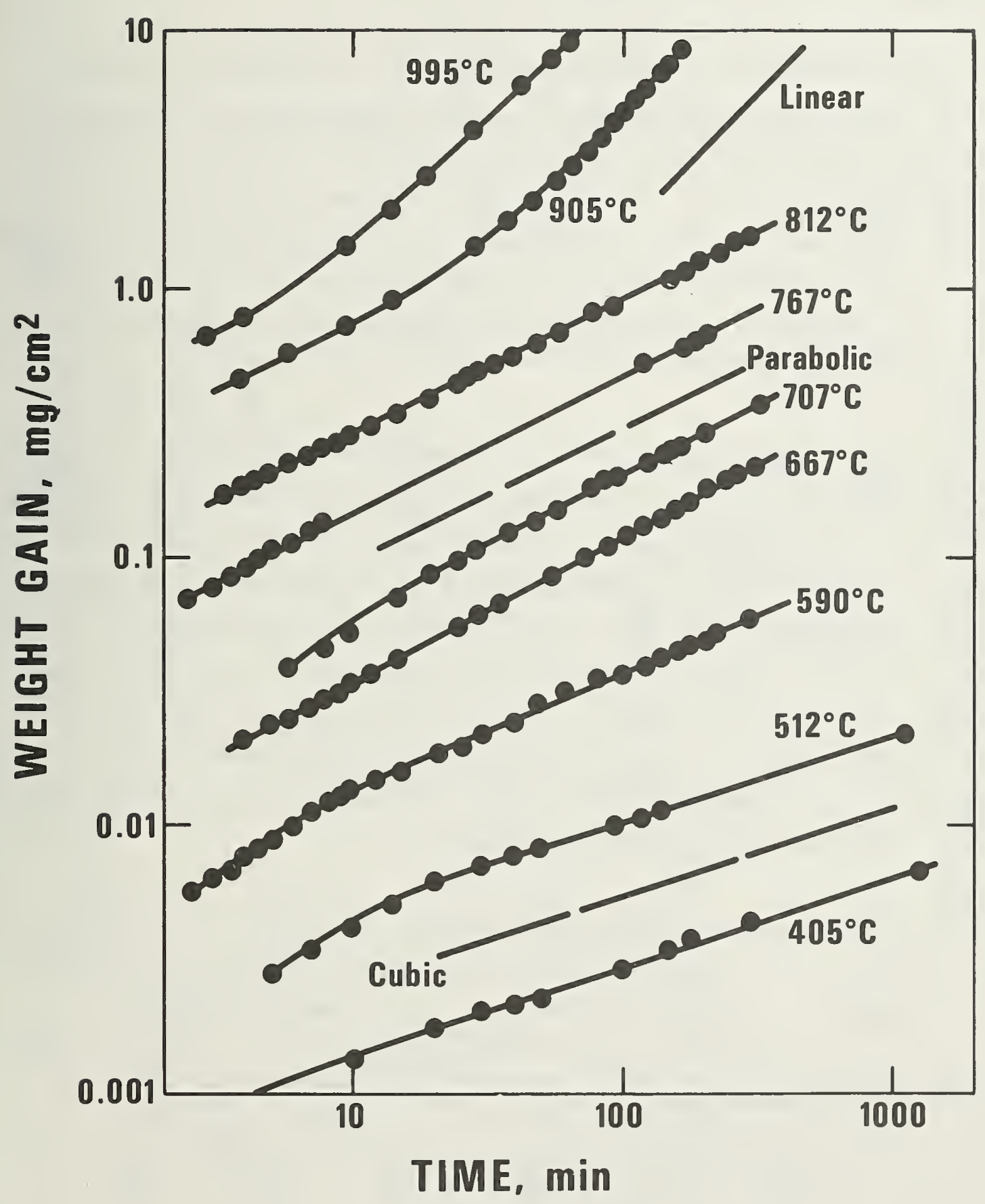

Figure 7. Weight gain versus time for oxidation of titanium. Afterreference[18]. 
oxidation is observed. Above $600-700^{\circ} \mathrm{C}$ the oxidation is parabolic and, after extended reaction, transforms into an approximately linear rate. Above $900-1000^{\circ} \mathrm{C}$ the linear oxidation is followed by a decreasing rate of oxidation."

The mechanisms of oxidation during low temperature logarithmic and cubic oxidation have not been established definitely, but parabolic oxidation is generally thought to involve simultaneous parabolic oxide film formation and oxygen dissolution in the metal. The high solubility of oxygen in titanium (up to 30 atomic percent at $1173 \mathrm{~K}\left(900^{\circ} \mathrm{C}\right)$ ) is obvious from the phase diagram shown in figure 8 . Oxygen dissolution probably becomes important at $673 \mathrm{~K}\left(400^{\circ} \mathrm{C}\right)$.

The change to non-protective linear oxidation kinetics at $1073-1273 \mathrm{~K}\left(800-1000^{\circ} \mathrm{C}\right)$ is accompanied by an increase in the rate of reaction. The reason for the transition is not clear, but it has been suggested that the oxide loses its protective character due to growth stresses in the oxide scale. An alternative proposal is that the breakdown in protective behavior occurs after an outer layer of titanium reaches a critical oxygen concentration. The latter mechanism is supported by $x$-ray studies which show that the outer layer of metal tends toward a limiting oxygen concentration of approximately 35 atomic percent.

Following extended linear oxidation, titanium's oxidation rate again begins to diminish with time, which appears to be related to sintering and grain growth in the outer portion of the oxide layer. In oxidation above $1473 \mathrm{~K}\left(1200^{\circ} \mathrm{C}\right)$ the linear oxidation stage is not observed at all. 


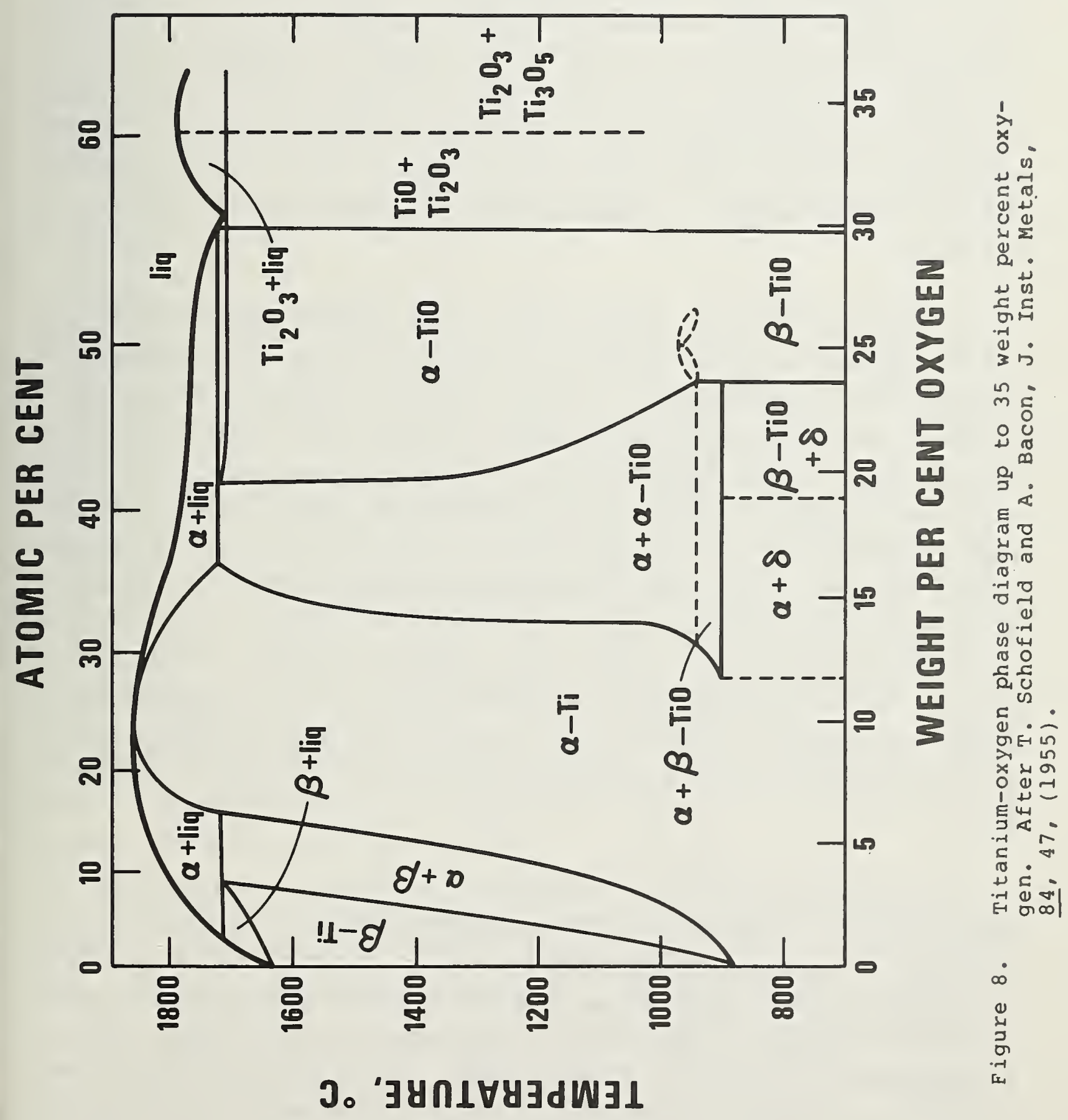


The kinetics of titanium oxidation under conditions of rapid heating are of considerable importance to an understanding of $t i-$ tanium ignition, since in most practical cases ignition occurs during rapid anisothermal heating caused by some external energy source. Studies of this nature have been performed by wolf, et al.[29-32] using an infrared furnace and a volumetric oxidation apparatus. The effect of subjecting thin plates of commercially pure titanium to heating rates of from $0.5^{\circ} \mathrm{C} / \mathrm{s}$ to $100^{\circ} \mathrm{C} / \mathrm{s}$ was studied for 0.25 atm (3.67 psia) oxygen. A thermocouple 1ocated near the bottom of the specimen was used to record specimen temperature during experiments while another thermocouple near the specimen's top was used to provide feedback to the temperature control 1oop. Oxygen consumption was monitored with a pressure transducer.

These experiments showed that at $10 \mathrm{w}$ heating rates $\left(\leq 0.5^{\circ} \mathrm{C} / \mathrm{s}\right)$ the oxidation could be described by parabolic reaction kinetics. Intermediate heating rates $\left(10^{\circ} \mathrm{C} / \mathrm{s}\right)$ led to asymptotic kinetics followed by parabolic kinetics after a time delay that depended on temperature. Higher heating rates $\left(\geq 20^{\circ} \mathrm{C} / \mathrm{s}\right)$ apparently led to an effective reaction area multiplication which permits an initially rapid oxidation rate. To explain the oxidation kinetics at these higher heating rates it was necessary to account for this expansion of the reaction zone and to include the effects of heat deposition within the oxide scale, near the metal-oxygen interface. Wolf and his colleagues also observed that many of the specimens ignited at heating rates greater than $40^{\circ} \mathrm{C} / \mathrm{s}$. These observations will be discussed in the following section on ignition (Section $6.2)$.

To summarize briefly, titanium is observed to follow protective oxidation kinetics under prolonged exposure to constant temperatures below about $1123 \mathrm{~K}\left(850^{\circ} \mathrm{C}\right)$. Thus, titanium would not be expected to ignite spontaneously during exposure to constant temperatures in this range, without an external energy input. At temperatures in excess of $1123 \mathrm{~K}\left(850^{\circ} \mathrm{C}\right)$, non-protective oxidation kinetics are observed, which would lead to a greater likelihood of ignition at temperatures exceeding this value. 
The ignition of titanium in air and various other oxygen-containing atmospheres has been studied frequently because of titanium's widespread application in aerospace programs. These studies have attempted to establish a lower limit to the conditions for ignition, especially where no supplemental energy is provided by means such as mechanical impact or fracture. Schmidt and Forney[33] have plotted all the spontaneous ignition data as a function of temperature and pressure, which is shown in figure 9. The solid line indicates a probable lower limit to spontaneous ignition of bulk titanium extending from about $1873 \mathrm{~K}\left(1600^{\circ} \mathrm{C}\right)$ for air at one atm. to as low as $1073 \mathrm{~K}\left(800^{\circ} \mathrm{C}\right)$ in pure oxygen at about 20 atm (300 psia).

Several factors can affect this limit, including the size of the specimens, the flow or makeup of the oxidizer, or any supplemental energy provided. Powders or very small section specimens will ignite much more readily as the oxidizing surface to volume ratio gets higher. Fine powders of titanium wil? spontaneously ignite in air at room temperature and pressure. The data plotted in figure 9 are thought to be representative of bulk titanium specimens, although actual specimen dimensions were not reported in every case. The effect of flow on the ignition temperature is small[34] but, as will be seen later, has a much larger effect on propagation limits. The presence of moisture, nitrogen, or carbon dioxide also has a small effect, raising the ignition temperature slightly for equivalent pressures[35]. In experiments with a high velocity flow of oxygen through a small orifice of titanium, the metal did not ignite.

The addition of supplemental energy, however, is a different matter. In all cases the added energy lowers the ignition temperature. This could come, for example, from two surfaces rubbing together, impact by another object, or fracture and exposure of a fresh surface to oxidation. This latter experiment[36] is also plotted as a dashed line on figure 9 to show the effect. Other energy sources could alter the curve in other ways. 


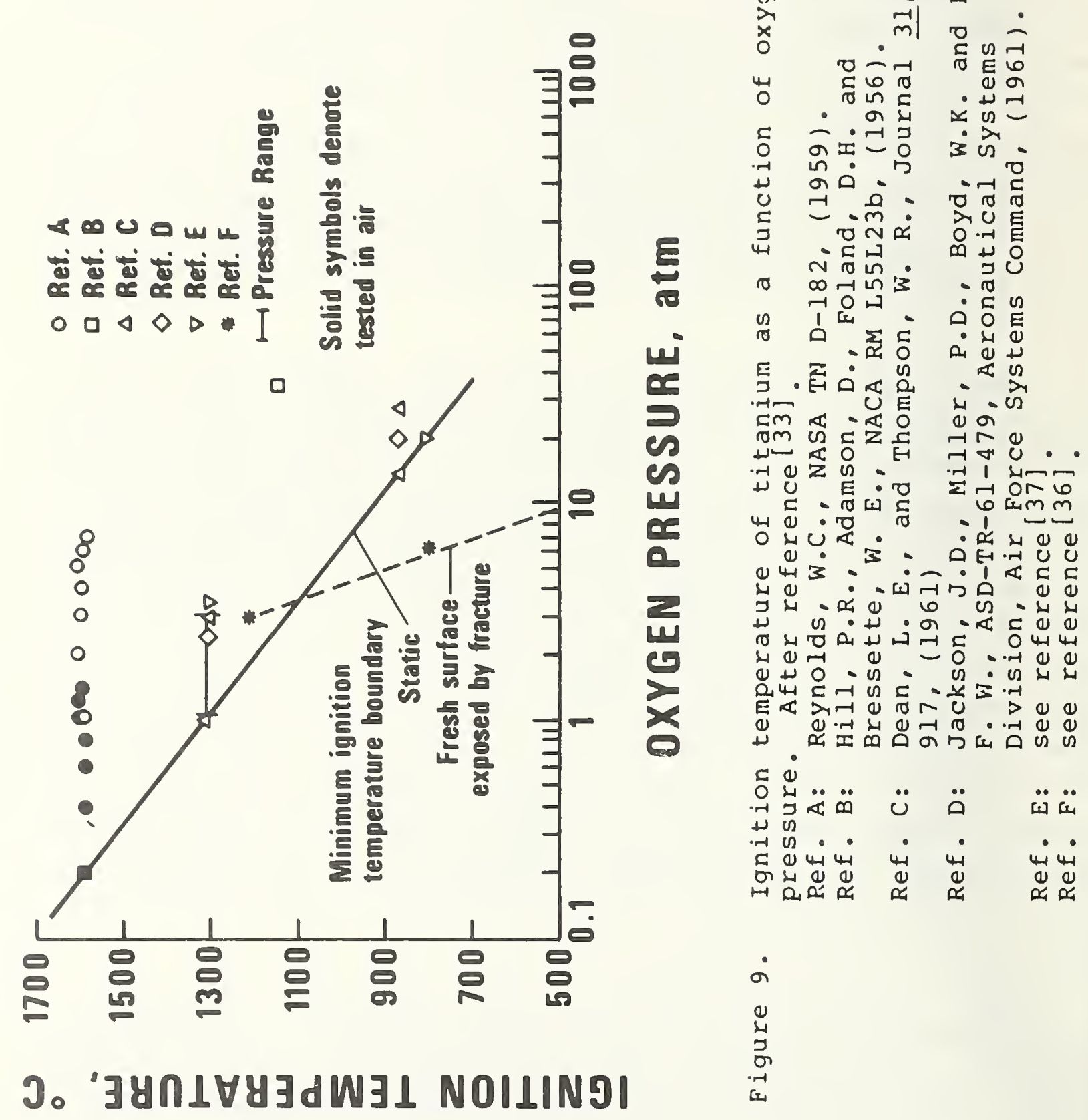


Static tests will always give the highest ignition limit, dynamic tests of ignition a lower limit, and the propagation of combustion is possible at even lower temperatures and pressures. This is clearly shown in figure 10 by the results of an experiment determining the relation between total pressure and oxygen content for liniting behavior under these three conditions, i.e., static ignition, dynamic ignition (flow), and propagation. Thus, once ignited, titanium combustion will readily propagate under the same, or even less severe conditions. There have been several other ignition studies under special conditions which are summarized by white and Ward[35].

Dynamic heating to ignition at very rapid heating rates also dramatically reduces ignition temperatures. In their studies of anisothermal oxidation kinetics, Wolf and his colleagues observed that many of the specimens ignited when subjected to heating rates greater than $40^{\circ} \mathrm{C} / \mathrm{s} \cdot[29-32]$. Furthermore, the apparent ignition temperature decreased as the heating rate was increased. For $0.010 \mathrm{~cm}$-thick specimens which were heated in 0.25 atm oxygen from room temperature at a constant rate, $r\left({ }^{\circ} \mathrm{C} / \mathrm{s}\right)$, the "sensible" ignition temperature could be fit to the equation [32]:

$$
\mathrm{T}_{\text {ig }}=338+{\frac{4.97 \times 10^{5}}{r^{2}}}^{\circ} \cdot \dot{\mathrm{C}}
$$

This relation extrapolates to the accepted value for the bulk ignition temperature of titanium, $1866 \mathrm{~K}\left(1593^{\circ} \mathrm{C}\right)$ at a heating rate of $20^{\circ} \mathrm{C} / \mathrm{s}$.

When similar specimens were first slowly heated to $1073 \mathrm{~K}$ $\left(800^{\circ} \mathrm{C}\right)$ and held at this temperature for $t$ seconds, then heated to ignition at $75^{\circ} \mathrm{C} / \mathrm{s}$, it was found that the ignition temperature followed the expression 


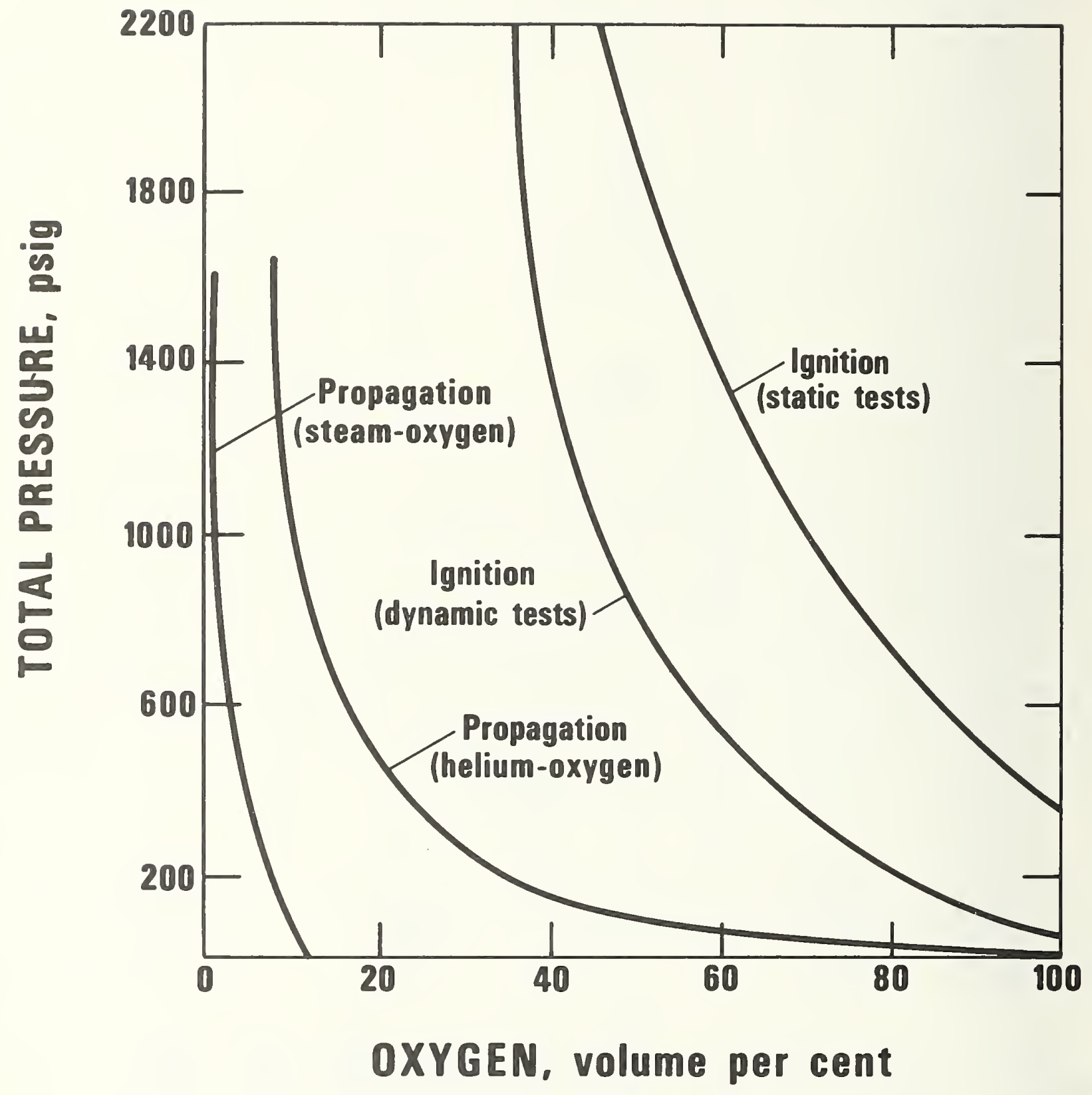

Figure 10. Ignition and propagation limits for titanium in heliumoxygen and steam-oxygen mixtures. After reference[36]. 


$$
\mathrm{T}_{\text {ig }}=\left(900+2.58 \mathrm{t}^{1 / 2}\right)^{\circ} \mathrm{C}
$$

Further experiments showed that this inhibiting effect of preoxidation was apparently due to solution of oxygen in the metal and not to the formation of a thicker oxide scale.

The observation of ignition temperatures as low as $648 \mathrm{~K}$ $\left(375^{\circ} \mathrm{C}\right)$ is quite puzzling when compared to the bulk ignition temperatures measured with slower heating rates. Another discrepancy with earlier investigations in the high-heating-rate experiments was the absence of any strong effect of oxygen pressure, 0.13-0.53 atm (1.9-7.6 psia), on the ignition iemperature[32]. Although Wolf does not discuss the lack of pressure dependence in any detail, he does suggest that the low sensible ignition temperatures imply that ignition is probably precipitated by localized deposition of heat in small hot spots with an attendant rapid increase in the local oxidation rate and a subsequent thermal runaway. That is to say, the metal temperature at ignition as measured with a thermocouple near the bottom of the specimen may not accurately reflect the local temperature in the hot spot where ignition begins. Another consideration that probably affects these results is the high surface-to-volume ratio $\left(S_{V}\right)$ of the specimens (200 $\mathrm{cm}^{-1}$ for the $0.010 \mathrm{~cm}$-thick specimens). As pointed out above, the surface-to-volume ratio is important in metal ignition, and specimens with high values of $\mathrm{S}_{\mathrm{V}}$ can ignite at much lower temperatures than bulk specimens. Mellor [37] estimates the limiting value of $\mathrm{S}_{\mathrm{V}}$ for titanium to behave as a bulk material as $\mathrm{S}_{\mathrm{V}} \leqq 25.6 \mathrm{~cm}^{-1}$, and cites several earlier studies that found much-reduced ignition temperatures for titanium powders with $\mathrm{S}_{\mathrm{V}} \geqq 400 \mathrm{~cm}^{-1}$.

Wolf also compared several titanium alloys for ease of ignition under rapid heating[32] in a limited number of tests. The results showed that $\mathrm{TiAl}$ and $\mathrm{Ti}_{3} \mathrm{Al}$ were most resistant to ignition (did not ignite), Ti-13 Cu and Ti-BIII alloys were less 
resistant to ignition $\left(\mathrm{T}_{\text {ig }} \approx 1173 \mathrm{~K}\left(900^{\circ} \mathrm{C}\right)\right)$, while commercially pure titanium, Ti-8Mn, and $\mathrm{Ti}-6 \mathrm{Al}-4 \mathrm{~V}$ were the least resistant to ignition $\left(\mathrm{T}_{\mathrm{ig}} \approx 1023-1073 \mathrm{~K}\left(750-800^{\circ} \mathrm{C}\right)\right)$.

In summary then, the ignition studies show several things relevant to the use of titanium in turbine engines. First, a probable lower limit to ignition can be established for given tempera ture and pressure conditions (e.g. about $1866 \mathrm{~K}\left(1593^{\circ} \mathrm{C}\right)$ in 1 atmosphere air), but any supplemental energy will lower these limits. Higher pressure also lowers the ignition temperature. Second, titanium will ignite and burn in a variety of atmospheres, including nitrogen and carbon dioxide. Once ignited it will burn readily, even in carbon dioxide. Third, bulk titanium, which will not spontaneously ignite at moderate temperatures and pressures, will ignite and burn readily if subject to supplemental energy such as impact, rubbing, or fracture leading to exposure of a fresh surface. Fourth, when thin specimens $\left(\mathrm{S}_{\mathrm{V}}=200 \mathrm{~cm}^{-1}\right)$ of titanium are heated at rates greater than $40^{\circ} \mathrm{C} / \mathrm{s}$, they are observed to ignite readily at temperatures below the bulk ignition temperature, $1866 \mathrm{~K}$ $\left(1593^{\circ} \mathrm{C}\right)$. If heated at $100^{\circ} \mathrm{C} / \mathrm{s}$, these specimens can ignite when their average (or "sensible") temperatures are as low as 573 to $673 \mathrm{~K}\left(300\right.$ to $\left.400^{\circ} \mathrm{C}\right)$. Conditions that lead to oxygen solution in the base titanium prior to rapid heating result in an inhibition of titanium ignition. For different titanium alloys, the relative resistance to ignition decreased in the order: TiAl, Ti ${ }_{3} \mathrm{Al}>$ $\mathrm{Ti}-13 \mathrm{Cu}, \mathrm{Ti}-\beta \mathrm{III}>\mathrm{CP} \mathrm{Ti}, \mathrm{Ti}-8 \mathrm{Mn}, \mathrm{Ti}-6 \mathrm{Al}-4 \mathrm{~V}$. 
There has been surprisingly little fundamental research on the basic rates and mechanisms of steady-state titanium combustion. The only detailed studies are the early wire-burning experiments of Harrison and Yoffee[38,39] and the more recent work of the authors at $\mathrm{NBS}[16,19,23,40-45]$ with small (0.2-0.5g) bulk specimens.

Between 1954 and 1961, Harrison[38,39] reported measurements of the burning rates of small wires of aluminum, iron, magnesium, molybdenum, titanium and zirconium. Vertical wires were ignited at the lower end by a small titanium coil and photographed while burning in various oxygen concentrations up to 100 percent oxygen at 1 atmosphere. Harrison found that the burning velocity of titanium wires was proportional to the square root of the pressure for pressures below one atmosphere. He also found that a critical oxygen concentration exists, below which combustion does not propagate; this minimum concentration increased with increase in wire diameter and varied for different materials. Photographic images of the burning titanium wires were clear and distinct, with no evidence of a diffuse vapor phase combustion zone, leading Harrison to conclude that titanium burns at the surface of a molten mixture of the metal and its oxide. The color temperature of the burning titanium varied from $2700 \mathrm{~K}\left(2430^{\circ} \mathrm{C}\right)$ at an oxygen pressure of $0.05 \mathrm{~atm}$ to $3330 \mathrm{~K}\left(3060^{\circ} \mathrm{C}\right)$ at 1.0 atmosphere.

Some of Harrison's observations on the way combustion propagated along titanium wires are particularly germane to the present discussion. The propagation of combustion into the unburned wire was oscillatory in nature. A nearly spherical globule of molten metal would form at the end of the wire, remaining stationary in space as the melted zone moved up the wire. When the globule became large enough to overcome its surface tension, it would 
separate from the wire and fall while a small amount of melt would jump up to form a new globule further up the wire, starting a new cycle. Harrison found that the droplets that fell from the wire were only about 15 percent oxidized. From this observation Harrison concluded that[38] "... no great significance can be placed upon the absolute values of the propagation rates..." As he recognized, however, propagation rates are valuable as a relative measure for comparing different materials or environmental conditions.

The distinction between burning velocity and the more fundamental combustion rate is an important one that will arise again when we discuss propagating combustion in dynamic environments. In this section we discuss measurements of the combustion rate, the actual rate at which oxygen is absorbed by molten titanium. We will see that this rate is mass transport limited; under most conditions oxygen is absorbed as fast as it can diffuse to the surface. We will also see that the combustion rate does not vary significantly for different alloys, since the factors that govern the rate of oxygen diffusion to the surface will be essentially the same for different alloys. Then, in section 6.4 we will discuss measurements of the burning velocity, the rate at which titanium is lost from a blade-like specimen as it burns in a simulated compressor environment. It should be clear that the combustion rate and the burning velocity are quite different parameters. Although the burning velocity will depend to some extent on the combustion rate, it will also be affected by a number of other parameters such as the thermal diffusivity, surface tension and viscosity of liquid titanium, the Reynolds number at the leading edge, and the viscous drag of the airstream. Unlike the combustion rate, which varies only slightly for different alloys, the burning velocity shows significant variations for different alloys. This does not mean that the results of the two experiments are at odds; rather, it implies that factors other than the combustion rate must be the cause of these variations in burning velocity. 
The authors' research has extended over several years and has been directed toward developing new quantitative techniques for studying metal combustion and extending fundamental studies to samples of larger dimensions. The use of larger, stationary specimens has considerably eased some of the experimental difficulties associated with metal combustion research and more closely approximates the conditions prevailing in large-scale accidental metal fires. The objectives of this research have been to better define the heterogeneous combustion process for bulk titanium metal, identify the reacting species and products, determine the reaction location, and discover the primary rate-limiting mechanisms.

Early stages of the NBS research program included literature surveys $[16,40]$, studies of the ignition and combustion of various steels and alloys of aluminum, titanium, and copper[41], and preliminary experiments on laser-initiated combustion of pure titanium using a new optical technique[23]. Several novel analytical techniques were developed and, together with more conventional techniques, applied to the combustion of bulk titanium and titanium alloys. The results of experiments employing these newly developed methods have yielded substantial data on the rates and mechanisms of titanium combustion and considerable insight into the very complex heterogeneous reactions involved in metal combustion.

The experimental techniques used include: a new gravimetric technique employing an electronic weight sensor to determine oxidation rates during self-sustained combustion[19], temperature measurements during combustion using two-color pyrometry[19]; time-resolved spectroscopy to identify vapor-phase reactants and products and their location and duration during combustion $[42,43]$ novel laser technique for phase contrast visualization of flame structure and temperature fields in vapor-phase combustion zones [23]; high-speed cinematography of burning metals[23]; as well as $x$-ray and chemical analysis, metallography, and scanning electron microscopy (SEM) of combustion products [23]. 
Most recently, a dramatic improvement in the method of timeresolved spectroscopy was achieved through the use of an electronically-scanned spectrometer, with periodic sampling and digital storage of the spectral scans[44]. This technique was used to study the role of condensed products in metal flames and to explore a newly discovered laser-flame interaction [45].

In the experimental arrangement a 100 watt $\mathrm{Cw} \mathrm{CO}_{2}$ laser provided a clean, remote and controllable ignition source for 130-500 mg specimens of commercially pure (99.2\%) titanium and various titanium alloys. Cleaned and etched specimens were placed on a polished graphite block in one atmosphere of gently flowing oxygen, permitting an unobstructed view for a high-speed camera, photodiodes and the entrance optics of the spectrometer. A typical experimental arrangement used to measure temperature and oxidation rate during titanium combustion is shown in figure 11.

The controllability of the laser ignition source and constant specimen sizes permitted readily reproducible experimental conditions. A characteristic total luminosity versus time curve, as measured by a photodiode, was remarkably reproducible and provided a convenient time scale as a reference for the other analytical techniques. These were:

(a) High-speed color cinematography to study the general behavior, approximate color temperature, and the relative rates of reaction.

(b) High-speed Hilbert transform cinematography to visualize the general morphology of the molten metal surface, normally obscured by self luminosity, and to provide estimates of the temperature gradients in the vapor zone surrounding the specimen.

(c) Time- and space-resolved visible spectroscopy to identify vapor species and possible excitation mechanisms. 


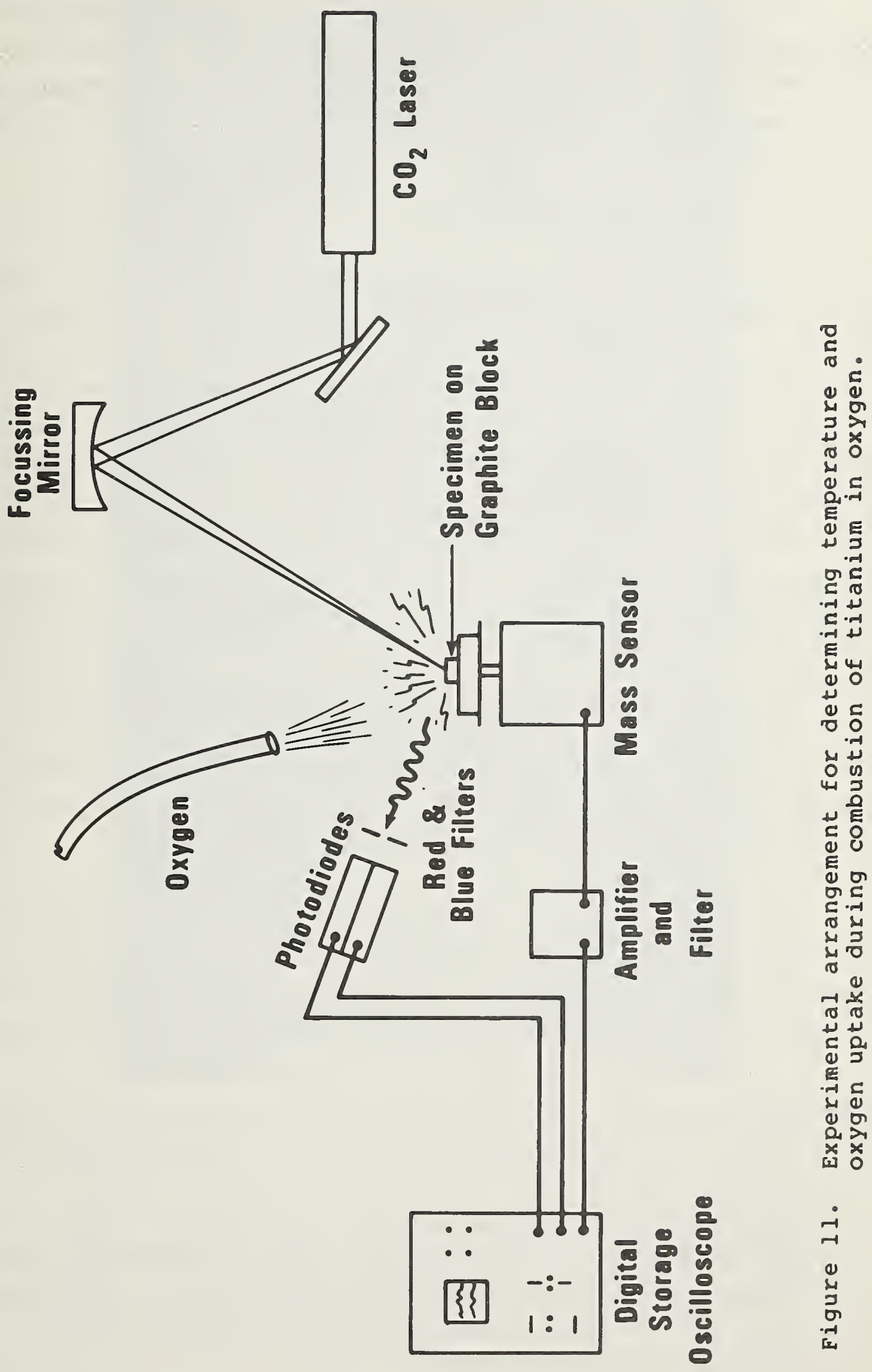


(d) Two-color pyrometry to determine surface temperatures. (e) Dynamic gravimetry to provide a direct measure of the uptake of oxygen during combustion.

(f) Metallography and scanning electron microscopy of specimens quenched at various stages in the process to identify reactants and products and their locations.

(g) X-ray and chemical analyses of products.

Visual observations and high-speeed movies showed relatively few differences in the combustion of titanium and various titanium alloys. Following the ignition (and melting) stage, which is accompanied by a very steep rise in total luminosity, specimens assume a characteristic sessile-drop shape and burn steadily and quietly by surface reactions for a little more than half of their combustion history (the total combustion event lasts only 3-4 s). The end of this steady burning stage of combustion is marked by the specimen erupting into violent boiling, with the ejection of a shower of particles that continues until self-extinguishment and solidification of the specimen. Metallographic exmaination of the residue has shown that combustion is always incomplete, with a core of titanium and oxygen in solid solution overlain by layers of TiO and $\mathrm{TiO}_{2}$. Oscilloscope traces of the total luminosity during the event show it to be quite reproducible. The various stages of titanium combustion are shown in Figure 12.

To summarize our current state of knowledge of the ignition and combustion of titanium and its alloys, the highlights of our research are listed below for the three distinct stages of titanium combustion, which were idenţified very early in our studies.

STAGE 1 - IGNITION. The specimen is heated in oxygen with a $\mathrm{CO}_{2}$ laser until a self-sustaining combustion reaction is obtained.

*Local ignition possible. High speed movies show small regions can ignite and exhibit signs of advanced stages of combustion, e.g. ejected particles. The heat of combustion contributes to the rapid melting and ignition of the remainder of the specimen. 


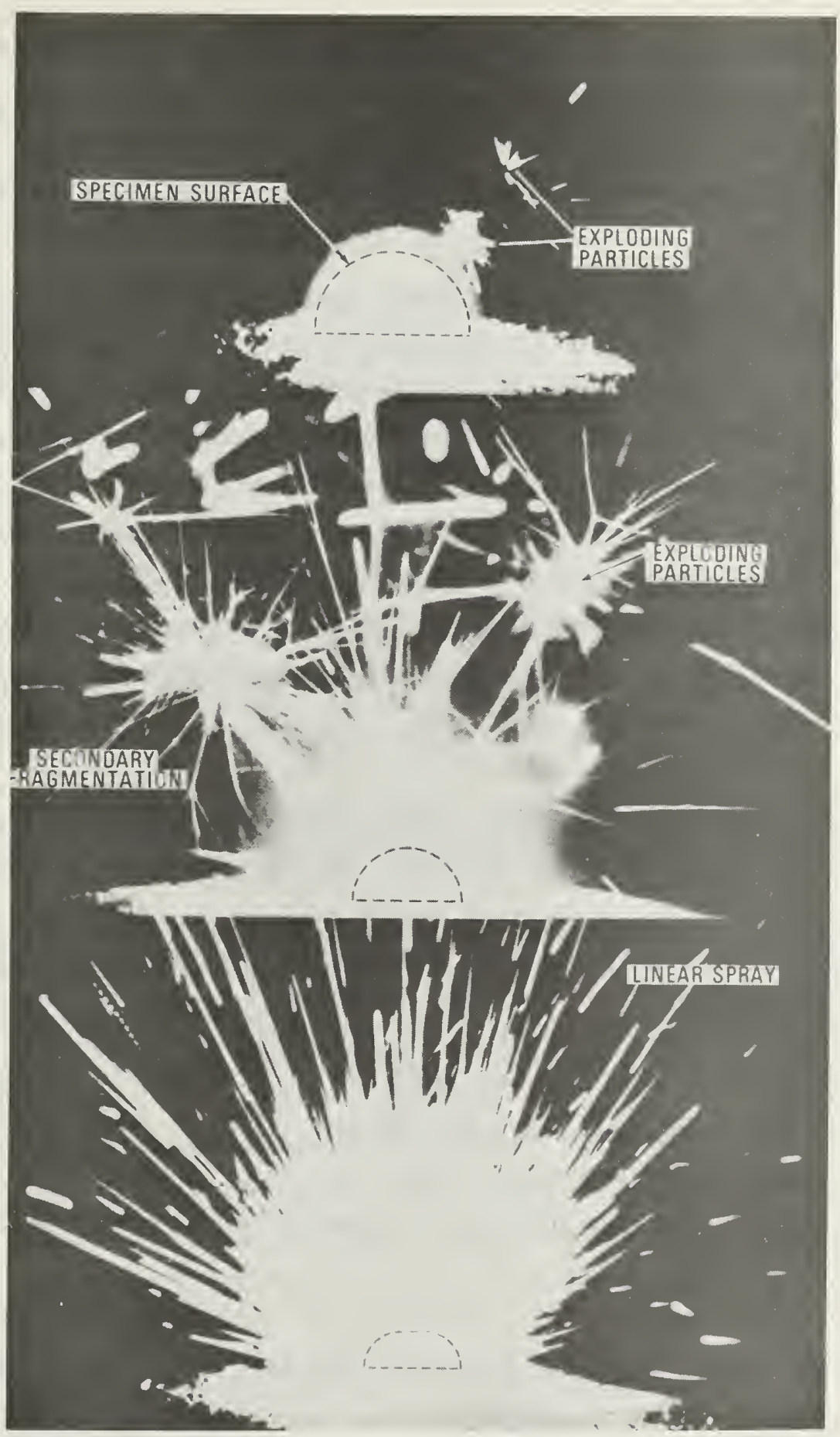

Figure 12. Three frames from high-speed movies of titanium burning in one atmosphere oxygen. Top: after ignition, titanium burns steadily and quietly by surface reactions, with occasional ejection of particles. Surface is obscured by intense continuum radiation from vapor region. Middle: about halfway through combustion process, specimen erupts into violent boiling, ejecting a shower of molten droplets. Some of these particles explode violently. Bottom: towards end of combustion, shower forms "linear spray" with no further explosions. After reference [23]. 
*Temperature spikes observed. Two-color pyrometry indicates temperature peaks as high as $4000 \mathrm{~K}\left(3727^{\circ} \mathrm{C}\right)$ correlated with ignition flares, whereas steady burning temperatures are consistently about $3200 \mathrm{~K}\left(2930^{\circ} \mathrm{C}\right)$, near the boiling point of $\mathrm{TiO}_{2}$

*Influence of vapor phase combustion on ignition possible. Spectroscopy and phase contrast cinematography show 'an initial surge of titanium vapor during ignition, which may contribute to the temperature spikes. Time-resolved spectra reveal the prompt appearance of alloying elements in this vapor cloud, suggesting that vapor phase processes could enhance ignition for alloys containing highly volatile and combustible components. Phase contrast movies show that the vapor cloud collapses to a narrow boundary layer l-2mm thick after ignition.

STAGE 2 - STEADY BURNING. The specimen appears to burn steadily and quiescently on the surface following ignition and melting.

*Two rate-controlling processes determined. Mass uptake measurements reveal two distinct rates for this stage of the combustion process, differing by a factor of about three. The change from an initially fast, linear rate of oxygen uptake to a slower rate correlates with the disappearance of the vapor zone and its associated spectra, a decrease in temperature and the appearance of accumulating oxides which hinder the flow of oxygen to the metal fuel.

* Combustion rate shown to be mass-transport limited. Studies of the effect of oxygen velocity on titanium's combustion rate show that gas-side diffusion is rate-limiting during the initial part of the reaction. An exchange of control to liquid-side diffusion occurs when oxides begin to accumulate.

*Alloying shown to have little influence on combustion. The measured rates of oxygen uptake, the color temperatures and visual observations of the steady burning stage show remarkably little variation for the alloys studied. 
STAGE 3 - SHOWER. The steady burning stage ends abruptly with an extensive and violent shower of particles.

*Subsurface combustion reaction discovered. The high speed cinematography shows violent oxide motion on the surface during this stage. Metallurgical and SEM observations of quenched specimens indicate a subsurface boundary between the outer layer of $\mathrm{TiO}_{2}$ and the core, consisting of a Ti-0 solid solution. The subsurface combustion appears to create voids, segregate alloy components, and provide the necessary driving force to blow off molten droplets of the burning specimen.

\section{*Products of the shower are hollow spheres of $\mathrm{TiO}_{2}$.}

Early in the shower when the ejected droplets are incompletely burned, the same subsurface reactions that cause the violent boiling lead to explosive fragmentation of ejected particles. Later in the shower the driving force is insufficient to cause explosive fragmentations and the collected products of the shower are hollow spheres of nearly stoichiometric $\mathrm{TiO}_{2}$, as revealed by scanning electron microscopy and chemical analysis.

*Accumulated oxides shut off reaction. The decreased rate of oxygen uptake towards the end of combustion and the metallurgical observation of a thicker and thicker oxide layer lead to the conclusion that limitation of oxygen diffusing to the subsurface combustion zone soon quenches the reaction. Increased oxygen flow across the surface stirs the molten oxide permitting a faster combustion rate. 
As discussed in the preceeding synopsis, the steady burning phase of titanium combustion is kinetically governed by two sequential rate-controlling processes. The initial rate-limiting step, which is the faster of the two, is the diffusion of oyxgen to the specimen's surface through a boundary layer of vapor products. The second rate-limiting step, which takes control when oxides begin to accumulate on the surface, is the diffusion of oxygen through a growing liquid oxide layer. Preliminary experiments with commercially pure titanium showed that the flow of oxidizer can markedly increase combustion rates during both stages of the reaction.

More recently, measurements were extended to study the effects of flow on the combustion rates for Ti-6Al-4V over a greater range of flow velocities. The results of this experiment are shown in figure 13. The rate of 'oxygen uptake during both stages of combustion increases with increasing flow of oxygen to a maximum, beyond which the average rate decreases. Although there is as yet no detailed theoretical model with which to compare this data, it seems plausible that increasing the flow of oxygen increases the combustion rate during the first part of the reaction by blowing away products and reducing the thickness of the vapor diffusion barrier. The effect of flow on combustion rate during the second part of the reaction is more difficult to explain, but high speed movies of burning titanium suggest that stirring of the oxide layer by the flowing gas may be the cause. There is a maximum for both curves at a flow velocity which is near the limit for laminar flow from the oxygen supply tube. Turbulence disturbs the oxygen flow pattern, causing a decrease in the average combustion rate and an increase in the scatter of the data. Clearly, however, much work remains to fully explain these effects. 


\section{OXYGEN VELOCITY, $\mathrm{cm} \cdot \mathrm{s}^{-1}$}

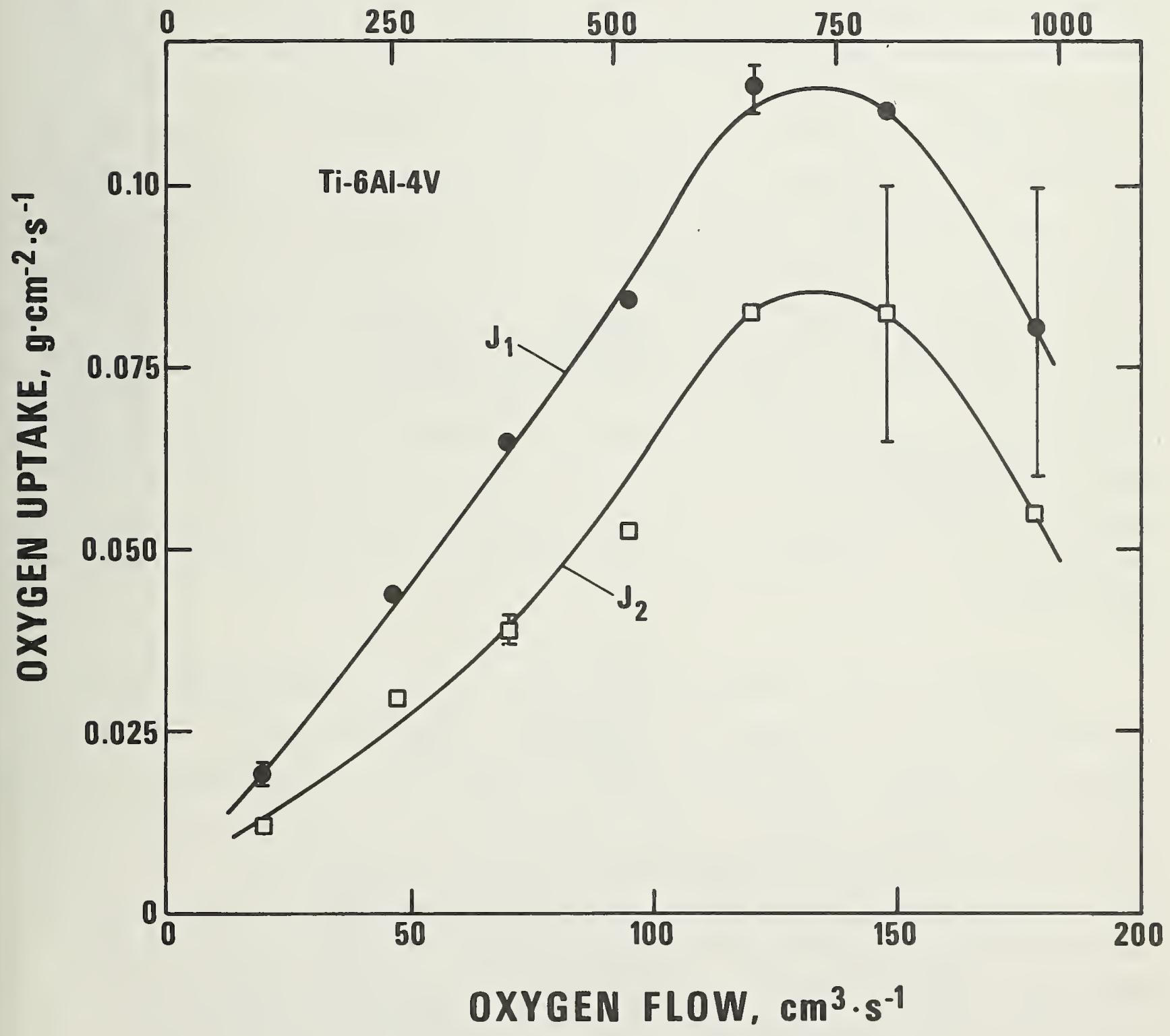

Figure 13. The effect of flow on the rate of oxygen uptake during combustion of $\mathrm{Ti}-6 \mathrm{Al}-4 \mathrm{~V} . \mathrm{J}_{1}$ and $\mathrm{J}_{2}$ are the rates of oxygen uptake during the first and second parts of the steady-burning stage of combustion. 
One goal of the studies of titanium combustion by dynamic gravimetry was to measure the combustion rates for a number of different alloys to see if the addition of certain alloying elements could reduce the rate of oxygen uptake. It is known, for example, that the addition of small amounts of silicon to iron or copper systems can markedly reduce their rates of oxygen absorption during combustion by forming a thin slag layer on the surface. The combustion rates for commercially pure titanium and a series of 23 titanium alloys were measured in a gentle flow of oxygen $\left(\sim 65 \mathrm{~cm}^{3} / \mathrm{s}\right)$ at atmospheric pressure. The combustion rates for these alloys during the first $\left(J_{1}\right)$ and second $\left(J_{2}\right)$ parts of the combustion reaction are presented in Table 6. These results are the average from several specimens of each alloy. With only two exceptions, little variation in combustion rate was observed among the alloys studied; the rate during the first part of the reaction varied from a high of $0.12 \mathrm{grams} \mathrm{O}_{2} / \mathrm{cm}^{2} \mathrm{~s}$ for $\mathrm{Ti}-5 \mathrm{MO}$ to a low of $0.07 \mathrm{grams} \mathrm{O}_{2} / \mathrm{cm}^{2} \mathrm{~s}$ for $\mathrm{Ti}-5.8$ Al-2Mo-2.1Sn-1.9Cr-1.8Zr. The two exceptions, Ti-6Sn and Ti-9Sn, exhibited a curious bimodal behavior. Specimens of these two alloys either burned in a "fast" mode comparable to the combustion rates of other alloys, or in a "slow" mode that was lower by a factor of 30-50 percent. No explanation for this behavior has yet been found.

In general, the addition of tin or tin in combination with aluminum seemed to result in the lowest observed rates. But the rates for alloys containing these elements were only about 20 percent lower than average. This difference is not much greater than the estimated experimental uncertainty of \pm 10 percent. One factor that may help to explain the lower rates observed for tin- and aluminum-bearing alloys is the high vapor pressure of these elements at $3200 \mathrm{~K}\left(2930^{\circ} \mathrm{C}\right)$. Loss of mass from the specimen by $v a-$ porization of tin or aluminum during combustion would result in a lower apparent combustion rate as determined by dynamic gravimetry. Spectroscopic observations of the prompt appearance of aluminum vapor during ignition[44] tend to support this hypothesis. 


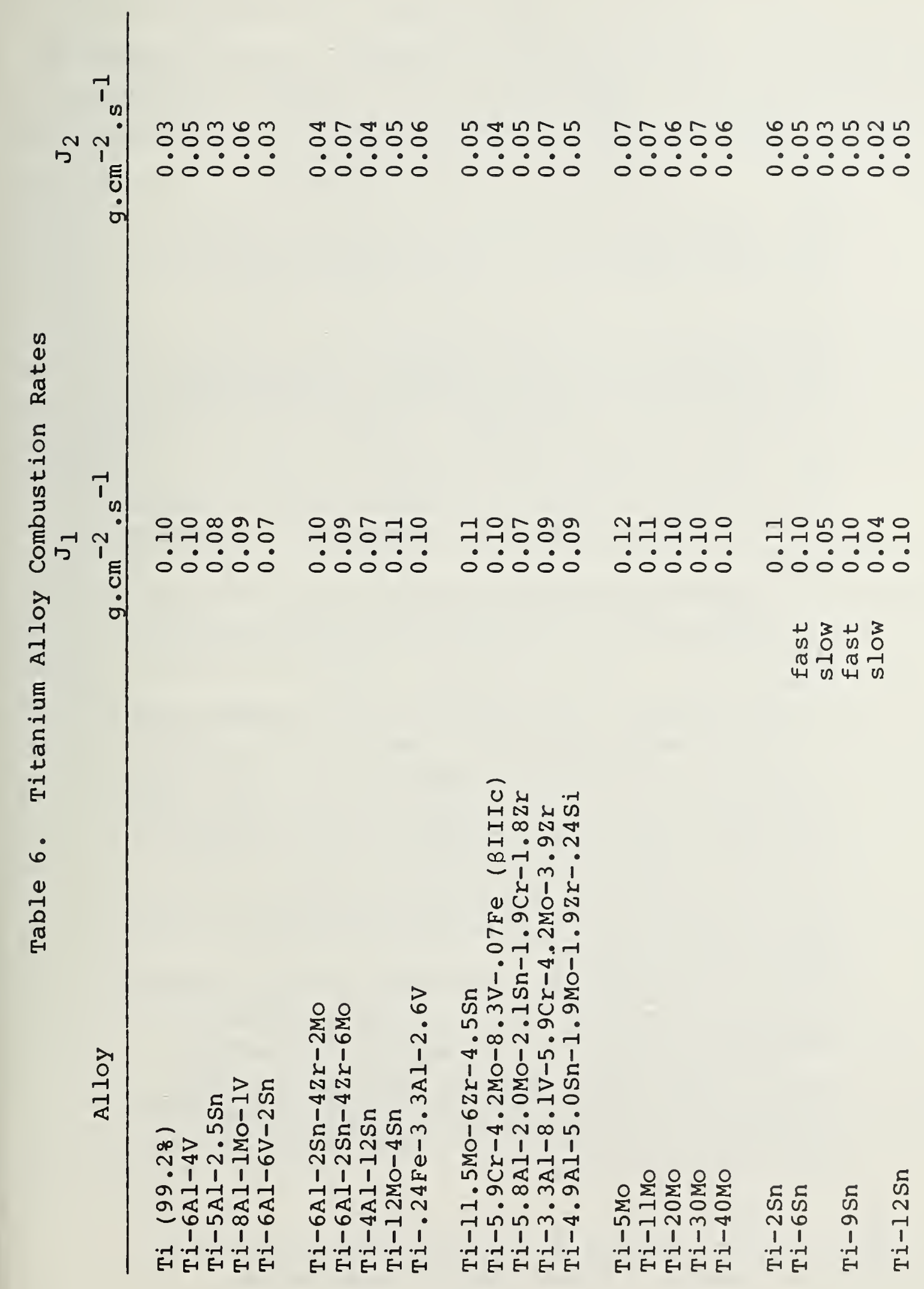


These static experiments and the experiments at low flow rates have helped to elucidate the basic phenomena of titanium combustion. The experimental conditions, necessarily simplified in order to permit analytical observations, are quite different from those found in turbine engines. However, for the purposes of this review we can list several aspects of titanium combustion that are pertinent to further discussion of the dynamic experiments and the use of titanium in turbine engines.

- Under the proper conditions, titanium is readily ignitable and, as long as sufficient oxygen and fresh metal are available, it will continue to burn.

- These conditions are well above room temperature and pressure and ambient oxygen concentrations. As will be seen, the dynamic experiments will help quantify these conditions.

- When titanium does burn, it does so violently with large amounts of heat and molten material released which can contribute to the propagation of combustion.

- The combustion reaction occurs on the surface of the molten metal. Initially the reaction rate is limited by transport of oxygen to the metal surface.

- In later stages of the reaction, the accumulation of molten oxides drives the reaction zone beneath the surface, slowing the reaction rate. This behavior would not be expected to occur in an engine fire where aerodynamic forces constantly remove the molten metal, exposing fresh metal.

- Increasing the flow of oxidizer increases the combustion rate by increasing the availability of oxygen at the surface.

- Alloying titanium, at least for the alloys studied in these experiments, has little effect on its combustion rate but may affect its ignitability. The fact that the combustion rate for different alloys is constant does not necessarily imply that their burning velocities in a compressor environment will be the same.

Further relevant aspects of titanium combustion can be obtained from a summary of recent dynamic experiments. 
6.4 Titanium Combustion in Dynamic Environments

Compared to the quiescent environments used to study steadystate titanium combustion, the inside of a jet engine is a veritable maelstrom. Centripetal acceleration can exceed $10^{4} \mathrm{~g}^{\prime} \mathrm{s}$; typical modern compressors achieve pressures and temperatures in excess of $30 \mathrm{~atm}(450 \mathrm{psia})$ and $870 \mathrm{~K}\left(597^{\circ} \mathrm{C}\right)$, at airstream velocities of $300 \mathrm{~m} / \mathrm{s}(1000 \mathrm{ft} / \mathrm{s})$. It is obvious that the progress of a metal fire in this environment will depend to a great extent on the effect of these extreme conditions on the propagating molten mass of burning metal. Metal fires involve propagating combustion, and the propagation of burning must be understood as well as fundamental reaction mechanisms in order to eventually prevent fires.

In an engine, the high airstream velocity and pressure will act to increase the combustion rate by increasing the availability of oxygen and by removing any gas phase products that might impede the flow of oxygen to the surface. It is quite likely that the actual combustion rate (see glossary for distinctions between combustion rate, burning velocity and propagation velocity) will be limited by mass transfer of oxygen to the surface by diffusion through the aerodynamic boundary layer. While combustion rate, and therefore the heat generation rate, will be controlled by mass transport, the burning velocity and propagation characteristics will probably be controlled by the balance between the aerodynamic and centrifugal forces tending to remove the molten metal and the surface tension and viscosity effects that make it adhere to the surface. The heat and oxygen content of the molten material sloughed from the burning titanium, as well as the size of the droplets, will affect the propagation of a fire from one stage of the engine to another. 
In order to understand these complex phenomena, techniques have been developed to study titanium combustion in small experimental wind tunnels. This, at least, can simulate the pressure, temperature, and velocity of the airstream in a compressor environment for static components (stators, guide vanes, etc.) and give some insight into the behavior of rotating components, which will tend to sling molten metal off tangentially. All the dynamic combustion experiments reported in the open literature were performed at two facilities: the Air Force Electric Aerodynamic Laser Test Facility at wright-Patterson $A F B[13,47,48]$ and in the laboratories of an engine manufacturer $[7,46,50,51]$. This work has also led to an analytical model for predicting self- sustained combustion in titanium airfoils[10,46]. Much of the work done by these two groups is complementary and has been summarized in an excellent joint paper[10]. Other manufacturers have similar experimental capabilities and have performed tests similar to those discussed here, however, the reports of these studies have not been published in the open literature.

In the Air Force experiments, flat, plane-parallel Ti-6Al-4V specimens with overall dimensions similar to compressor blades were clamped at one end in the wind tunnel and ignited at the upper leading edge corner with a high power $\mathrm{CO}_{2}$ laser. Combustion was menitored with closed-circuit TV and high speed movies. In the experiments of the engine manufacturer, uncambered, airfoil-shaped specimens of Ti-8Al-lMo-lV were clamped at both ends in the experimental chamber and ignited with a $\mathrm{CO}_{2}$ laser focused on the middle of the leading edge. TV monitoring and high speed movies were also used to observe behavior in these tests. Some early tests used different ignition sources, including electrical arc[46] and impingement of molten titanium[13]. 
Both groups of experimenters found it necessary to coat the laser irradiated areas of the specimens with black coatings to improve laser coupling and insure ignition. Because of the difference in experimental configurations, the nature of combustion propagation was different. The Air Force tests usually resulted in rapid propagation of combustion along the chordwise direction of the top edge (parallel to flow), followed by more-or-less uniform spanwise burning down the specimen (perpendicular to flow). In the manufacturer's tests, combustion following ignition spread in the streamwise direction across the chord at midspan. When the blade had been burned completely through in the chordwise direction, burning progressed spanwise, perpendicular to the exposed edges. Composite time sequences from high speed movies showing the propagation of combustion in these two different types of test shown in figure 14.

Specimens were ignited over a wide range of pressure, temperature and velocity of the airstream and the results reported in terms of percent damage as a function of the environmental conditions. Since the Air Force specimens had a uniform cross section, the rate of mass removal (burning velocity) could be measured from the high speed films.

The results showed that self-sustained combustion of Ti-6Al-4V and Ti-8Al-1Mo-1V depends strongly on pressure, with lesser effects being noted for temperature and velocity. The spanwise burning velocity was essentially constant in time for given conditions, but varied depending on pressure and velocity of the airstream. At low pressures (near atmospheric) there was almost no dependence of burning velocity on airstream velocity, while at higher pressures the rate of burning was influenced by both pressure and velocity. 


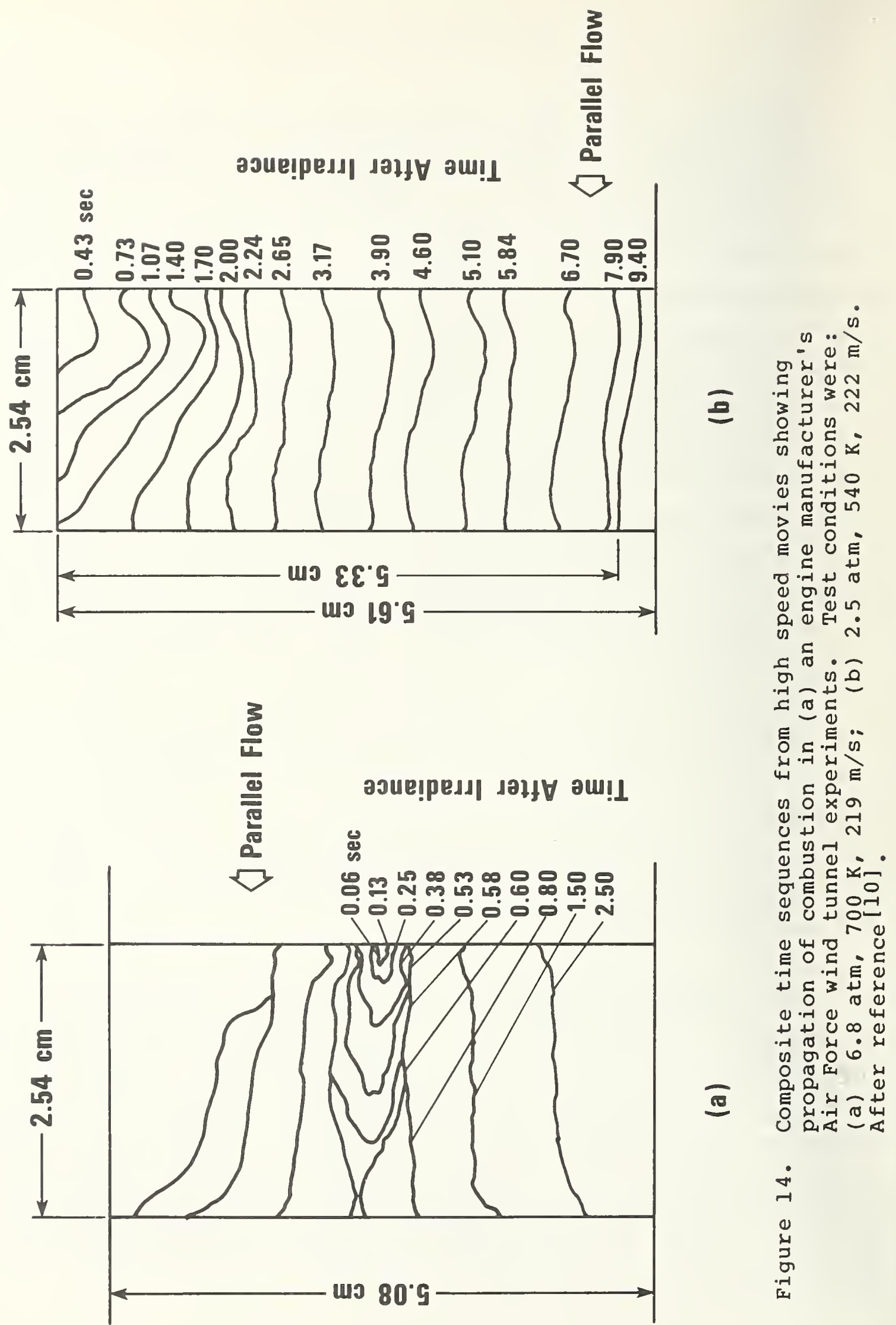


The complex dependence of degree of damage on environmental conditions is summarized in reference 10 :

\begin{abstract}
"The degree of damage from combustion is observed to be significantly pressure dependent over the entire temperature-velocity region investigated. As velocity increases, temperature-pressure regions of no combustion decrease in area until, at approximately $600 \mathrm{ft} / \mathrm{sec}$, no region of non-sustained combustion is observed.
\end{abstract}

At velocities above $600 \mathrm{ft} / \mathrm{sec}$, areas of massive burning (virtually total combustion) are observed at higher temperatures and damage is temperature dependent.

While damage is observed to increase with increasing velocity at most pressures, this trend is reversed above $900 \mathrm{ft} / \mathrm{sec}$. The early extinguishment observed at these higher velocities is the result of a more rapid melt removal and greater convective cooling."

The importance of metal removal by aerodynamic forces was readily apparent in high speed films. At low airstream velocities considerable amounts of liquid metal flowed over the surface of the unburned portion of the specimen, aiding in the spread of combustion. As airstream velocity was increased, more rapid removal of molten metal occurred due to the greater aerodynamic forces. As the airstream velocity increased, the droplet size of metal removed from the surface decreased from large globules to a finer and finer spray. This behavior has obvious implications for the rapid propagation of a titanium fire to downstream components and structures. 
Another interesting result was the effect of angle-of-attack on degree of damage sustained. In one test, a specimen inclined at a $10^{\circ}$ angle-of-attack suffered 80 percent damage (essentially complete combustion) while an identical specimen burned in the same environmental conditions but with $0^{\circ}$ angle-of-attack sustained only 30 percent damage[10]. This behavior is illustrated in figure 15. The difference in damage appears to be due to boundary layer separation on one side of the airfoil, which results in more molten metal adhering to the surface. However, recent tests at the Air Force Aero Propulsion Laboratory have so far failed to confirm this behavior[3].

More recent experiments by Anderson and Manty $[7,50,51]$ have employed dynamic test methods to investigate the effects of alloying elements on the combustibility of titanium and to begin studies on the efficacy of coatings for preventing ignition and combustion of titanium alloys. For these experiments either airfoil-shaped specimens or plane-parallel specimens (with the leading edge machined to a knife edge to promote ignition) were clamped in the test fixture as in figure 14 a and ignited with a laser. The environmental variables of temperature, pressure and airstream velocity varied somewhat from one experiment to another, but generally only two or three sets of test conditions were used in any one experiment; typical values were[7] $700 \mathrm{~K}\left(427^{\circ} \mathrm{C}\right)$, $4.7 \mathrm{~atm}(70 \mathrm{psia})$, and $240 \mathrm{~m} / \mathrm{s}(789 \mathrm{ft} / \mathrm{s})$ or $480 \mathrm{~K}\left(207^{\circ} \mathrm{C}\right), 6.0$ $\operatorname{atm}(90 \mathrm{psia})$ and $115 \mathrm{~m} / \mathrm{s}(376 \mathrm{ft} / \mathrm{s})$.

The alloys tested to date include:

$$
\begin{aligned}
& \text { Ti-6Al-4V } \\
& \text { Ti-8Al-1Mo- } 1 \mathrm{~V} \\
& \text { Ti-6Al-6Vo-2Sn } \\
& \text { Ti-6Al-2Sn-4 Zr-2Mo } \\
& \text { Ti-6Al-2Sn-4Zr-6Mo } \\
& \text { Ti-8Mn } \\
& \text { Ti-1l. } 5 \mathrm{Mn}-6 \mathrm{Zr}-4.5 \mathrm{Zn} \text { ( III) }
\end{aligned}
$$




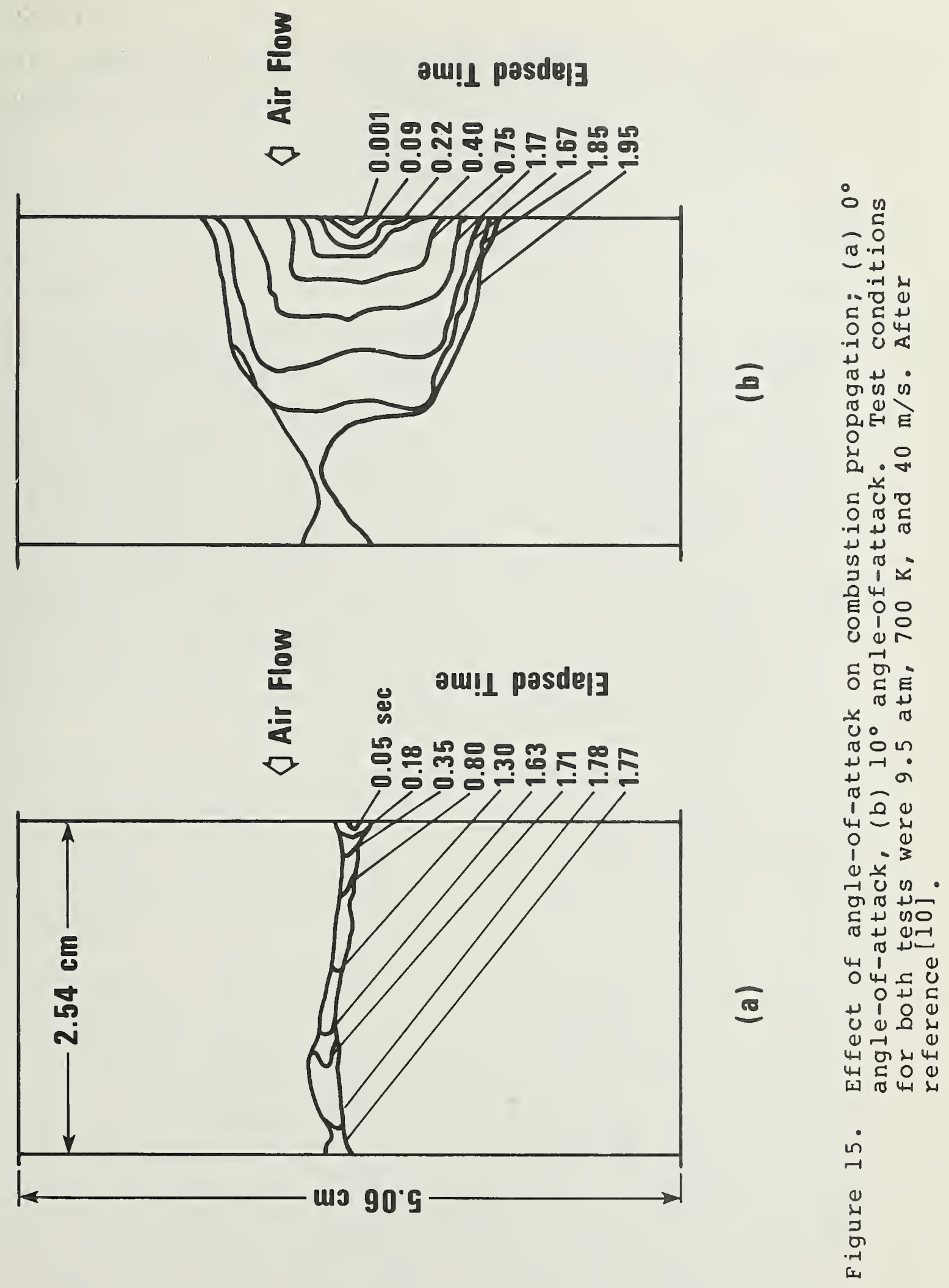




$$
\begin{aligned}
& \text { Ti-13.5Al-2l.5Nb } \\
& \text { Ti-13V-1 } 1 \mathrm{Cr}-3 \mathrm{Al} \\
& \text { Ti-5Ni } \\
& \text { Ti-10Ni } \\
& \text { Ti-20Ni } \\
& \text { Ti-13Cu } \\
& \text { Ti }_{3} \mathrm{Al}
\end{aligned}
$$

Most of these alloys sustained significant damage from combustion under the conditions of the tests. Although alloys could be ranked by the severity of damage sustained, the, rankings were different for different sets of environmental conditions, making generalizations impractical. Of all the alloys tested, only three did not burn under any of the test conditions: Ti ${ }_{3} \mathrm{Al}, \mathrm{Ti}-20 \mathrm{Ni}$, and Ti-13Cu. A fourth alloy, Ti-i3V-llCr-3Al, burned in only one of four tests at different environmental conditions; ironically, it was under the least severe test conditions that this alloy burned. $\mathrm{Ti}_{3} \mathrm{Al}$ was found to be combustible in Air Force tests using a more powerful laser for ignition[3].

Unfortunately, with the possible exception of Ti-l3Cu, none of the combustion-resistant titanium alloys so far identified have adequate mechanical properties for aircraft turbine engine service. Most are excessively brittle or suffer some other serious degradation of mechanical properties. But this research has helped to identify the properties that contribute to an alloy's ability to resist combustion. One of these is a melting point substantially below the ignition temperature of titanium. A low melting point alloy resists ignition because it can melt and flow away from an ignition source before reaching the ignition temperature; Ti-20Ni is such an alloy. Other characteristics that enhance combustion resistance are high thermal conductivity, high heat of fusion and low heat of combustion. In short, anything that reduces the buildup of heat in an alloy subjected to an external energy input helps to prevent the material from reaching its ignition temperature. 
Manty and Anderson have also started preliminary studies on the effectiveness of coatings in preventing titanium combustion $[7,50]$. Two different types of coating were investigated: a chromium-molybdenum coating plated on Ti-8Al-1Mo-1V and Ti-6Al-2Sn-4Zr-2Mo, and an aluminum coating applied to $\mathrm{Ti}-8-1-1$ by ion vapor deposition (IVD). Both coatings gave a significant degree of protection to the titanium alloys for the two environmental conditions studied; uncoated specimens of both alloys suffered significant damage at both conditions. The IVD aluminum coating totally prevented sustained combustion of Ti-8-1-1 at both test conditions. The chromium-molybdenum coatings prevented combustion in the less severe tests, but only reduced the degree of damage sustained in tests at a higher temperature and airstream velocity. The success of the IVD aluminum coating was attributed to aluminum's low melting temperature, high thermal conductivity and high heat of fusion. Aluminum coatings are not considered viable for aircraft turbine engines, however, because the aluminum forms intermetallic compounds with titanium, degrading its mechanical properties. But these encouraging preliminary results should help stimulate further research on coating development. The influence of the type and intensity of the ignition source on coating effectiveness should be addressed in any further studies, since recent Air Force tests have succeeded in igniting coated alloy specimens using a more powerful laser ignition source[3].

We have seen in this section that as experimental conditions come closer to the actual environment encountered in an aircraft turbine engine, the combustion behavior of titanium becomes much more complex. Changes in environmental conditions affect not only the reaction kinetics, but such physical processes as melt flow and retention as well. The importance of these physical processes to the spread of combustion over a titanium blade also means that specimen size, shape and orientation come into play. In order to explain and predict this complex behavior, Glickstein $[10,46]$ has developed an analytical model of the self-sustained combustion of titanium airfoils. In the next section we discuss the evolution and capabilities of this model. 
6.5 Analytical Models of Titanium Combustion

Because of the complexity of the titanium fire problem and the large number of factors affecting combustion, it is most desirable to have an analytical model that, given the relevant material properties, environmental conditions, and ignition sources, can predict the ignition and subsequent quench or self-sustained combustion of titanium alloys in engine environments. The model could be of great benefit to engine designers, enabling them to evaluate a large number of candidate alloys without the need for extensive experimental tests. Just such a model is currently being developed by $M$. R. Glickstein $[10,46]$ and substantiated by dynamic combustion experiments of the type discussed in the previous section. The model has been under development for several years now, with new capabilities being added as they are developed.

Glickstein's first approach to modeling involved several simplifying assumptions to allow the results to be expressed analytically in closed form. [46] These assumptions include: (1) ignition has already occurred, (2) the leading edge region can be represented as a flat plate with a cylindrical edge, (3) combustion proceeds on the cylindrical surface at a steady rate limited only by diffusion of oxygen to the surface, (4) thermal conduction is one-dimensional (a function of the chordwise distance from the leading edge), (5) boundary layer flow over the leading edge region is laminar, and (6) combustion occurs at the melting temperature of the metal, and liquid metal is blown away as soon as it is formed.

The analysis is based on the heat balance between the heat generated at the leading edge due to combustion and the heat lost by conduction, convection and radiation. The variables that are 
considered are the blade thickness, the airstream conditions, the heat of reaction, and the thermophysical properties of the metal. The result is an expression for the burning velocity as a function of airstream temperature and the leading edge Reynolds number, based on edge thickness. A thermal stability analysis of this functional relationship yields a definition of the limiting conditions for self-sustained combustion.

When the predictions of the model were compared to the results of a limited number of wind tunnel experiments [46] it was found that the predicted limits for self-sustained combustion agreed well with experiment. But the predicted burning velocity was an order of magnitude lower than the rate observed in experiments performed at temperatures and pressures well above the sustained combustion limit. The low predicted burning rates were attributed to two factors: disruption of laminar flow near the leading edge by vigorous combustion leading to highly turbulent flow and higher oxygen diffusion rates, and heating of the boundary layer air by the combustion zone at the leading edge. Empirical correlations were devised to modify the model so that the predicted burning rates agreed with the observed rates for all conditions.

The good agreement between the combustion limits predicted by Glickstein's model and the experimental results is quite encouraging. It suggests that self-sustained titanium combustion may be reliably predicted on the basis of such a model, and thus that such an analytical model may be used to help establish guidelines for using titanium alloys in turbine engines within the limitations of the model (i.e., thin static parts at $0^{\circ}$ angle-ofattack). Since the validation of the model's predictions is based on a limited number of data published in reference 46 , it is 
important to correlate more of the available data with the predicted limits. As part of this review, we have undertaken this task; the results are discussed in detail in section 7 .

Further evolution of Glickstein's analytical model has been based upon the new knowledge about titanium combustion that has been obtained since 1974. Of particular importance are modifications to the model to account for the flow of molten titanium across the titanium surface, a phenomenon that was not included in the first model. The need to account for the effects of molten metal flow became apparent from observing high speed films of wind tunnel combustion experiments. Another important difference in the current model is the use of numerical finite-difference techniques to simultaneously solve the equations for heat and mass transfer in the aerodynamic boundary layer, transient thermal conduction in the solid metal, melting and liquid metal flow from the leading edge, and retention of the molten metal on the solid substrate with attendant thermal interaction. Instead of assuming ignition to have occurred, the current model is capable of predicting ignition from a variety of ignition sources including radiation, mechanical friction, and exposure to high ambient temperatures.

The mathematical model itself is based on a physical model of the combustion process. This physical model, shown in figure 16 , assumes that liquid metal is formed at the leading edge, with part being blown away by the airstream while the remainder flows across the surface driven by aerodynamic shear and drag forces. As the molten metal flows across the surface, part of it resolidifies, giving up its latent heat of fusion to the underlying solid metal. Heat from the reacting molten metal together with any heat supplied from external sources constitute the driving force for 


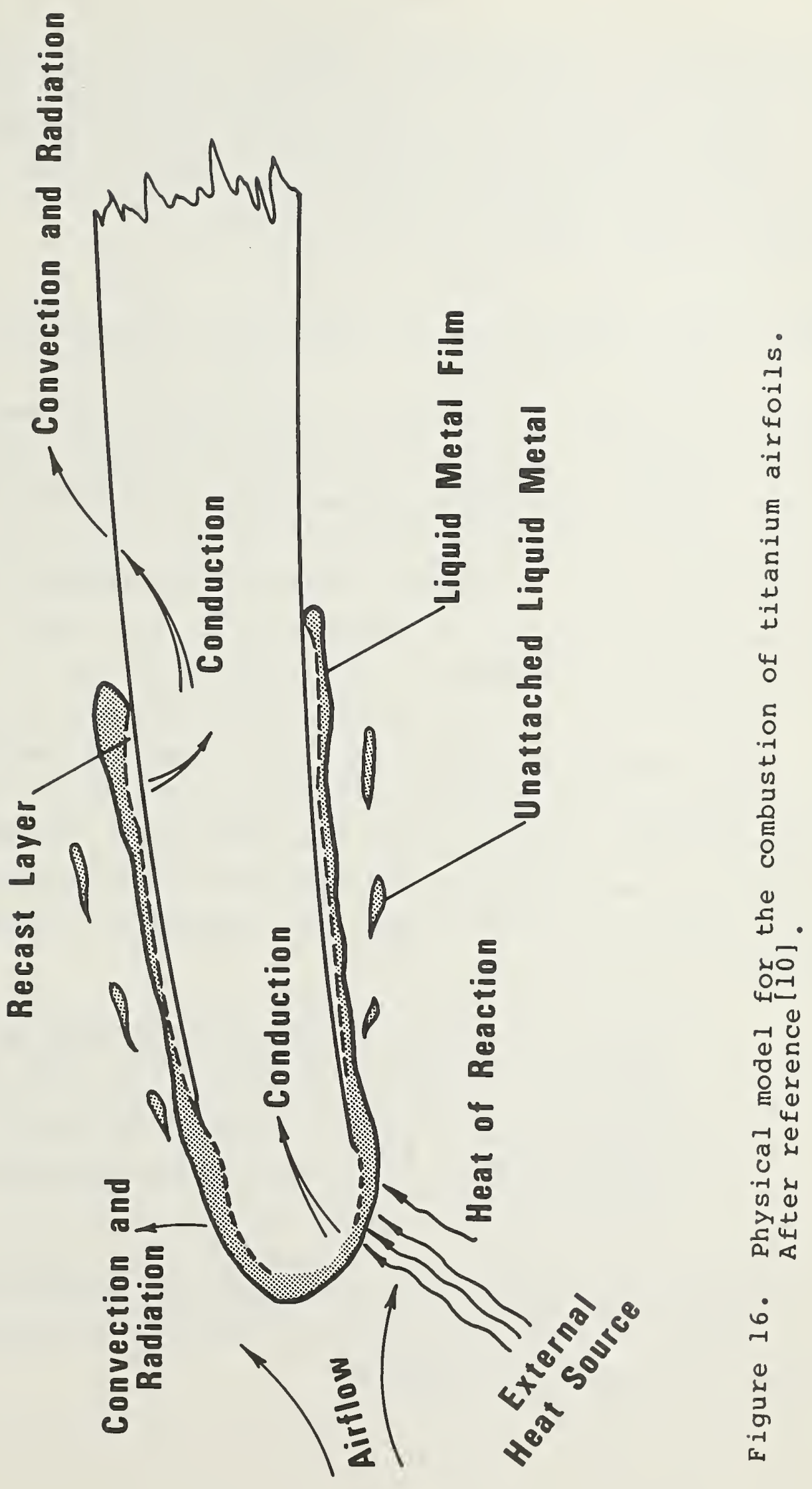


propagation of the process. Whether or not the process will be self-sustaining and if so, the burning velocity, are determined by the energy balance between these heat gains and the heat lost to the environment by radiation and convection. The rate of internal energy change is given by the relation:[10]

$\frac{d E}{d t}=q_{\text {conduction }}{ }^{+q_{\text {convection }}}{ }^{+q_{\text {radiation }}}{ }^{-q_{\text {input }}}{ }^{-q_{\text {reaction }}}(6-3)$

where the various q's refer to the heat lost or gained by different mechanisms. A change in internal energy may be manifested as either sensible heating or phase change. A discussion of the derivation of the mathematical expressions relating the various heat losses and gains to the environmental conditions and material properties would be much too complex to include here. The interested reader is referred to the original papers.

The analytical model as it now stands is incomplete, but work is continuing to add the capability to consider a number of other factors. Most recently, the model has been extended to allow evaluation of the combustion of rotating blades, although there is not yet any experimental data to validate the model. Still to be added to the model are: [10]

"Effect of alloys and surface coatings on surface
properties related to liquid metal flow and melt
retention.
Effects of aerodynamic angle-of-attack on combustion
propagation.
$\begin{aligned} & \text { Susceptibility to liquid metal impingement in airfoil } \\ & \text { cascades." }\end{aligned}$

Some of the above will help to refine the analysis, while others will allow the modeling to more accurately simulate actual conditions in an operating engine. 


\section{CORRELATION OF COMBUSTION EXPERIMENTS}

As discussed in the preceding section, several titanium combustion wind tunnel experiments have been reported $[7,10,13,46$, $47,48]$, wherein both airfoil-shaped and flat specimens of typical blade size have been tested at varying pressures, temperatures and velocities. In some experiments, the specimens were ignited with a $\mathrm{CO}_{2}$ laser. In others, a titanium bar was melted electrically so that liquid blown downstream to the specimen caused ignition. The tests have been performed in several wind tunnels located at Wright-Patterson Air Force Base and at an engine manufacturer's laboratory. All have pressure, temperature and flow instrumentation and high-speed photography equipment.

7.1 Prediction of Self-sustained Combustion

Glickstein's analytical model of the combustion process takes into account heat and mass transfer through the boundary layer, transient heat transfer and melt behavior. Among other things, the model is intended to predict whether or not ignition will occur for various conditions and energy inputs and whether or not there will be subsequent self-sustained combustion. In addition the model generally predicts the lower limit for combustion.

Glickstein suggests that a discrimination line between quenching and self-sustained combustion can be described in terms of ambient air static temperature and blade or vane leading edge Reynolds number, where the charactertistic dimension is taken as the leading edge diameter or thickness, the velocity as the free stream velocity and the density and viscosity are evaluated at the mean of the air static temperature and the melting temperature of the metal, 2050K (3200F). Glickstein's discrimination line is shown in figure 17. 


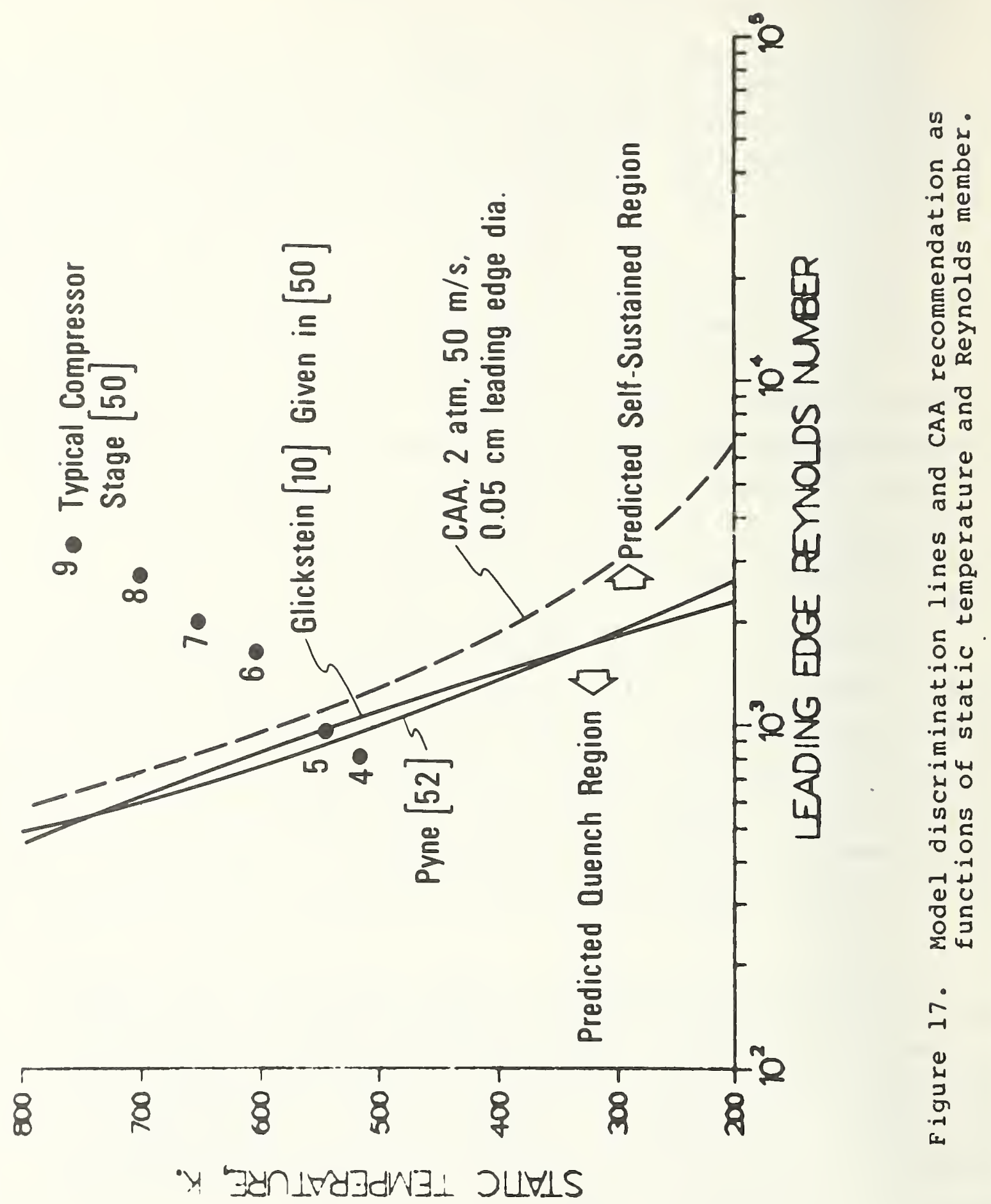


Pyne [52] has independently made a simplified analysis of the sustained combustion limit which, as seen also in figure 17, agrees well with Glickstein's criteria. This analysis, considering heat loss from the combustion site by convection and the oxygen diffusion rate to the surface, leads to the expression

$$
\mathrm{T}_{\mathrm{a}}=2000-\mathrm{CN}_{\mathrm{Re}}(\mathrm{m}-\mathrm{n} / 2)
$$

where $m$ and $n$ are coefficients related to diffusion and convection respectively that have values of 0.5 for laminar and 0.8 for turbulent flow. $\mathrm{T}_{\mathrm{a}}$ is the free stream static temperature, $\mathrm{C}$ is an empirical constant and $\mathrm{N}_{\mathrm{Re}}$ is the leading edge Reynolds number. Pyne concludes that at the leading edge, the flow should be laminar. Thus $m=n=0.5$ and $c$ is determined from the experimental data. Equation $(7-1)$ becomes

$$
\mathrm{T}_{\mathrm{a}}=2000-259.3 \mathrm{~N}_{\mathrm{Re}}^{0.25}
$$

For comparison with the CAA recommendation (no thin static titanium structures above $2 \mathrm{~atm}$ and $50 \mathrm{~m} / \mathrm{s}$ velocity) we assumed a leading edge diameter of $0.05 \mathrm{~cm}(0.025 \mathrm{in})$ and show the temperatureReynolds number relationship as a dashed line in figure 17. Good agreement between Glickstein, Pyne and the CAA is seen above about $400 \mathrm{~K}(260 \mathrm{~F})$. Also shown are temperatures and Reynolds numbers for typical rotor inlet conditions [50] where the numbers indicate compression stage.

\subsection{Analysis of Experimental Data}

Using this type of analysis we can now assess some of the experimental data available. The figures will be in pairs; the upper figure in each pair will show the temperature and Reynolds numbers for those specimens which exhibited self-sustained combustion. The companion figure will show the same information for those samples that quenched after the ignition source was removed or consumed. 
In interpreting the data from all sources, we made the decision to term an event self-sustained combustion if seven percent or more of the sample was consumed or, if given, we accepted the experimenter's judgment of whether or not there was self-sustained combustion.

Where the amount of material consumed is given for a data set, the quenching cases group between zero and our seven percent cutoff, then there is a gap in the population with few cases recorded between seven and about 25 percent, followed by the remainder of the specimens which were more heavily damaged. This supports our assumption of a 7 percent cutoff. Seven percent is also approximately equal to the mass consumed by the igniting source.

Figure 18 a shows the self-sustained cases reported in reference[10] and [46]. The discrimination line is from[52], the most conservative of the three criteria. We see that seven of the specimens suffered over seven percent damage when tested in the predicted quench zone. Also it may be seen that at the lower temperatures, the CAA criteria would allow titanium use under conditions that are demonstrated to have supported self-stained combustion. Here we must note that none of the source documents give any estimates of systematic or random errors; only one gives estimates of inaccuracies in the measurements. We suspect that the leading edge diameters given for airfoil shapes are subject to variation from the test articles. Without estimates of errors and inaccuracies it is difficult to correctly compare the data sets directly. Nevertheless, the discrimination line closely approximates the lower limit of self-sustained combustion in terms of temperature and Reynolds number. The experimental data shown in figure 18a that support the prediction are for two currently popular titanium alloys (and a few others) in thin static sections at $0^{\circ}$ angle-ofattack. 

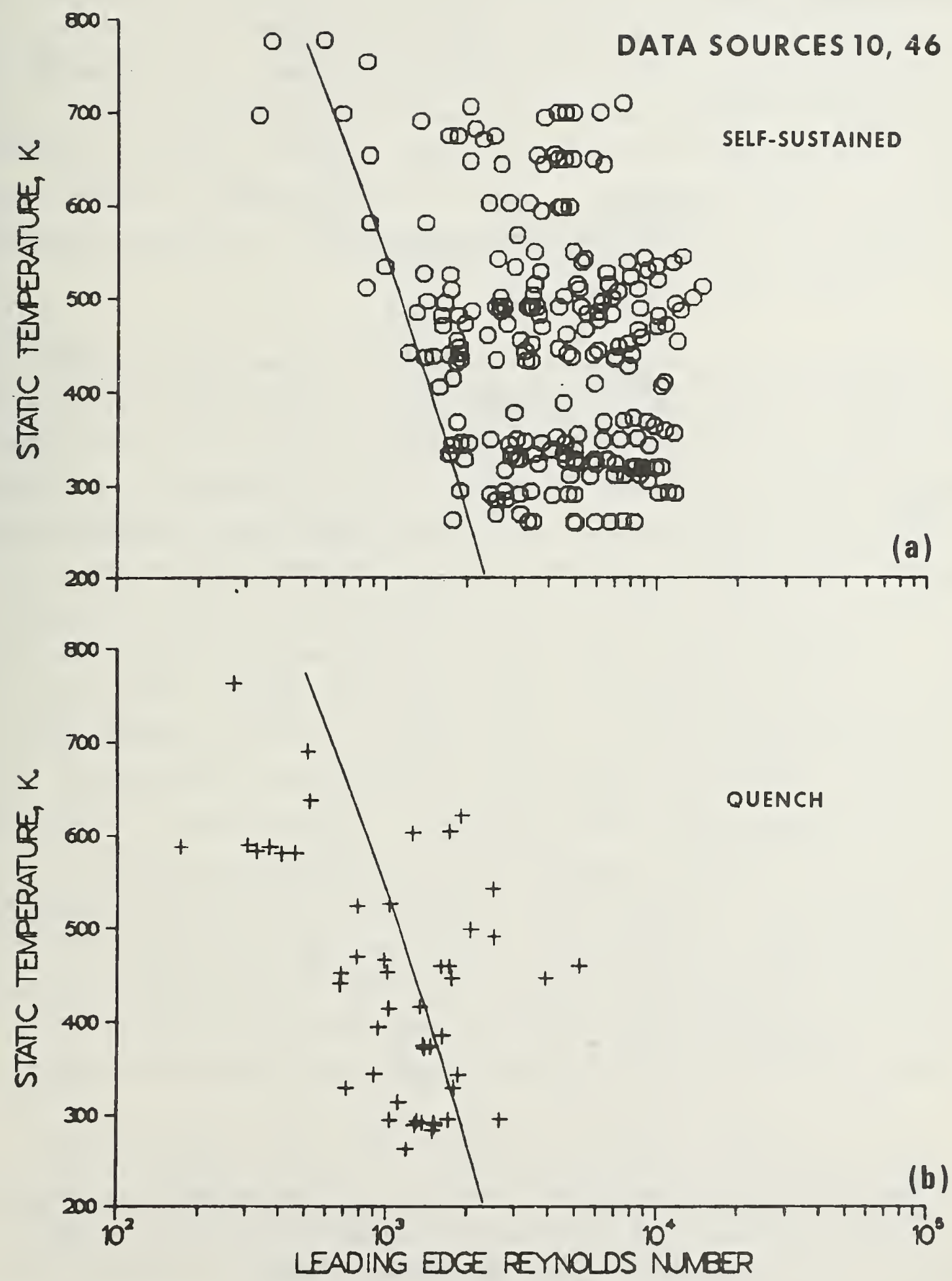

Figure 18. Experimental titanium combustion data from references 10 and 46 . 
Figure 18b, shows the temperature and Reynolds number values for all of the specimens that quenched after ignition. It is readily apparent that not every specimen exposed to conditions to the right and above the discrimination line will exhibit self-sustained combustion if ignited. (We have removed all data for those specimens which are known not to have ignited). The reasons for quenching under these conditions are not understood but we must point out that these combustion events. involve, and may be controlled by, many phenomena. Thus it is difficult to experimentally regulate all of the necessary parameters to exactly the same value for each test.

Examination of the data given in [10] shows that perhaps differences in experimental methods have some effect on quenching in the predicted self-sustaining region. The data in [10] were taken in two wind tunnels. Figures 19a and $19 \mathrm{~b}$ show the data from one and figures $20 \mathrm{a}$ and $20 \mathrm{~b}$, data from the other. We see in both instances (figures $19 \mathrm{a}$ and $20 \mathrm{a}$ ) the self-sustained cases are, with very few exceptions, shown to the right of the discrimination line. In figure 19b, only a few of the quenched cases are to the right of the discrimination line, while in figure 20b, about half of the quenched cases are to the right. In both experiments, equilibrium pressure, temperature and flow are established and then the specimens are laser ignited. In one case, the specimen is held at one end and ignited on the leading edge tip; in the other apparatus, the specimen is held at both ends and ignited on the leading edge at mid-span. Which configuration more closely approximates engine conditions is debatable and perhaps immaterial, but it appears that quenching at conditions to the right of the discrimination 1 ine is more probable in the latter apparatus.

Data from[46], believed taken in the same apparatus as the data given in figures $20 \mathrm{a}$ and $20 \mathrm{~b}$, do not show in figures $21 \mathrm{a}$ and $21 b$ any quenching in the predicted self-sustained region. However, we believe that these data were taken to substantiate the analytical model development and therefore lie only along the discrimination line, not far to the right. 

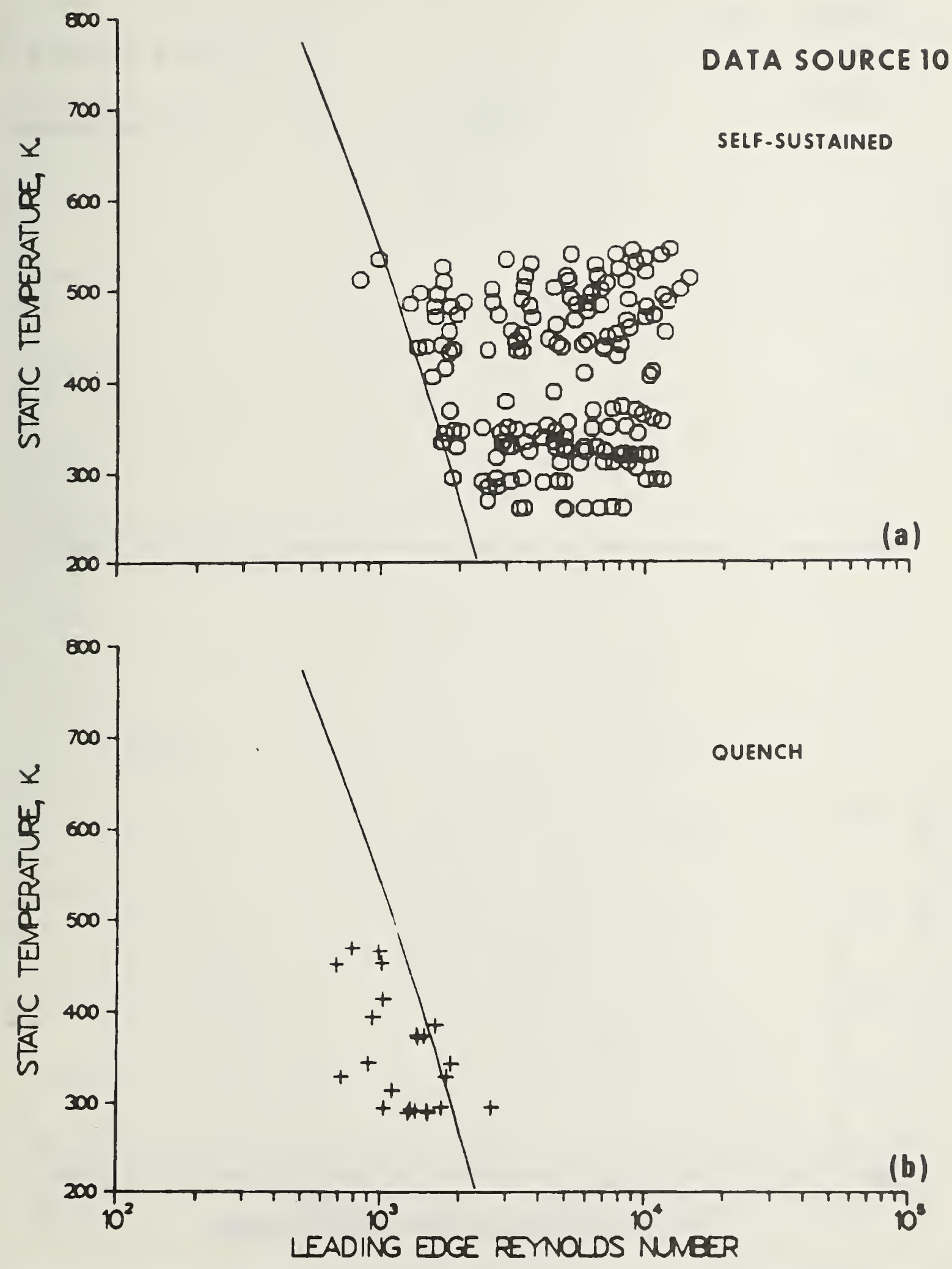

Figure 19. Experimental titanium combustion data from reference 10. 

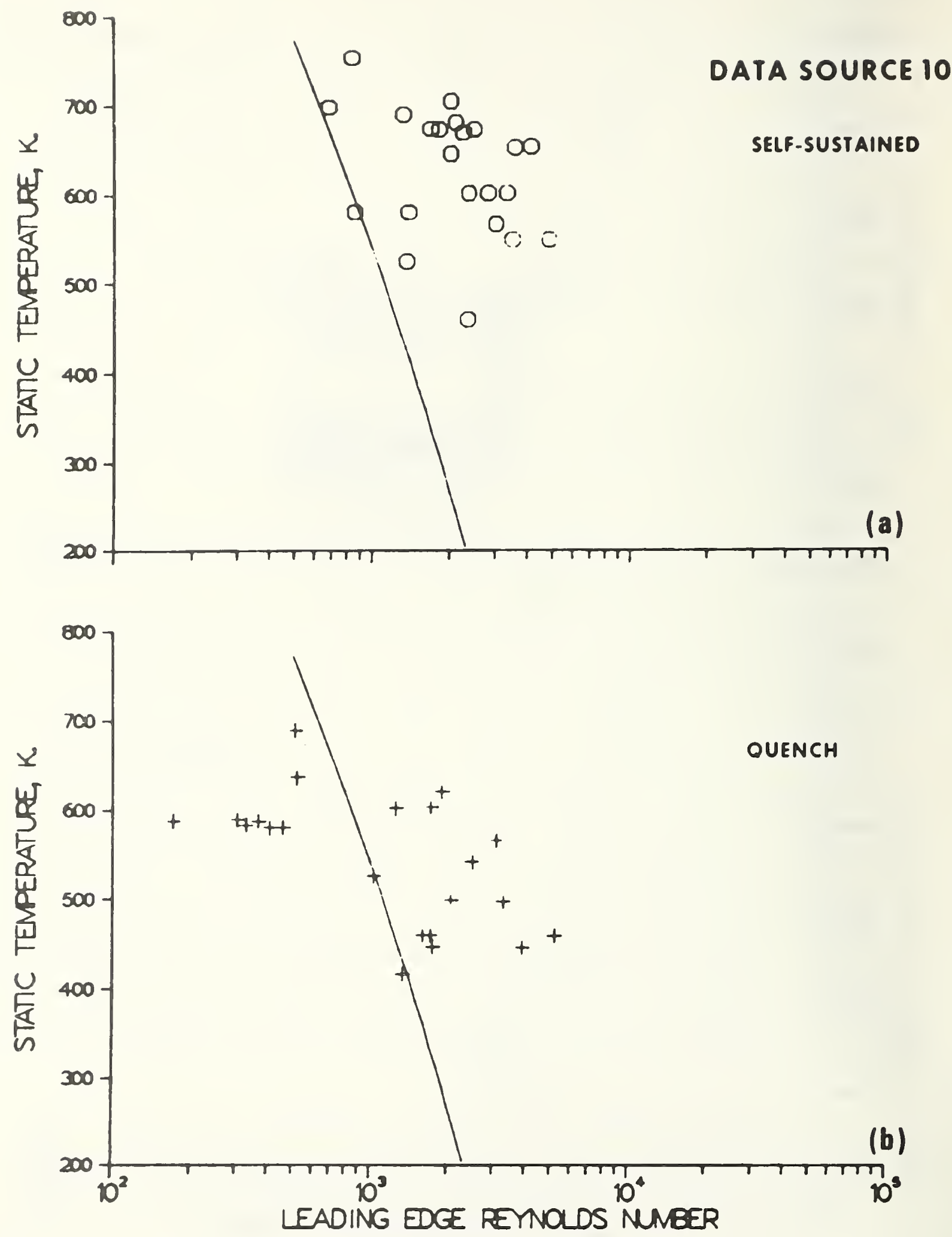

Figure 20. Experimental titanium combustion data from reference 10 . 

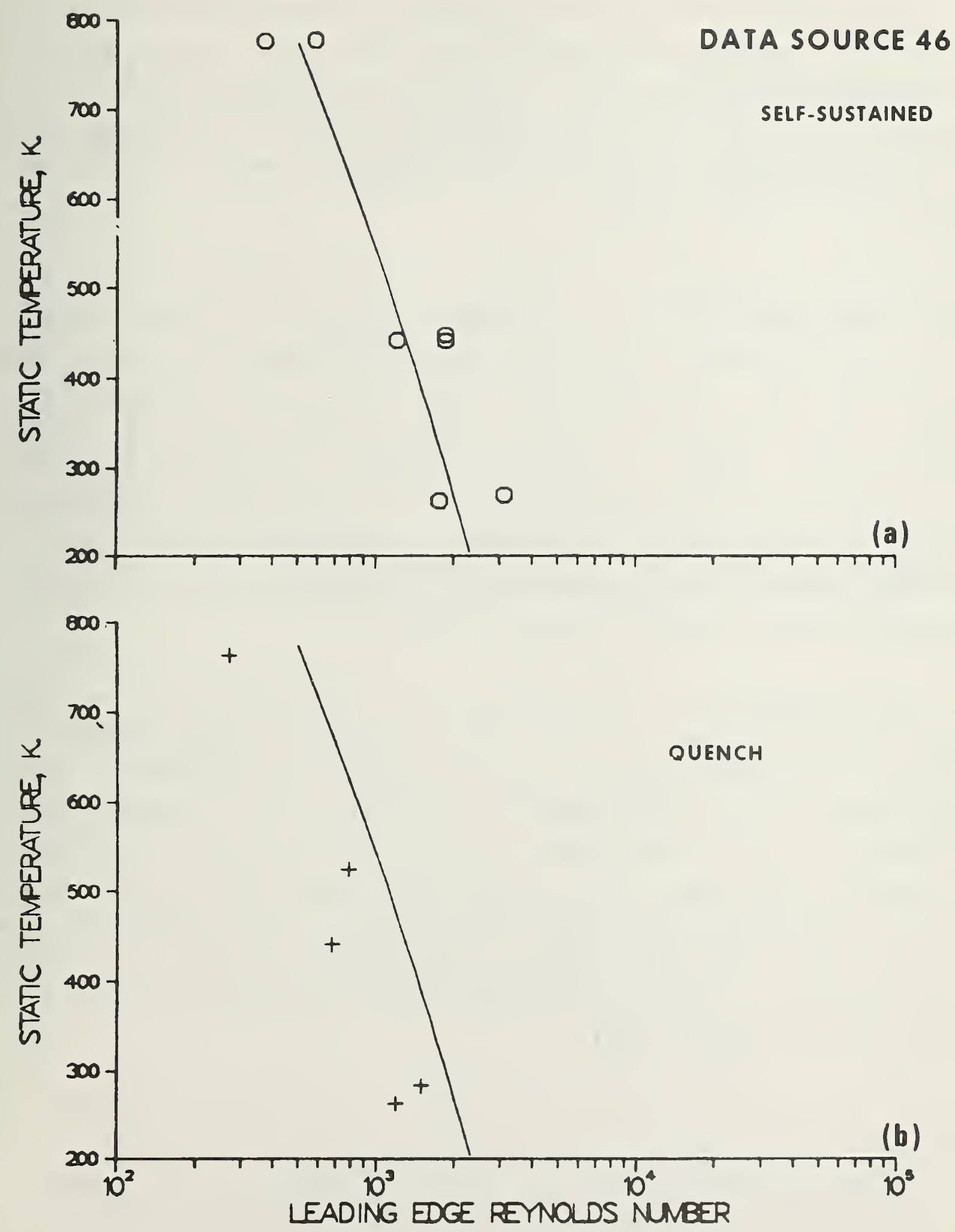

Figure 21. Experimental titanium combustion data from reference 46. 
Data given in [7] were not included in figures 18 because the actual leading edge diameters were not given. These data, figures $22 \mathrm{a}$ and $22 \mathrm{~b}$, would not significantly have changed the character of figure 18 and the specimens were divided among several alloys and several coating materials which could have altered the behavior significantly.

Some of the effects of angle-of-attack are seen in figure 23 which comes from[13]. All specimens, held at the bottom, were set at a $40^{\circ}$ angle-of-attack for these tests and were ignited with melt at the tip. Two trends are apparent. First, a significant number of self-sustained events appear to the left of the discrimination line. Second, a significant number of quenches appear to the right of the discrimination line, an effect more pronounced than in the other data. This effect is an indication that the Reynolds number is not sufficient to describe the heat and mass transfer along a steeply angled airfoil.

Figure 18, which displays all of the experimental data, shows that a rough boundary for the limits of self-sustained combustion in these experiments exists and is predicted by the models. However, given a sufficient energy input, titanium structures normally operating in the predicted quench zone may burn until the energy source is removed. Also, it must be remembered that the boundary applies to the experiments, not to real engine conditions. We conclude that such models may be applicable to present and future engine designs, however the analysis and interpretation must be made by engine specialists. 

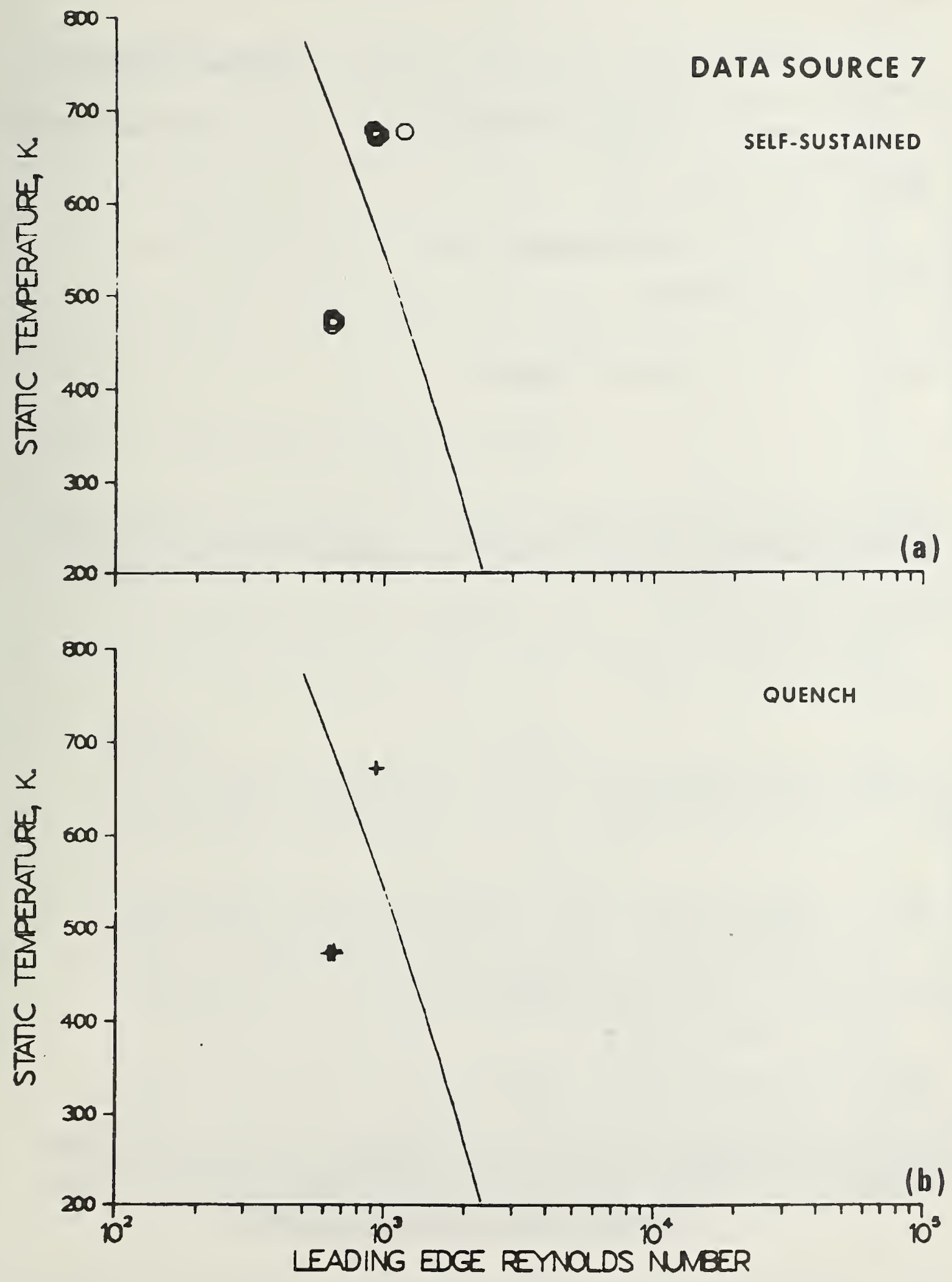

Figure 22. Experimental titanium combustion data from reference 7. 

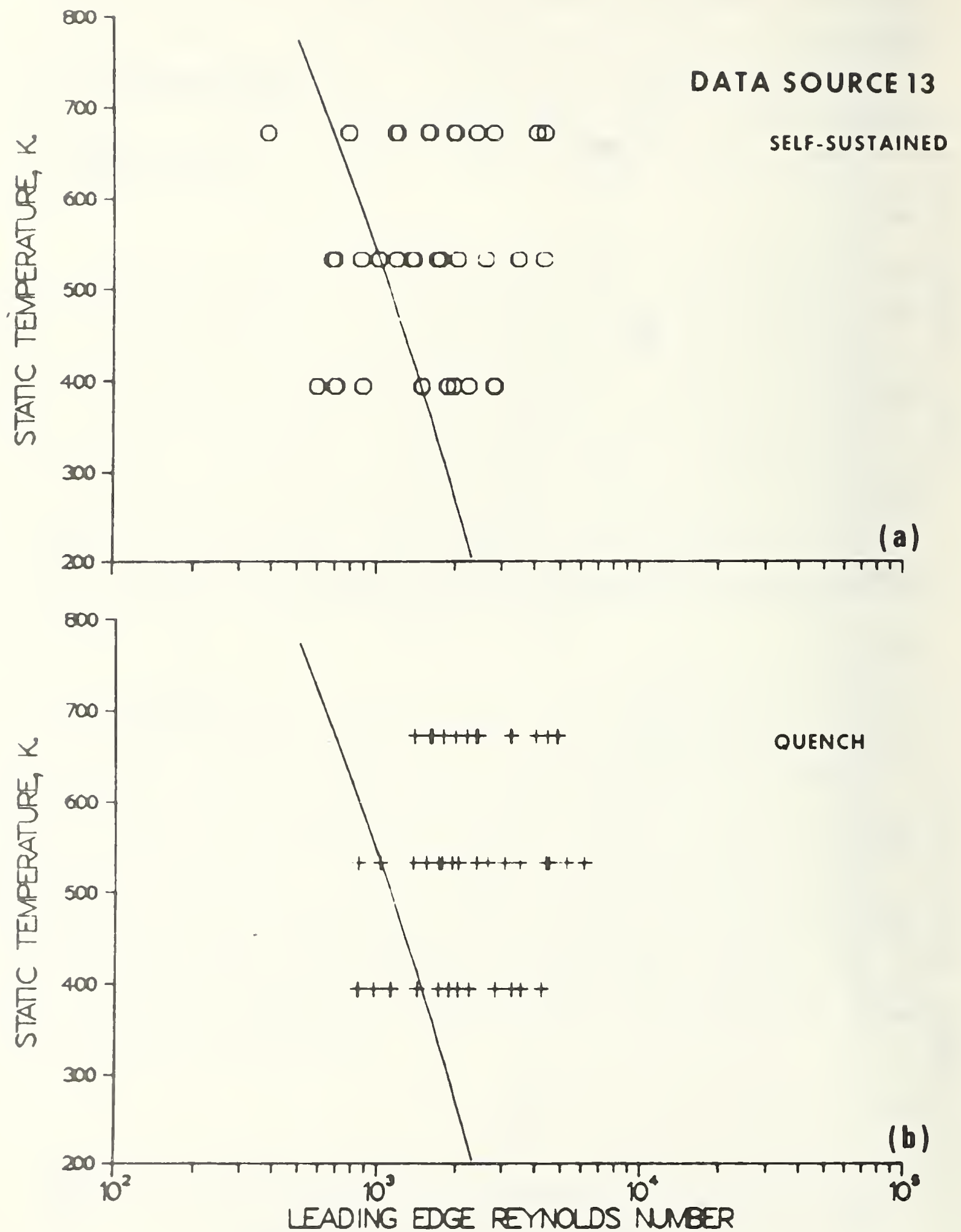

Figure 23. Experimental titanium combustion data from reference 13. 
This section contains the conclusions that we feel can be drawn from the information gathered, summarized and analyzed in the rest of the report. These conclusions are 1 isted below along with a short discussion of each. Many of the points are based on 1 imited information and/or have further qualifications which can only be understood from the more complete discussion in the body of the report. To assist the reader, each point has listed the section where it is discussed in more detail; we urge that these be read also.

USE OF TITANIUM IN TURBINE ENGINES

- Titanium is the optimum material for certain turbine engine components. At this time there are no suitable alternate materials for large fans and other components even though extensive materials development efforts have been expended. For example, the high strength to weight ratios exhibited by some composites are not accompanied by other necessary properties such as impact strength. stiffness, erosion resistance and so on (See Sec. I, 1.1).

- Originally. titanium was used as far aft in engines as its mechanical properties would permit. The primary I imitation was reduced creep strength at elevated temperatures (See Sec. 1.1).

- Recent combustion experience has led to further limitations, i.e.e less 'agressive' use of titanium. Some newer designs have accepted the weight penalty and use steel or other materials instead of titanium for certain components in the aft compressor section, particularly for static components such as stator vanes and cases.

There are several reasons for this substitution: the weight penalty for static parts is less than for rotating parts, titanium rubbing on titanium has a high ignition potential, and static parts can trap molten metal thrown off by rotating parts, leading to rapid propagation of a fire. (See Sec. 4.1). 
- The combustion incident data base is very poor in quality and quantity. Our tabulation (Table 3 ) shows 67 percent of the incidents as cause "unknown". For others, the two or three word cause-description does little to add to scientific understanding of the incident. There is no information available about titanium combustion incidents short of complete engine shut down. Information about such "partial burns" could help in understanding the conditions for non-propagating combustion (See Sec. 3.2).

- Forty percent of the titanium combustion incidents known to us have resulted in case penetration. penetrations ranged from small holes in the case or air extraction manifolds to $360^{\circ}$ circumferential burn through. Essentially no information about subsequent, external damage was available. This high percentage of case penetrations may also reflect the lack of statistics on non-propagating combustion incidents (See Sec. 3.2).

- The cause of most combustion events (as we know them now) is a mechanical upset of some kind--FOD, DOD, blade or vane failure, bearing failure, etc. The most common of all known causes is failure of a blade or disc (42\%). However, it is not inconceivable that a stall could lead to mechanical damage sufficient for ignition and yet the incident be interpreted as DOD followed by a stall. (See Sec. 3.2).

\section{IGNITION AND COMBUSTION BEHAVIOR OF TITANIUM}

- Fundamental metal combustion mechanisms are not well understood. Metal ignition and combustion phenomena are affected by many factors, including the thermophysical properties of the metal and its oxides, environmental conditions, and the history and configuration of the metal. Not enough basic research has been done to fully characterize the influence of all these parameters. It is known that under most practical conditions the titanium combustion reaction occurs on the surface of the molten metal at a rate limited only by the availability of oxygen. Very little is known about titanium reactions with nitrogen or $\mathrm{CO}_{2}$. (See Sec. 6.3) 

of temperature and pressure or oxygen concentration. These limits apply only to bulk specimens heated relatively slowly to the ignition temperature in an oxidizing atmosphere. It has been amply demonstrated that any one of several factors can lower the ignition limit; in particular, heating at rates greater than $20^{\circ} \mathrm{C} / \mathrm{s}$, surface- to-volume ratios in excess of 25 $\mathrm{cm}^{-1}$, exposure of a fresh surface, or the addition of supplemental energy in any form (friction, impact or fracture) all have been shown to lower the temperature and/or pressure at which titanium ignites. (See Sec. $6.2)$.

- BUT, accidental ignition is nearly always associated with a supplemental energy source so the spontaneous ignition limit cannot be used in practice. Although ignition limits can be established for well characterized supplemental energy sources, it is impractical to design around these limits because there is no way to reliably predict what the external energy inputs will be during a mechanical failure. Furthermore, it is apparent that sufficient energy may be released during a failure to exceed even the spontaneous ignition limit.(See Sec.6.2).

- The major mechanism for combustion propagation is molten titanium and its oxides thrown or blown agi inst other titanium structures. Since rotating parts will tend to slough off any molten material, static structures are much more susceptible to impingement by molten metal and rapid propagation of a fire. Further damage may be caused downstream from a fire by molten titanium lodging against nickel alloy structures and melting them by formation of a low-melting Ti-Ni eutectic. (See Sec. $6.4)$.

- Alloying does not in a practical sense affect combustion in engines for the alloys commonly used today. While some alloys have been shown to resist ignition and combustion, those alloys do not have other properties suitable for engine environments; for example, they may be too brittle or have low fatigue strength. (See Sec. 6.4 ).

- Coatings and surface treatments show some promise to inhibit ignition and combustion but practical systems are not yet developed. Coatings may affect other properties such as fatigue resistance or may not tolerate the engine operating conditions. (See Sec. 6.4). 
- Several design precautions are now in practice. There is general agreement that titanium on titanium rubs are a predictable ignition source. Rub strips or coatings are commonly used to prevent, insofar as practical, titanium on titanium rubs while allowing closer operating clearances, and to absorb molten titanium and its oxides without igniting. Thin, static titanium structures which can be susceptible to ignition have not been used above certain pressures and temperatures in some modern designs with apparently good results, as evidenced by the lack of titanium fires. Wider clearances reduce the possibility and severity of rubs.

Increased tolerance to foreign objects and designs to reduce domestic object damage lower the probability of system upsets that can lead to ignition. (See Sec. 4).

Self-sustaining combustion limits can be established analytically and experimentally in terms of temperature and Reynolds number for thin static structures. These limits are lower than the spontaneous ignition limits and are very dependent on configuration and surrounding conditions. Most of the experimental work has been at $0^{\circ}$ angle-of-attack; however there is evidence that angle-ofattack is an important parameter. Although the sustained combustion limits have not been determined for rotating parts, those for static parts are expected to be a lower limit. (See Sec. 7).

Extinguishing titanium fires in turbine engines is probably not practical at this time. The events are of short duration $(4-20 \mathrm{~s})$ and large volumes of special extinguishing agents would be required. Sixty percent argon in air is effective but $\mathrm{CO}_{2}$ actually increases the rate of titanium combustion. Suitable techniques for detecting titanium fires would also have to be developed. ( See Sec. 4.3). 
Several areas of concern and lack of understanding would benefit from further work. We have listed below several areas for continued effort that would provide the best return in terms of alleviating present problems and increasing our understanding in order to promote safer future designs.

Incident data. A thorough and uniform method of gathering and analyzing the data from accidental titanium combustion in turbine engines would provide a sound basis for future design. These data should include probable cause and source of ignition, environmental conditions at the ignition point and in propagation zones, extent and direction of propagation, analysis of products, and the engine's past history and operating conditions. Of particular help would be data from minor events which could give some indication of conditions which have inhibited propagation.

Properties data for combustion modeling. Fundamental properties data for liquid and solid titanium and its alloys are needed for accurate modeling of the titanium combustion process. These data include the surface tension of titanium and its alloys as a function of oxygen concentration, the interfacial energy (wetting behavior) under oxidizing conditions that lead to fire propagation, and the viscosity of liquid titanium as a function of oxygen content.

- Minimum ignition conditions. Methods must be devised to determine the minimum ignition conditions for titanium in a dynamic environment. These could use highly controllable, pulsed-laser techniques for accurate energy input, rate and location for comparison to molten drop propagation studies.

- Ignition by molten-titanium. Because propagation is largely controlled by impingement of molten, burning metal on static structures, the ignition of titanium by burning droplets of the metal should be studied. These experiments should try to define the minimum size and temperature of a molten titanium droplet necessary to ignite titanium plates of varying thickness.

- Coatings and alloys. Research on ignition- and propagation-inhibiting coatings and alloys should continue because several have shown some promise. Those that do should be included in the properties data and ignition studies for further evaluation. 
Dynamic experiments. Self-sustained titanium combustion should be further studied in wind tunnel experiments to provide a firm data base on the environmental conditions which will or will not propagate a burn. Further tests should concentrate on environmental conditions near the self-sustained combustion limit and the experimental uncertainties associated with this limit must be evaluated. Structures other than air foils, such as bleed air ducts and manifolds, should also be studied.

- Rotation effects. The one untested parameter in the dynamic experiments is that of rotation. The effect of centrifugal forces on the propagation of combustion on a rotating part should be determined as well as the effects of impact of molten metal on adjacent static components. Simple calculations indicate that the effect of centrifugal forces may be large and may well help curtail propagation of combustion on the rotating component.

- Analytical modeling. Efforts to develop a comprehensive analytical model to predict ignition and self-sustained combustion of titanium alloys in engine environments should be continued. The addition of the capability to consider the effects of angle-of-attack and surface coatings would considerably enhance the power and utility of the current model.

In summary, although titanium combustion damage has occurred in several instances, the technology exists to confine this damage to the engine. We therefore conclude that with proper application of good design and maintenance practices titanium can be used safely in present day turbine engines. 
The authors gratefully acknowledge the kind cooperation and assistance of the following organizations and individuals. The information and consultations provided by them contributed immeasurably to this report.

1. Airesearch Manufacturing Company

A. M. Walacavage

J. Pyne

W. Danesi

2. Air Force Aero Propulsion Laboratory

C. W. Elrod

3. Air Force Materials Laboratory

S. R. Lyon

4. Civil Aviation Authority

K. A. Burdon

5. Federal Aviation Administration

A. K. Forney

C. C. Troha

6. General Electric Company

B. L. Koff

J. Melink

P. Linko

7. National Transportation Safety Board

E. P. Wizniak

8. Pratt and Whitney Aircraft Company

A. W. Oberg

R. J. Makowski

W. F. Laverty

M. R. Glickstein

B. A. Manty

V. Anderson

9. National Aeronautics and Space Administration

L. Ludwig

S. Weiss 
10. Rolls-Royce Ltd.

K. R. Welling

J. B. Sheldon

R. Ebbs

P. A. Withers

P. B. Smith

B. Lewis

11. United Airlines

J. K. Goodwine

P. Sellers

J. Uh 1 
1. Bradley, E. F., Phinney, D. G., and Donachie, M. J. Jr., The Pratt and Whitney Gas Turbine Story, Metal Progress, 97 , No. $3,68,(1970)$.

2. Bradley, E. F., and Donachie, M. J., Changes and Evolution of Aircraft Engine Materials, Metals Engineering Quarterly, 15 , No. 2, 55, (1975).

3. Private communications from Forney, A. K., and Troha, C.C., Federal Aviation Administration; Koff, B. L., Melink, J., and Linko, P., General Electric Company; Oberg, A. W., Makowski, R. J., Laverty, W.F., Glickstein, M. R., Manty, B.A., and Anderson, V., Pratt and Whitney Aircraft Company; Walacavage, E. M., Pyne, J. and Danesi, W., Airesearch Manufacturing Company; Berdon, K. A., Civil Aeronautics Authority; Welling, K. R., Sheldon, J. B., Bobs, R., Withers, P. A., Smith, P. B. and Lewis, B., Rolls-Royce Ltd.; Elrod, C. W., Air Force Aero Propulsion Laboratory; Lyon, S.R., Air Force Materials Laboratory, Wizniak, E. P., National Transportation Safety

Board; Pinkel, I., National Aeronautics and Space Administration Consultant; Goodwine, J. K., Sellers, P. and Uhl, J., United Airlines.

4. Jahnke, L. P., Titanium in Jet Engines, in: The Science Technology and Application of Titanium, Pergamon Press, Oxford, (1970), 1099.

5. Glenny, R. J. E., Northwood, J. E., and Burwood-Smith, A., Materials for Gas Turbines, International Metallurgical Review, 20, 1, (1975).

6. Anon., Titanium and It's Alloys, Materials in Design Engineering, 123, (October 1965).

7. Anderson, V. G. and Manty, B. A., Titanium Alloy Ignition and Combustion, Report No. NADC-76083-30, Naval Air Development Center, Warminster, Pennsylvania, (15 January 1978 ).

8. Gray, A. G., Worldwide Titanium Technology, Metal Progress, 60 (September 1968 ).

9. Shaw, H. W., Recent Developments in Titanium, Journal of the Royal Aeronautical Society, 70, 777, (1966).

10. Glickstein, M. R., Manty, B. A., Lyon, S. R. and Elrod, C. W. Ignition and Self-Sustained Combustion of Titanium Alloys, Presented at the Third DoD Conference on Laser Effects, Vulnerability and Countermeasures, July 19-22, 1977, Naval Training Center, San Diego, CA.

11. Anon., Aviation Week and Space Technology, 108, No. 22, 31, $(1978)$. 
12. Anon., Aviation Week and Space Technology, 109, No. 16, 13, (1978).

13. Fox, D. G., Investigation of Titanium Combustion Characteristics and Suppression Techniques, AFAPL-75-73, Air Force Aero Propulsion Laboratory, Wright-Patterson AFB, Ohio, (February 1976).

14. Grosse, A. V., and Conway, J. B., Combustion of Metals in Oxygen, Ind. Eng. Chem. 50, 663, (1958).

15. Markstein, G. H., Combustion of Metals, A.I.A.A. Journal $\underline{\text {, }}$ $550,(1963)$.

16. Clark, A. F., and Hust, J. G., A Review of the Compatibility of Structural Materials with Oxygen, A.I.A.A. Journal 12, $441-454$ (1974).

17. Glassman, I., Metal Combustion Processes, ARS Preprint No. 938-59, (November 1959).

18. Kofstad, P., High Temperature Oxidation of Metals, Wiley New York, (1966).

19. Moulder, J.C., Michals, P.R., and Clark, A.F., Temperature and Oxidation Rates during the Combustion of Bulk Titanium and Titanium Alloys, J. Electrochem. Soc. 122, 260C, (1975).

20. Nelson, L.S., Combustion of Metal Droplets Ignited by Flash Heating, Eleventh Symposium (International) on Combustion, The Combustion Institute, Pittsburgh (1967), 409.

21. Nelson, L.S., Explosion of Burning Zirconium Droplets Caused by Nitrogen, Science 148, 1594, (1965).

22. Meyer, R.T., and Nelson, L.S., The Role of Nitrogen in the Formation of Microbubbles during the Explosive Combustion of Zirconium Droplets in $\mathrm{N}_{2} / \mathrm{O}_{2}$ Mixtures, High Temp. Sci. $\underline{2}$, $35,(1970)$.

23. Clark, A.F. and Moulder, J.C., The Combustion of Bulk Titanium in oxygen, Fifteenth Symposium (International) on Combustion, The Combustion Institute, Pittsburgh, (1975), 489 .

24. Stull, D. R., and Prophet, H., JANAF Thermochemical Tables, 2nd Ed., NSRDS-NBS 37 (June 1971). Available from Superintendent of Documents, U. S. Government Printing office, Washington, D. C., 20402 (Catalog Number C $13.48: 37)$. 
25. Chase, M. W., Curnett, J.L., Prophet, H., McDonald, R.A., and Syverud, A.N., JANAF Thermochemical Tables, 1975 supplement, J. Phys. Chem. Ref. Data $4,1,(1975)$.

26. Kubaschewski, O., and Evans, E. LL., Metallurgical Thermochemistry, 2nd Ed., Pergamon, London, (1958).

27. Darken, L.S., and Gurry, R.W., Physical Chemistry of Metals, McGraw-Hill, New York, (1953).

28. Lewis, G. N., Randall, M., Pitzer, K. S., and Brewer, L., Thermodynamics, 2nd Ed., McGraw-Hill, New York, (1961).

29. Wolf, J.S., Exploratory Development on Oxidation Behavior of Titanium Alloys under High Heating Rates, AFML TR-74-265, Air Force Materials Laboratory, Wright-Patterson AFB, Ohio, (April 1975).

30. Wolf, J.S., Grochowski, J.M., Nature of Gas-Metal Reactions under Conditions of Anisothermal oxidation, in: Stress Effects and the oxidation of Metals, ed. by J. V. Cathcart, TMS-AIME, (1975), 274 .

31. Wolf, J.S., Moyle, D.D., Pruitt, A.B., and Bader, J.H., Anisothermal Oxidation of Titanium: Initial Reactivity and Ignition, in: Proceedings of the symposium on Properties of High-Temperature Alloys, ed. by Z. A. Foroulis and F. S. Pettit, Electrochemical Society, Inc., (1976), 365.

32. Wolf, J.S., Anisothermal oxidation of Titanium and Its Alloys, Final Scientific Report, AFOSR-76-2919, Clemson University, Clemson, South Carolina, (December 1977).

33. Schmidt, H.W., and Forney, D.E., ASRDI Oxygen Technlogy Survey, Vol. IX., Oxygen Systems Engineering Review, NASA SP-3090, NASA Lewis Research Center, Cleveland, Ohio, $(1975)$.

34. Jackson, J.F., Boyd, W.K., and Miller, P.D., The Reactivity of Titanium With Liquid and Gaseous oxygen, Materials Protection, $\underline{4}$ (1), 30, (January 1965).

35. White, E.L. and Ward, J.J., Ignition of Metals in oxygen, Rept. DMIC-224, Defense Metals Information Center, Battelle Memorial Inst., Columbus, Ohio, (February 1966).

36. Littman, F.E., Church, F.M., and Kinderman, E.M., A Study of Metal Ignitions. I. The Spontaneous Ignition of Titanium, J. Less-Common Metals 3 , 367, (1961).

37. Mellor, A.M., Heterogeneous Ignition of Metals: Model and Experiment, $\mathrm{Ph}$. D. Thesis, Princeton University, Dept. of Aerospace and Mechanical Sciences, (1967).

38. Harrison, P.L., The Combustion of Titanium and Zirconium, 7 th International Symposium on Combustion, Butterworths, London, (1959), 913. 
39. Harrison, P.L. and Yoffe, A.D., The Burning of Metals, Proceedings of the Royal Society, London, A261, 357, (1961).

40. Hust, J.G., and Clark, A.F., A Survey of Compatibility of Materials with High Pressure Oxygen Service, Cryogenics 13 , $325,(1973)$.

41. Tench, A.H., Roder, H.M., and Clark, A.F., Combustion of Metals in Oxygen Phase II: Bulk Burning Experiments, NBSIR 73-345, National Bureau of Standards, Boulder, Colorado, (December 1973).

42. Runyan, C.C., Moulder,J.C., and Clark,A.F., Time-Resolved Spectra of Bulk Titanium Combustion, Combustion and Flame 23 , 129, (1974).

43. Moulder, J.C., Lund, D.S., and Clark, A.F., Observations of Continuum Radiation during Laser-Initiated Metal Combustion, J. Electrochem. Soc. 122, No. 8, 260C, (1975).

44. Moulder, J.C., and Clark, A.F.,Time-Resolved Spectroscopy of Laser-Initiated Metal Combustion, in: Unconventional Spectroscopy - Proceedings SPIE Vol. 82, ed. by J.M. Weinberg and T. Hirschfeld, SPIE, Palos Verdes Estates, (1976), 66. Also in Opt. Eng. 16, 393, (1977).

45. Moulder, J.C., and Clark, A.F., Luminescence in Metal Flames Irradiated with a $\mathrm{CO}^{2}$ Laser, Chem. Phys. Letters 49,471 , (1977).

46. Glickstein, M. R., A New Analytical Model for Prediction of Self-Sustained Combustion of Titanium Airfoils, FTDM No. 5589 , Pratt and Whitney Aircraft, West Palm Beach, Florida, ( June 28,1974 ).

47. Seward, W. A., Combustion of Titanium Laser-Initiated in a Controlled Airstream, Masters Thesis, Air Force Institute of Technology, Air University, Dayton, Ohio, GAE/AE/750-16, ADB009546L, (December 1975).

48. Elrod, C., River, R., and Rabe, D., Laser Ignition of Titanium, AFAPL-TR-76-12, ADB010387L, Air Force Aero Propulsion Laboratory, Wright-Patterson AFB, Ohio, (March 2, $1976)$.

50. Manty, B., Anderson, V. and Tankins, E., Titanium Alloy Ignition and Combustion studies and the Imact on Surviability of Naval Aircraft, presented at the Third Biennial Aircraft Survivability Symposium, Monterey, CA, October 30-November 2 , 1978 .

51. Manty, B., Anderson, V., and Tankins, E., Titanium Alloy Rapid Oxidation in Gas Turbine Environments, Tri-Service Conference on Corrosion, (1978).

52. Pyne, J., Report No. 76-212301,.Airesearch Mfg. Co. of Arizona, Phoenix, Arizona, (1976). 
A GLOSSARY of METAL COMBUStion TERMINOLOGY*

\section{Oxidation}

breakway oxidation: in the transition from protective oxidation kinetics to nonprotective, if the linear rate is faster than the instantaneous (tangential) rate before the transition, the oxidation is called breakaway. Titanium exhibits this type of behavior at temperatures greater than about $1170 \mathrm{~K}\left(900^{\circ} \mathrm{C}\right)$.

catastrophic oxidation: excessively fast oxidation leading to the disintegration of an alloy (but not necessarily combustion) that occurs when one component of the alloy forms a liquid oxide phase during oxidation.

nonprotective oxidation: metallic oxidation that proceeds at a constant rate, independent of exposure time. This may be due to the oxide's lacking sufficient volume to cover the metal surface completely or to the presence of cracks and pores in an otherwise coherent oxide film.

oxidation: the chemical reaction of any substance with oxygen or oxygen-bearing compounds to form oxides. When applied to metals, the term can also refer to the formation of an oxide film on metals exposed to oxygen.

oxidation rate: in order to distinguish between film formation and actual combustion, we limit use of the term "oxidation rate" to descriptions of the rate at which a solid oxide film or scale is formed on a metal at elevated temperatures. Oxidation rate may be expressed alternatively as the amount of oxygen uptake per unit surface per unit time, the amount of metal transformed to oxide per unit time, or the change in thickness of the oxide film per unit time (provided the film is uniform).

*This glossary is divided into four sections: I. Oxidation, II. Ignition, III. Combustion and IV. Propagation. Entries are arranged alphabetically within each section. 
oxidation rate law: refers to the form of the analytical expression describing the oxidation of a metal as a function of time. The most commonly observed rate laws are logarithmic, parabolic and linear. Occasionally cubic and quartic rate laws are observed. A logarithmic rate law applies when the amount of oxide formed per unit area (or, alternatively, the thickness of the oxide film) is proportional to the logarithm of the exposure time. The remaining rate laws are described by the expression.

$$
\mathrm{x}^{\mathrm{n}}=\mathrm{k}_{\mathrm{n}} \mathrm{t}+\mathrm{c},
$$

where $\mathrm{x}$ is the amount of oxide formed per unit area, $k_{n}$ is the rate constant, $t$ is exposure time at constant temperature and $c$ an integration constant. According to whether $\mathrm{n}=1,2,3$, or 4 , the rate law is termed linear, parabolic, cubic or quartic. These rate laws represent ideal behavior; often real metals exhibit deviations from the ideal rate equations. Also, a single metal may obey different rate laws at different temperatures.

Pilling and Bedworth ratio: the oxide/metal volume ratio (the ratio of the molar volume of the metal oxide to that of the metal). Used as a qualitative indication of whether a metal will undergo protective or non-protective oxidation. If the pilling and Bedworth ratio is greater than one, the oxide will occupy more volume than the metal it displaces and oxidation will be protective; if it is less than one, then the oxide will not cover the metal surface completely and nonprotective oxidation will be ob served. However, this principle is of somewhat limited applicability since many factors affecting nidation kinetics are not taken into account. 
protective oxidation: metallic oxidation that proceeds at a rate that diminishes with exposure time at constant temperature. Caused by the formation of a compact, coherent oxide film on the metal surface. The film acts as an increasingly effective barrier to the diffusion of oxygen.

transition temperature: the temperature at which protective oxidation kinetics give way to a nonprotective, linear rate law. 


\section{Ignition}

autogenous ignition temperature: the lowest temperature from which a metal can self-heat by oxidation to the spontaneous ignition temperature. The period of self-heating is termed the induction period or ignition delay.

bulk ignition temperature: experimentally, it is observed that the ignition temperature varies with the state of subdivision of a metal; small particles ignite at lower temperatures than massive specimens. The bulk ignition temperature is measured with a sufficiently large specimen that size effects play a negligible role. It is generally hypothesized that the bulk ignition temperature is a property of the metal itself, susceptible to measurement and independent verification. But the experimental evidence for this hypothesis is far from conclusive.

critical temperature: in the analytical treatment of ignition by a heat balance approach, the temperature at which the rate of heat generation by chemical reaction is equal to the rate of heat loss by radiation, conduction, and convection combined. Above the critical temperature, the system may self-heat to the spontarieous, ignition temperature; thus, the critical temperature corresponds to the autogenous ignition temperature.

ignition: the initiation of combustion. More specifically, a thermal instability that occurs when the heat-release rate during a chemical reaction exceeds the reactants' ability to dissipate it, leading to a rapid rise in temperature and a corresponding increase in the reaction rate until a new equilibrium state is attained.

ignition limit: minimum conditions of temperature and oxidizer pressure (or concentration) necessary for a metal to ignite spontaneously; thus, the minimum ignition temperature as a function of some other parameter such as pressure or airstream velocity or Reynolds number. Any factor that adds supplementary energy to the metal can lower the ignition limit. 
incendivity: the ability to ignite a flammable or explosive mixture; for example, the ability of grinding sparks from metal tools to ignite coal dust dispersions or methane-air mixtures in coal mines.

minimum ignition temperature: the lowest temperature at which a metal is experimentally observed to ignite.

pyrophoric: capable of igniting spontaneously in air at room temperature. This refers to the ability of extremely fine metal powders to self heat rapidly to the spontaneous ignition temperature upon exposure to ambient air. It is caused by the very large specific surface area $\left(\mathrm{cm}^{2} / \mathrm{g}\right)$ of small particles; as the particle diameter is decreased, the amount of surface area available for oxidation per gram of metal increases, leading to a reduction in the critical temperature.

spontaneous ignition temperature: the temperature at which instantaneous inflammation of a metal occurs. The spontaneous ignition temperature is always higher than the autogenous ignition temperature. Analytically, it corresponds to a maximum in the derivative of temperature with respect to time. 
II . Combustion

adiabatic flame temperature: the equilibrium combustion temperature calculated from the heat of reaction, taking into account the heat capacity of the products, the latent heat of fusion, and the heats of any allotropic phase transitions, but assuming no heat losses. Because metal oxides are stable and do not dissociate at high temperatures, the boiling point of the metal oxide provides an upper limit to the flame temperature.

Arrhenius equation: Experimentally it is found that for most chemical reactions the temperature dependence of the reaction rate follows an expression of the form

$$
k=A \exp (-E / R T)
$$

where $\mathrm{k}$ is an appropriate rate constant, $\mathrm{A}$ is a frequency factor (accounting for the frequency and geometry of collisions between reactants), $R$ is the universal gas constant, $T$ is the absolute temperature, and $\mathrm{E}$ is the activation energy of the reaction. Expressions of this form are called Arrhenius equations, after Svante August Arrhenius, the Swedish chemist who first proposed this type of temperature dependence for reaction rates in 1889.

chemically controlled reaction: a reaction in which the rate limiting step is an elementary chemical reaction rather than a transport process.

combustion: a rapid chemical reaction accompanied by heat and, usually, light. Synonymous with burning.

combustion limit: minimum conditions of temperature and oxidizer pressure (or concentration) necessary for a metal that has been ignited to undergo self-sustained combustion. In almost every case, the combustion limit for a particular metal will be lower 
than the ignition limit. This means that in order to extinguish a metal once ignited, it is necessary to reduce the temperature and/ or pressure to values below both the ignition and combustion limits. If, however, an external energy source causes ignition below the combustion limit, the combustion reaction would not sustain itself.

combustion rate: the rate at which oxygen is consumed during sustained metal combustion. For a metal that burns on the surface such as titanium, the combustion rate would be expressed as weight of oxygen taken up per unit area per unit time. $\left(\mathrm{g} / \mathrm{cm}^{2} \mathrm{~s}\right.$ or mole $\left./ \mathrm{cm}^{2} \mathrm{~s}\right)$. For a metal like magnesium that burns in the vapor phase, the combustion rate would be expressed as volume of oxygen consumed per mole of metal per second ( $1 / \mathrm{mole} s)$. A distinction should be maintained between the more fundamental combustion rate and burning or propagation velocity.

diffusion controlled reaction: a chemical reaction in which the rate limiting step is mass transport of one of the reactants or products. Most metal-oxygen reactions are diffusio. controlled under conditions of practical interest.

Glassman criterion: thermophysical criteria for predicting whether a metal will burn by the vapor phase or surface combustion mode. A necessary but not sufficient condition for combustion to occur in the vapor phase is that the metal oxide's boiling point exceed that of the metal. Conversely, a sufficient but not necessary condition for surface combustion is that the metal's boiling point exceed that of the oxide. The qualifications of necessary and sufficient imposed on these criteria are required because vapor phase combustion may be suppressed by the formation of a protective oxide layer and/or by reduction of the flame temperature below the metal boiling point by radiation losses. 
homogeneous reaction: a chemical reaction that takes place completely in one phase.

heterogeneous reaction: a chemical reaction with one or more condensed phases participating in the reaction.

mixed combustion: under certain conditions, the presence of condensed oxide phases in the combustion zone may lead to competition between heterogeneous and homogeneous reaction paths as, for example, in the low pressure combustion of magnesium. Here, the heterogeneous reaction of $\mathrm{Mg}$ and $\mathrm{O}_{2}$ occurs on MgO smoke particles which were nucleated from Mgo vapor originally formed by homogeneous gas phase reactions. This mode of combustion is called mixed combustion, and is relatively rare. It is not unusual for there to be a small amount of vapor phase combustion occuring during surface combustion of a metal owing to the high temperatures evolved. Likewise it is not uncommon for a metal that burns in the vapor phase to collect some oxides on the surface due to back diffusion and condensation of oxide vapor as well as some surface reaction. But the significance of these competing reaction modes is generally quite small and one mode of combustion will usually predominate.

mixed control: control of a reaction is said to be mixed when there is more than one rate limiting step; that is, when the rate constants for the two slowest steps of the reaction are comparable in magnitude. This situation ususally occurs during transfer of control from one rate limiting step to another as, for example, during the ignition of a metal. 


\section{APPENDIX B}

Excerpt from British Civil Airworthiness Requirements

Paragraph 3, Appendix to Chapter C3-2, Design and Construction, Turbine Engine for Aeroplanes, British Civil Airworthiness Requirements.

\section{TITANIUM FIRES (see $\mathrm{C} 3-2,1.3 .3$ )}

3.1 Experience has shown that most titanium alloys used for manufacturing engine rotor and stator blades will ignite and sustain combustion if the conditions are favourable. In such cases, the Engine casings may be penetrated allowing expulsion of molten or incandescent material which could, depending on the installation, hazard the aircraft.

3.2 Unless the constructor can produce adequate evidence that titanium items in the Engine are such that they will not ignite or will not support combustion, the Engine design should be assessed for vulnerability to titanium fires. It will normally be assumed that a titanium fire is possible if stationary titanium material exists in areas where:--

(a) pressure will exceed $200 \mathrm{kN} / \mathrm{m}^{2}$ (29.4 lbf/in $\left.{ }^{2}\right)$; and

(b) relative air velocities are in excess of approximatels $50 \mathrm{~m} / \mathrm{sec} \cdot(150 \mathrm{ft} / \mathrm{sec}) ;$ and

(c) the geometry is such that relatively thin titanium sections exist which can be rubbed, directly or after shedding, by rotating parts. Stator blades of conventional design, of up to $15 \mathrm{~cm}$ ( $5 \mathrm{in}$ ) of aerofoil height, are regarded as falling into this category.

NOTE: Theoretical studies have attempted to describe the conditions for ignition and continued burning of titanium (using fundamental parameters) in more scientific terms but because many of the parameters can adopt quite variable and unpredictable values during a damage process the above arbitrary values chosen from actual experience appear to provide the best guidance.

3.3 Where the assessment of 3.2 indicates that the possibility of a titanium fire cannot be ruled out on the particular design, it may be possible to show that a titanium fire will be confined to areas within the Engine where it cannot present a hazard, if necessary by the provision of additional protection. Otherwise the Engine approval will be endorsed to the effect that:--

"Some risk of non-contained titanium fires exists on this Engine design, and the Engine is thus approved only for use in aircraft where such fires are unlikely to be hazardous."

If the risk is dependent on specific circumstances (for example the danger only exists at low altitude) such circumstances may also be stated. 
3.4 Experience has shown that the following features can reduce the susceptibility of Engines to titanium fires and such aspects will be taken into account by the Authority in making judgements under 3.2

(a) The type of alloy, i.e. its constituents other than titanium.

(b) Blade coatings which inhibit ignition or subsequent combustion.

(c) Coatings, on casings and other parts, which resist fire penetration but can if necessary accommodate rubbing. (The possibility of eutectic reduction of the casing melting point by reaction with coating materials should be considered.)

(d) The way in which the design minimizes potentitally dangerous rubs by such methods as:--

(i) large interblade row clearances,

(ii) the provision of material in areas of potential rub which melts safely or otherwise clears the rub before ignition temperatures are reached, and which has sufficient depth to prevent direct rubbing between rotating and other parts of the Engine during maximum predicted rotor or casing deflections including those likely to occur in fault conditions,

(iii) not using titanium for adjacent rotating and static parts, i.e. avoiding titanium/titanium rubs,

(iv) attention to rotor movements under transient and bearing failure conditions,

(v) ensuring that any titanium features at the front of the Engine, e.g. entry guide vanes, are robust and unlikely to shed thin, easily-ignited sections.

See also: British Civil Aviation Authority, Paper No. 678, 26 November 1976 . 
METALLURGICAL EXAMINATION OF COMBUSTION SPECIMENS

During the course of this study, several pieces of a gas turbine engine that had experienced an in-flight titanium fire were obtained for metallurgical examination. Samples were taken from areas of the engine casing and the bleed air manifold that had been penetrated by combustion. The cause of this titanium fire was ascribed to blade failure, with one or more broken titanium blades lodging against downstream stator vanes where they were ignited by friction from the adjacent rotating stage.

Small specimens were cut from the burned engine parts, generally in the vicinity of a penetration site. One specimen was cut from an area far removed from the combustion zone for comparison with the burned specimens. All of the specimens were mounted, ground flat on a belt sander, sanded by hand on successively finer grades of sandpaper, and then mechanically polished. They were then examined metallographically and photographed at a magnification of 150 diameters. Selected regions of the specimens were traversed with a microhardness tester in order to estimate the depth of penetration of oxygen into the metal.

The limited time and resources available for this study necessarily limited its scope to these analytical techniques. Undoubtedly, more extensive analyses of specimens from actual titanium fires would yield much additional knowledge; chemical and $x$-ray analyses and scanning electron micrography would be particularly useful.

The visual appearance of the specimens as received was quite distinctive. The interior portions of the engine case showed little accumulation of molten metal or oxides; the interior edges of burned-through holes were relatively sharp, while the exterior of the case showed much more extensive melting and burning. The 
rub strips showed evidence of severe rubbing; very little abradable material was left on the rub strip land. The burned areas on the outside of the engine case were dark brown in color and extended several inches beyond penetration sites. Penetrations were generally elongated along the circumference. Splatters of bright, shiny metal were evident near some of the penetrations and these appeared to have been molten material from the rub strip; the bright metallic appearance of this material indicates that it did not participate in combustion. Subjectively, the rub strip seemed to inhibit rather than enhance combustion. There was no evidence that the rub strip coating burned and the pattern of propagation of the fire would tend to support the conclusion that the rub strip area was somewhat lcss combustible than adjacent areas. It should be emphasized, however, that these are qualitative and subjective observations that must be checked against other evidence before reaching any conclusions.

Photomicrographs of specimens cut from the combustion zone are shown in figures $\mathrm{C}-1$ to $\mathrm{C}-3$. The left half of figure $\mathrm{C}-1$ shows a cross section of the unburned rub strip side of the first specimen while the right half shows a typical burned area on the opposite side of the same specimen (the exterior surface of the engine case). Note that the rub strip layer is mostly gone, with only deformed fragments present above the bond layer. The burned surface of this specimen, shown in the right half of figure $\mathrm{C}-1$, illustrates several features that were common to all burned specimens examined. The outermost layer of metal (top of the photograph) is harder and more brittle than the underlying base metal, as evidenced by the lack of polishing scratches and the microhardness determinations. The morphology of the outer layer and the presence of numerous voids and bubbles suggest that this metal was. molten at some time during combustion and resolidified in its present location. This molten, recast layer is quite brittle and often exhibits cracks; it occasionally chipped off during cutting and grinding operations (figure $\mathrm{C}-2$ ). The thickness of the recast layer varied from 50-500 $\mathrm{m}$. To the unaided eye this layer retained a metallic luster, although often imbued with a brownish tint 


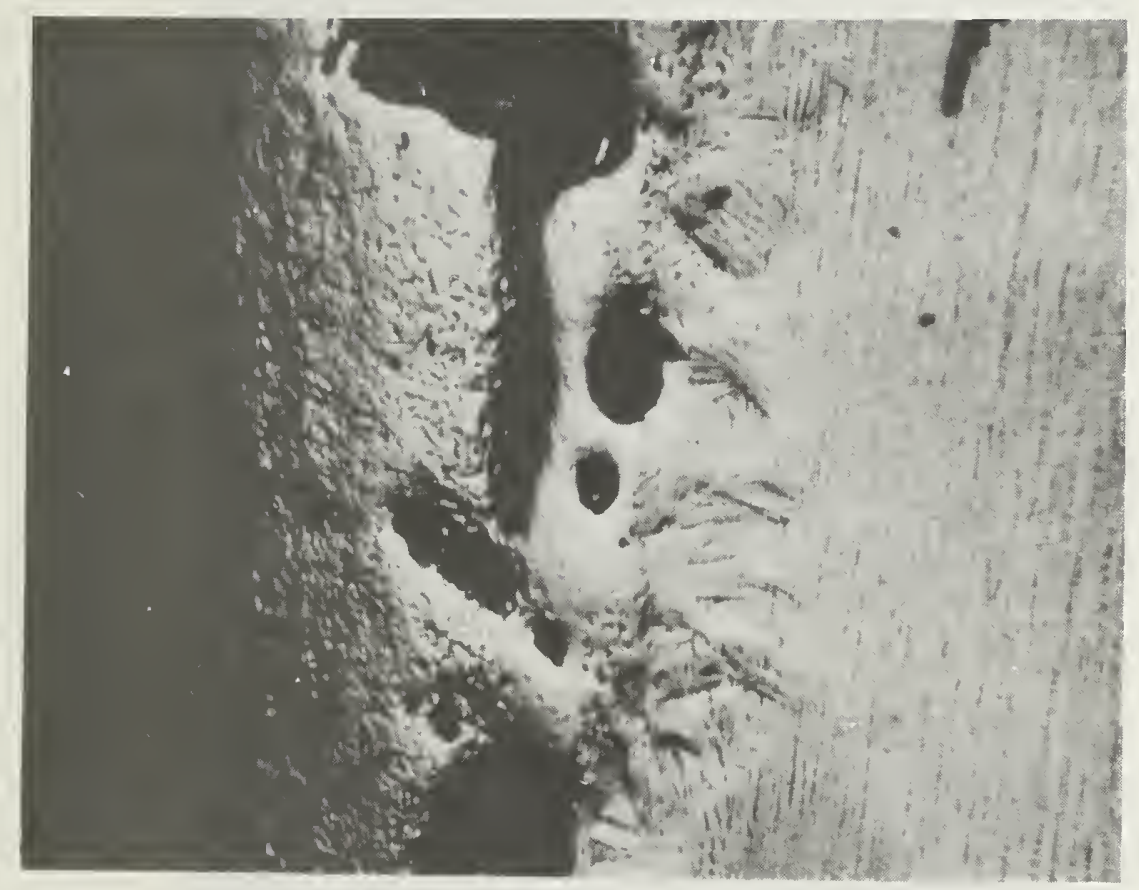

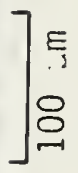

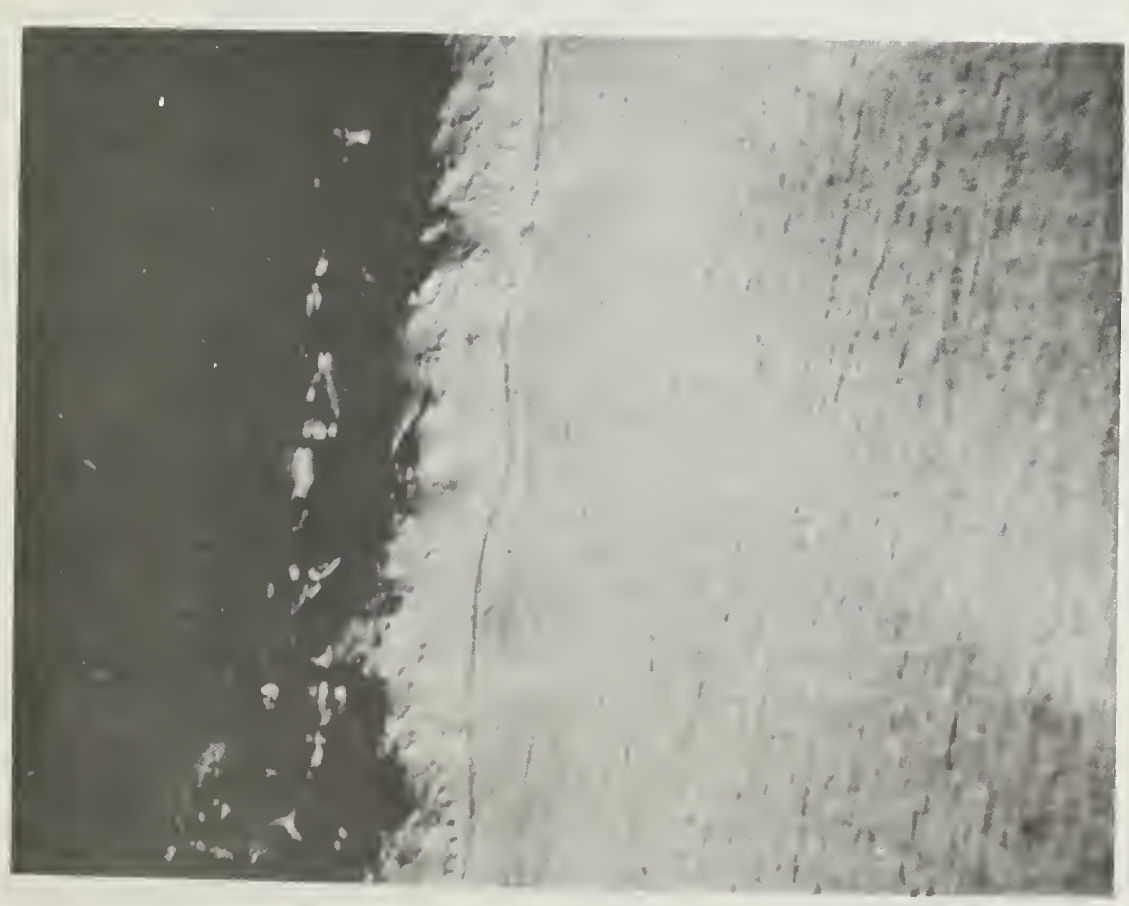

]

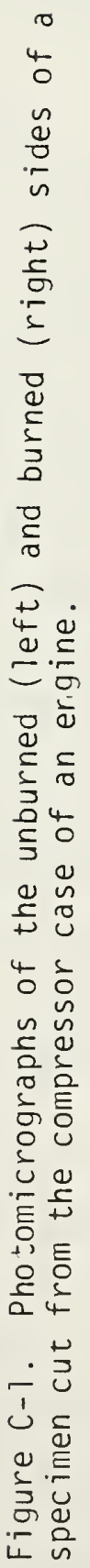


near the surface. Under the microscope, with a polarized light source, the recast layer shows no optical activity, indicating that oxides higher than Tio are not present. A tentative hypothesis is that this layer is composed of a mixture of alpha-Ti plus Ti0. The dark brown oxide layer observed visually on burned surfaces of the original specimens was not observed on the polished specimens; it apparently chipped off during specimen preparation. It is likely that this surface oxide layer was formed after the molten layer of metal resolidified.

Underneath the recast layer is a heat-affected zone, 50-300 $\mu \mathrm{m}$ thick, where the temperature of the metal exceeded the beta transus $\left(1270 \mathrm{~K}\left(1830^{\circ} \mathrm{F}\right)\right.$ for $\left.\mathrm{Ti}-6 \mathrm{Al}-4 \mathrm{~V}\right)$ but did not reach the melting point. Upon cooling from the beta field, thin, needle-like grains of alpha-Ti nucleate and grow; the grain size of the transformation product depends upon the rate of cooling. These needle-like grains are termed acicular alpha. Often the acicular alpha will form a basketweave structure, termed Widmanstätten, due to nucleation on preferred crystallographic planes of the parent beta phase. This type of structure is clearly visible in the center of the right half of figure C-1. Because the acicular alpha nucleates first on the beta grain boundaries, it leaves a definite outline of the prior beta grains. The prior beta grain size in figure $\mathrm{C}-1$ is on the order of $50 \mu \mathrm{m}$. This is rather a large grain size in view of the very short duration of a typical combustion event, and suggests that the temperature in the heat-affected zone could have been well over $1340 \mathrm{~K}\left(1950^{\circ} \mathrm{F}\right)$.

Beneath the heat-affected zone, there is no visible difference in the photomicrographs of burned and unburned regions.

Another specimen, cut from a different area of the rub strip, is shown in figure $\mathrm{C}-2$. Here, again, the rub strip did not burn as severely as the surface on the outside of the engine case. In this instance the recast layer broke off while the specimen was being cut. The heat-affected zone remains, but the acicular alpha is not as clearly defined as that in figure $\mathrm{C}-1$. 

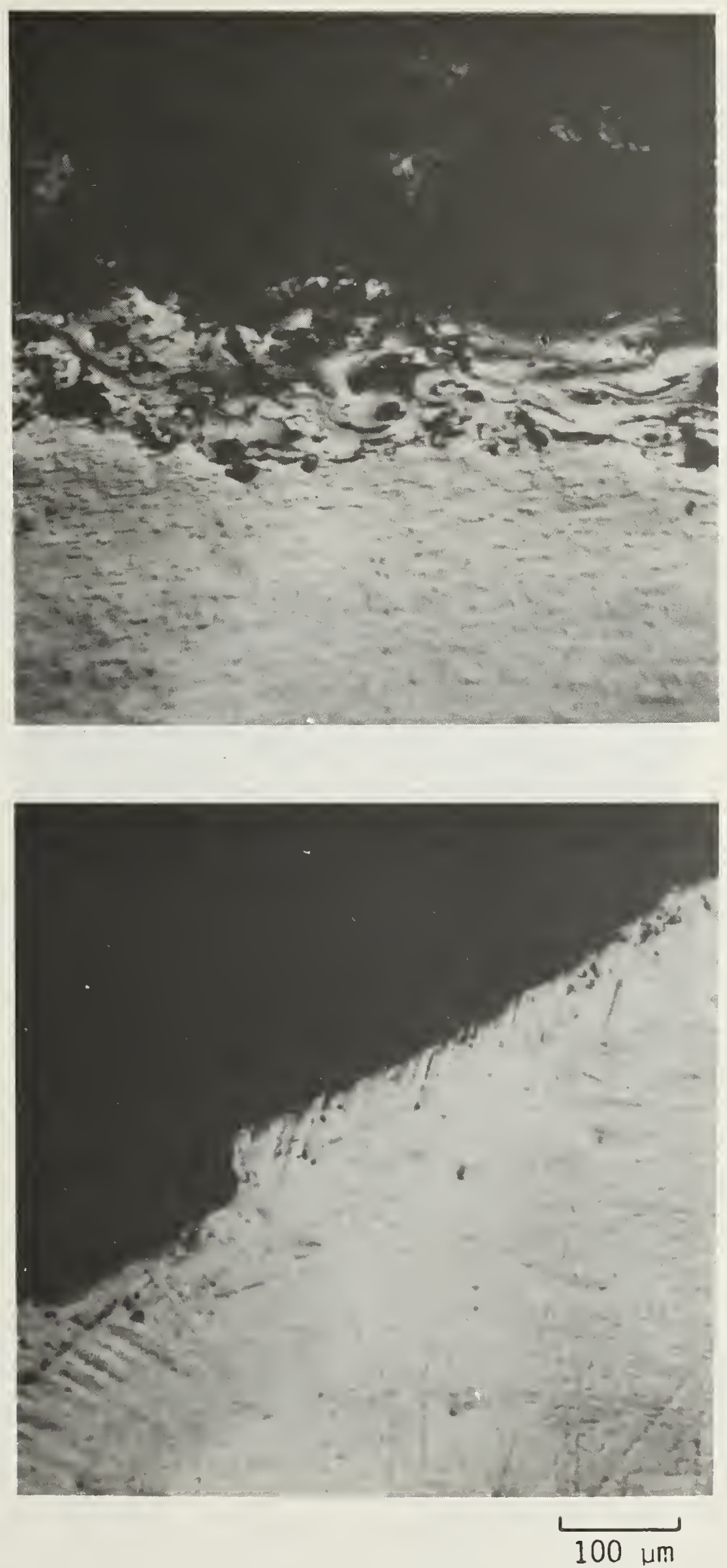

Figure $\mathrm{C}-2$. Unburned (top) and burned (bottom) portions of a specimen from the compressor case. 


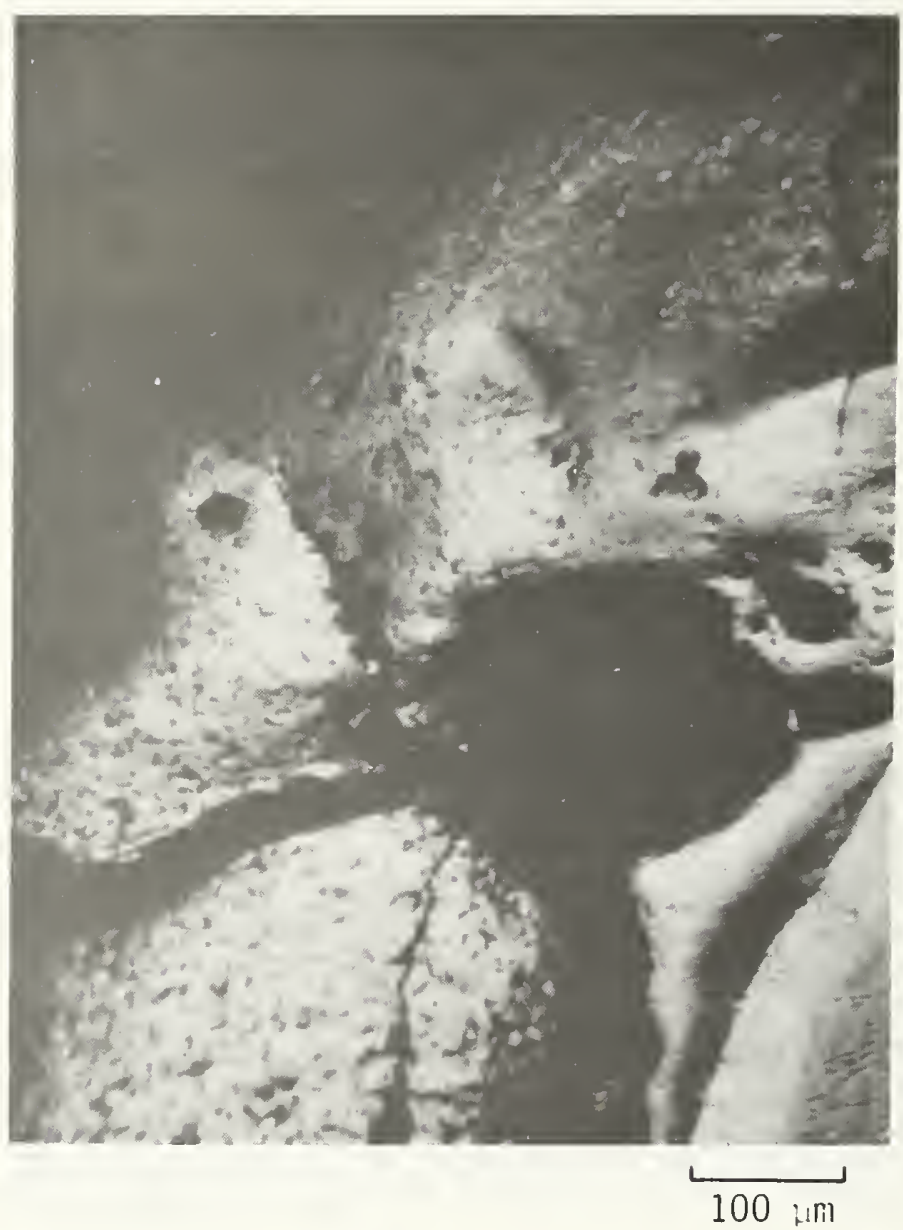

Figure $\mathrm{C}$-3. Recast layer near a penetration in the bleed air manifold. 
A very thick recast layer $(\sim 500 \mu \mathrm{m})$ is shown in figure C-3. This specimen was cut from the bleed air manifold; the photomicrograph in figure $\mathrm{C}-3$ shows a cross-section of the outside edge of a burn-through. Note the extensive cracking in this layer.

Microhardness testing is a useful technique for sudying concentration gradients of oxygen dissolved in titanium. Hardness increases with increasing oxygen content of the metal to a peak, beyond which the hardness falls off as the concentration approaches the solubility limit ( 35 atomic percent for pure titanium). Thus, by measuring hardness as a function of depth below the burned surface, the oxygen penetration depth may be detrmined. For the present investigations, a diamond pyramid indenter was employed with a load of $500 \mathrm{~g}$. The results of microhardness traverses of four specimens, including one unburned specimen, are presented in figures $\mathrm{C}-4$ to $\mathrm{C}-7$.

Hardness as a function of depth below the surface of the rub strip for an unburned specimen is shown in figure C-4, which serves to illustrate the relatively low hardness of the rub strip material and an average diamond pyramid hardness number (DPHN) of 325 for the bulk titanium prior to combustion. Figures C-5 and C- 6 show hardness profiles for two specimens cut from the engine case; figure $\mathrm{C}-7$ is the hardness profile for a specimen cut from the bleed air manifold.

The results reveal several interesting facts. The oxygen penetration depth ranged from 500 to $1000 \mu \mathrm{m}$, well beyond the heataffected zone in all specimens. The hardness of the outermost, recast layer was difficult to determine because of its tendency to crack under the indenter, and so only one value of the DPHN for this layer was determined for each specimen. These values ranged from 398-1345. The highest hardness values were found in the heat-affected zone, but this is consistent with a decreasing oxygen content since the curve of hardness vs. oxygen concentration goes through a maximum. Below the heat-affected zone the hardness 


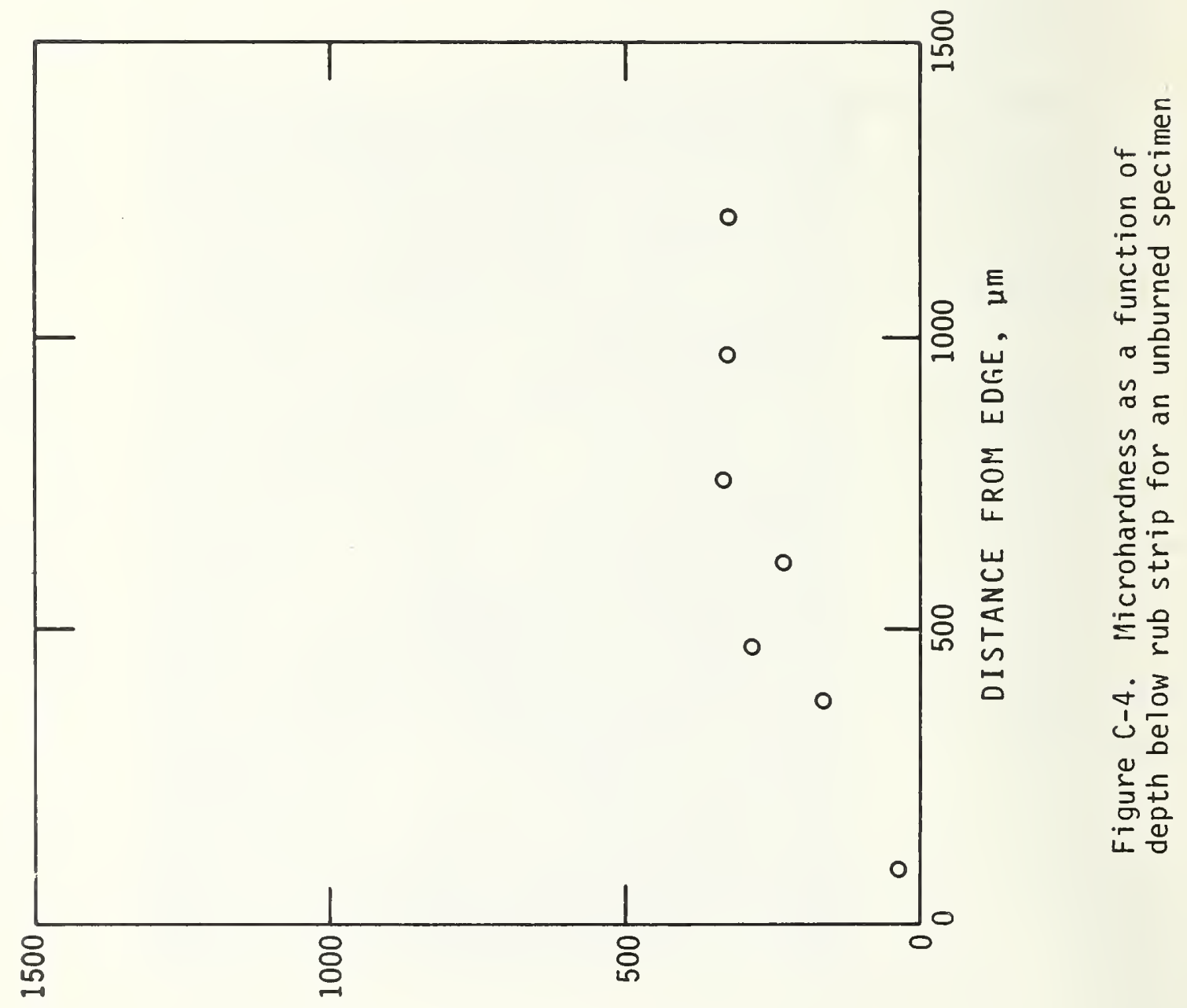

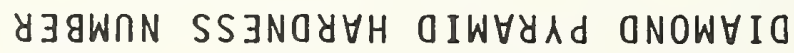




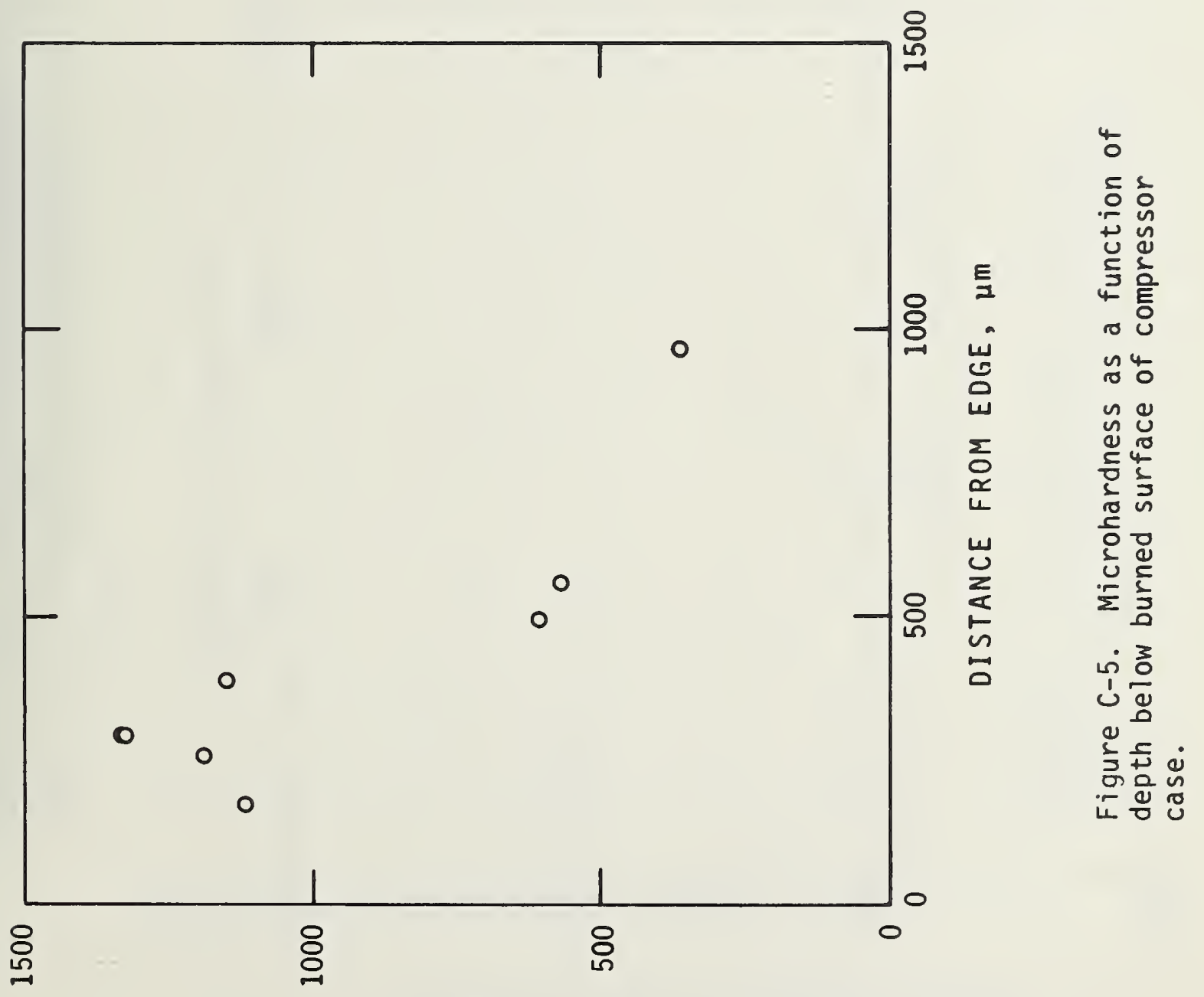

YJGWกN SS JNOYGH OIWHYAD ONOWHIO 


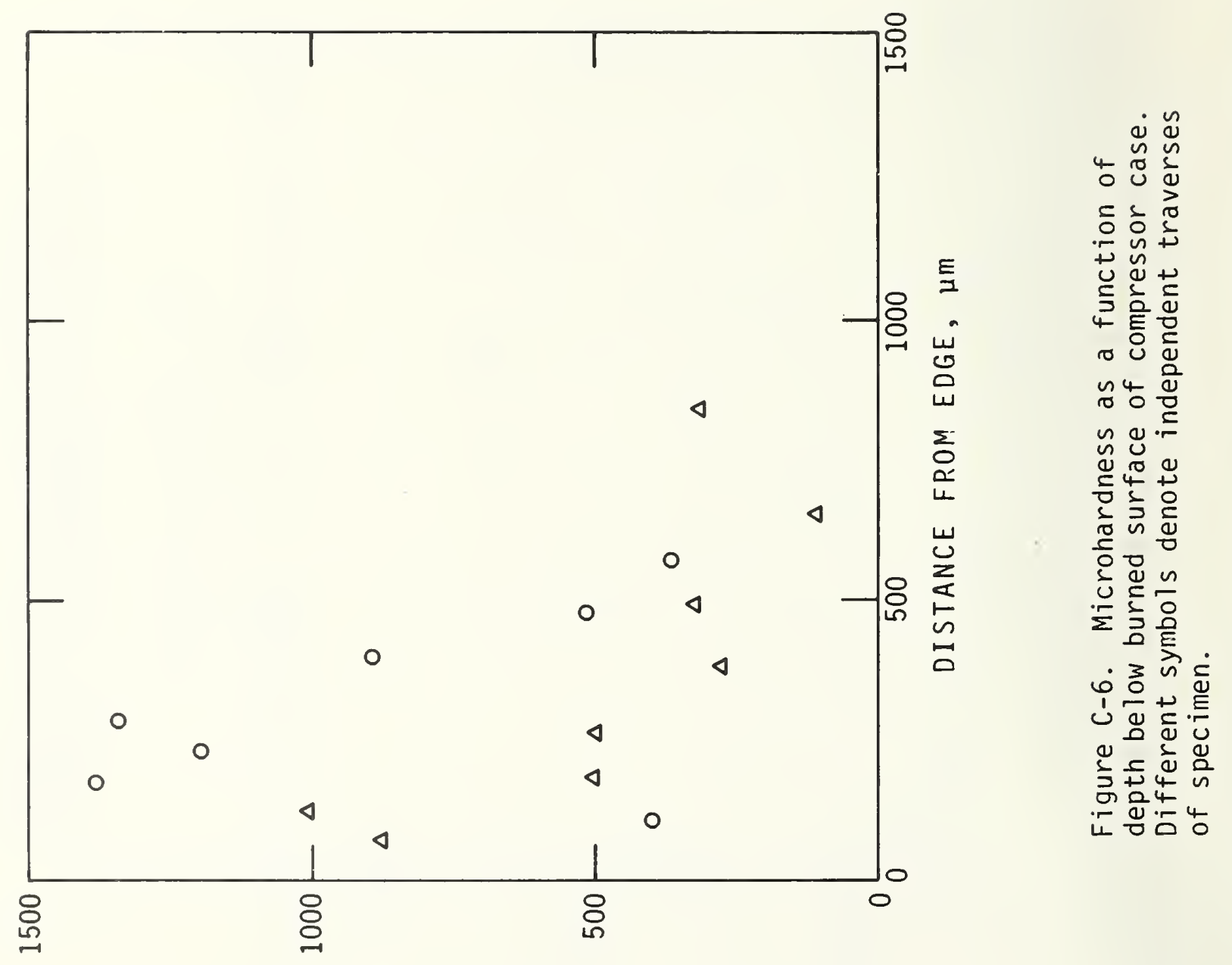

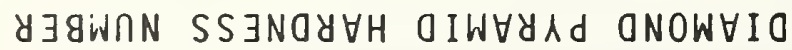




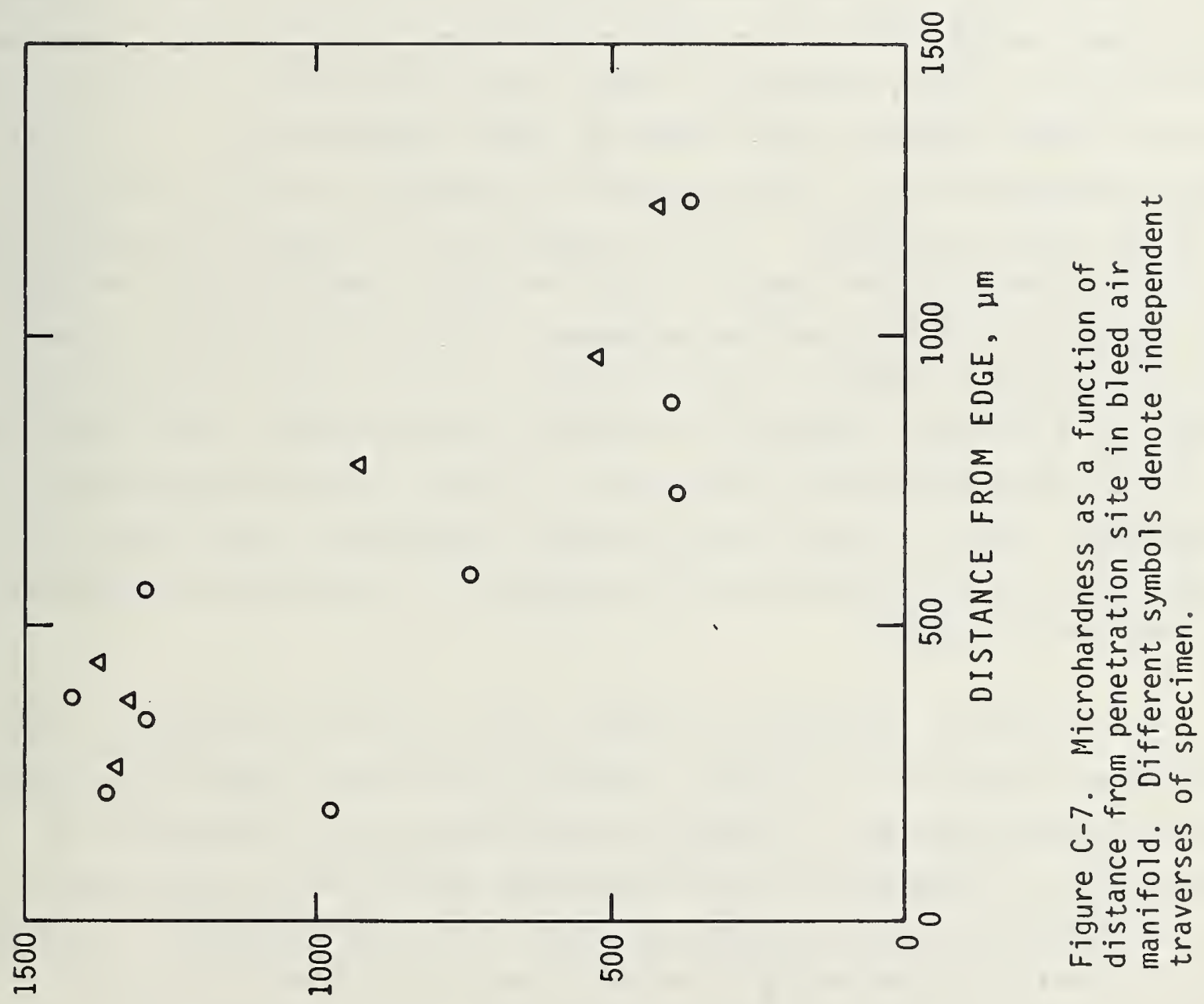

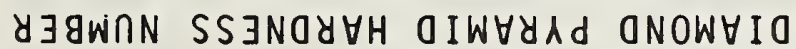


fell off rapidly with increasing depth; for most specimens the hardness was down to normal levels within $750 \mu \mathrm{m}$.

One question does arise from the results of the microhardness testing: how can the high values of hardness measured in the heat-affected zone be reconciled with the fact, noted earlier, that this layer is transformed beta? At its highest temperature, this layer would have had a beta structure, but the beta phase has a much lower oxygen solubility than the alpha phase ( 8 atomic percent at $1970 \mathrm{~K}\left(3086^{\circ} \mathrm{F}\right)$, and less at lower temperature). Yet the oxygen concentration in this layer is thought to be on the order of 20-30 atomic percent. If this quantity of oxygen diffused into the heat-affected zone while it was at high temperature, the crystal structure would have transformed to an $\alpha-\beta$ mixture, or perhaps even pure $\alpha$, without any cooling. If this had occurred it would not have been possible to form acicular alpha, since the alpha would have had sufficient time to form a plate-like microstructure. Thus, we are drawn to the conclusion that oxygen diffused into the heat-affected zone after this layer had cooled below the beta transus.

One possible sequence of events that could rationalize this conclusion would be if liquid, burning titanium flowed across the solid titanium surface, rapidly resolidifying by giving up its latent heat of fusion to the underlying solid metal and raising the temperature of this material above the beta transus. Both the recast layer and the heat-affected zone would then cool fairly rapidly below the beta transus by conduction, convection and radiation. While these two layers cooled, oxygen would diffuse from the oxygen-rich recast layer to. the heat-affected zone, but this would not occur rapidly enough to exceed the solubility limit of the beta phase. Of course this sequence of events is quite similar to the mechanism that has been proposed to explain propagating 
titanium fires; the only difference is that if the molten, flowing titanium has sufficient enthalpy, it may succeed in igniting more metal rather than quenching itself. Thus, the metallurgical examination of specimens from an actual titanium fire helps to confirm the model of titanium combustion that is emerging from the extensive experimental studies in industry and government laboratories. 
$181 \%$ 





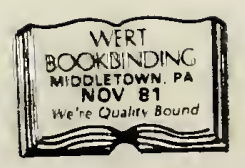


